Check for updates

Cite this: Mater. Adv., 2020 1,1546

Received 31st March 2020 , Accepted 31st May 2020

DOI: 10.1039/d0ma00153h

rsc.li/materials-advances

\title{
Perspectives regarding metal/mineral-incorporating materials for water purification: with special focus on $\mathrm{Cr}(\mathrm{vI})$ removal
}

\section{Introduction}

Pollution refers to the contamination of water by foreign matter such as microorganisms, chemicals, and industrial or other waste or sewage. ${ }^{1}$ Among essentials for human beings, water is vital. Water contamination renders it undrinkable and not suitable for human consumption. The foremost consequence of water pollution is severe damage to the ecosystem. Changes in natural water's chemical or physical properties affect aquatic biodiversity and the usability of water. There are ecological, social, and economic identifiers. ${ }^{2}$ Pollution of water occasioned by different toxic contaminants, mostly including heavy metals, organics, and oil, has steadfastly become one of the most impactful environmental challenges globally. ${ }^{3}$ Water is usually taken for granted when produce safety is taken into consideration. Not only it is vital for crop growth but also in their processing as well. Water usage spans multiple functions: produce cooling,

\footnotetext{
${ }^{a}$ University of Jeddah, College of Science, Department of Chemistry, Jeddah, Saudi Arabia. E-mail: kelwkeel@uj.edu.sa, khalid_elwakeel@sci.psu.edu.eg

${ }^{b}$ Environmental Science Department, Faculty of Science, Port-Said University, Port-Said, Egypt

${ }^{c}$ Zoology Department, Faculty of Science, Port-Said University, Port-Said, Egypt
}

decontamination, debris removal, personal hygiene, and equipment washing. ${ }^{4}$ Water contamination takes place within and outside of cities. Although in-city contamination impacts fewer water tables, it can severely affect not only water procurement and quality but also public health. ${ }^{5}$ Water pollution is the presence of chemical, physical, or biological components or factors affecting water's integrity, although certain natural events can cause water pollution. ${ }^{6}$ Water pollution is becoming increasingly serious in coastal waters. To make full use of marine resources and develop the marine economy, national authorities are paying increasing attention to this issue. ${ }^{7}$ The release of residential and modern waste spillage from water tanks, marine dumping, radioactive waste, and climactic effects are significant causes of water contamination. Water pollutants are categorized as point or nonpoint sources. ${ }^{8}$ The type of contaminant depends on the nature of the business. Lethal metals enter into water and decrease the drinkability of water.

In environmental pollution, heavy metals mainly refer to mercury, cadmium, chromium, lead, and arsenic, which have significant biological toxicity. Usually, the natural background concentrations of heavy metals do not reach harmful levels. Poisonous and harmful metals get into the atmosphere, water, and soil and cause serious environmental pollution because of 
human activities such as heavy metal mining. As major toxicants, heavy metals are found in industrial wastewater and possess severe effects on wastewater biological treatment. Heavy metals' sources in wastewater treatment plants are from industrial discharge and urban stormwater runoff. Some of the heavy metals, e.g., $\mathrm{Cd}, \mathrm{Cr}, \mathrm{Pb}, \mathrm{Hg}$, and $\mathrm{Ag}$, are priority pollutants. Heavy metal toxicity is caused by the fact that they are soluble metals. The toxicity is managed by various factors such as $\mathrm{pH}$ and the type and concentration of complexing agents in wastewater. ${ }^{9}$ Due to their discharge into the environment, heavy metal concentrations in sediments and suspended solids in water have increased sharply and major water pollution problems have occurred. ${ }^{10}$ Many heavy metals, especially at high concentrations, are deadly to even the most resistant species of bacteria, algae, and fungi. Therefore, in many cases of highly contaminated industrial wastewater, biological treatment would be impractical or even impossible. ${ }^{11}$ High concentrations of trace metals can also be found in groundwater near contaminated sources; however, these may pose potential health threats. Some trace constituents are associated with industrial pollution, such as $\operatorname{As}(\mathrm{v})$ and $\mathrm{Cr}(\mathrm{vI}) .{ }^{12,13}$ Chromium is present in the zerovalent state, while in the environment, trivalent and hexavalent chromium species are the most thermodynamically stable. Hexavalent chromium usually occurs as $\mathrm{CrO}_{4}{ }^{2-}$ or $\mathrm{HCrO}^{4-}$, whereas $\mathrm{Cr}$ (III) as $\mathrm{Cr}(\mathrm{OH})_{n(3-n)}{ }^{+}$. Chromium(III) is an essential nutrient while $\mathrm{Cr}(\mathrm{VI})$ is strongly carcinogenic. ${ }^{14}$ It has long been recognized that $\mathrm{Cr}(\mathrm{III})$ occurs naturally in most environmental media, while $\mathrm{Cr}(\mathrm{vI})$ only naturally in groundwater.

The World Health Organization recommended the total value of chromium in drinking water to be $0.05 \mathrm{mg} \mathrm{L}^{-1} \cdot{ }^{15}$ The European Union has also recommended the same value in its council directive 98/83/EC on drinkable water quality. ${ }^{16}$ However, the United States Environmental Protection Agency has established $0.1 \mathrm{mg} \mathrm{L}^{-1}$ as the maximum allowed contaminant level for total chromium. ${ }^{17}$

Chromium(vi) is one of the most toxic heavy metals existing in wastewater. Until now, various adsorbents were broadly tested for the displacement of $\mathrm{Cr}(\mathrm{vI})$ from contaminated water, but the results illustrate a low and hindered adsorption capacity. Chromium, as well as its compounds, is usually used in steel production and metallurgy, the chemical industry, leather tanning, protection and decorative coatings, the automotive industry, pigment manufacture, and wood treatment. Due to such an extensive range of use, large amounts of chromium are released into the atmosphere and terrestrial and aquatic environments. As a result of developed industrial activities, huge amounts of chromium-rich waste materials are generated. ${ }^{18}$ Waste from the steelmaking industry may often be reused in civil engineering, while other chromium-containing waste materials are in general disposed of. ${ }^{19}$ In nature, under environmental conditions, $\mathrm{Cr}(\mathrm{III})$ species prevail, while $\mathrm{Cr}(\mathrm{VI})$ compounds are mainly of anthropogenic origin. The essentiality and toxic nature of $\mathrm{Cr}$ depend primarily on its chemical forms. Generally, $\mathrm{Cr}$ (III) compounds are of lower toxicity compared with $\mathrm{Cr}(\mathrm{VI})$. $\mathrm{Cr}(\mathrm{III})$ is a crucial micronutrient present in glucose and lipid metabolism. For minimizing the health hazards of $\mathrm{Cr}(\mathrm{vI})$ to occupationally exposed workers, the Occupational Safety and Health Administration standardized the limits of exposure to $\mathrm{Cr}(\mathrm{vI})$ compounds in the workplace. Chromium(vi) usage is limited by different regulative acts, and measures are also taken to diminish the environmental impacts of disposed of and reused chromium waste materials. ${ }^{20}$ The soluble $\mathrm{Cr}(\mathrm{vI})$ species are readily released into soil solution and ground- and surface water and can be taken up by plants. To prevent harmful effects of $\mathrm{Cr}(\mathrm{vI})$ on terrestrial and aquatic environments and safely dispose of or reuse chromium-rich waste materials, reliable determination of $\mathrm{Cr}(\mathrm{vI})$ is of paramount importance. ${ }^{21}$ Accurately determining $\mathrm{Cr}(\mathrm{vI})$ is also crucial in the investigations of the oxidation-reduction processes of $\mathrm{Cr}$ in soil and the evaluation of the efficiencies of the remediation processes of Cr-contaminated soil. Chromium(vI) exists in aqueous solution in the form of dichromate $\left(\mathrm{Cr}_{2} \mathrm{O}^{7-}\right)$, hydrochlorate $\left(\mathrm{HCrO}^{4-}\right)$, or chromate $\left(\mathrm{CrO}_{4}{ }^{2-}\right){ }^{22}$ These anionic species are usually not adequately adsorbed by negatively charged soil particles due to the nonrepulsive electrostatic interaction. Therefore, $\mathrm{Cr}(\mathrm{vI})$ is capable of mobility and prevails only in aqueous solutions. Most chromite mine discharge water contains higher $\mathrm{Cr}(\mathrm{vI})$ concentration and electroplating effluent and ferrochrome, and leather tanning industries contain even higher $\mathrm{Cr}(\mathrm{vI})$ concentrations than the permissible limit. ${ }^{23}$ Chromium compounds, of some significance considering human intake of the metal, can be used as an additive in water to prevent corrosion in industrial and various cooling systems. Opinions suggest that this utilization could cause a significant amount of environmental contamination from industrial emissions. As we will elaborate later, chromium salt utilization as a passivation agent on tin plate sometimes causes high levels of contamination in tinned foodstuffs. Although water may contain chromium, especially if it is affected by industrial emissions, it is not likely to account for impactful contributions to dietary intake of the element. Chromium's common form in drinking water is $\mathrm{Cr}(\mathrm{VI})$ and it is more soluble than hydrated $\mathrm{Cr}(\mathrm{III})$ oxide. $^{22}$

Conditions have been documented in which residents in the vicinity of a chromium-contaminated site were potentially exposed to $\mathrm{Cr}(\mathrm{vI})$ in their drinking water at levels up to 10 ppm. ${ }^{24}$ Whether prolonged exposure to low concentrations of $\mathrm{Cr}(\mathrm{VI})$ in drinking water can lead to cancer is directly related to the current concern about the dangers of environmental exposure to $\mathrm{Cr}(\mathrm{vI})$. Subsequent poor disposal practices, such as dumping of $\mathrm{Cr}(\mathrm{vI})$ into unlined ponds, have led to $\mathrm{Cr}$ seepage into waterways and consequent contamination of irrigation and drinking water. ${ }^{25}$ Chromium compounds' emissions in water and air are mainly caused by chemical manufacturing industries (rubber, dyes, pharmaceuticals, and plastic products). In humans, sufficient evidence exists for the carcinogenicity of $\mathrm{Cr}(\mathrm{vI})$ compounds which are found in chromate production, chromate pigment production, and chromium plating industries. $^{26}$ Extremely toxic contaminants like $\mathrm{As}(\mathrm{v}), \mathrm{Cr}(\mathrm{vI})$, and $\mathrm{Pb}$ (II) were found in the chrome-tanning process of animal skin to produce leather; these industries were located in Riyadh and Jeddah, in Saudi Arabia, industrial cities. ${ }^{27}$ Chromium enters the oceans in two-way riverine discharge 
and atmospheric deposition. Almost no rivers flow into the Red Sea; hence, the major likely source of higher concentrations of $\mathrm{Cr}$ near Al Wahj and Jazan could be atmospheric deposition, activities of the Al Wajh Port, or wastewater streams from the local community. ${ }^{28}$ Chromium abundantly exists in the Earth's crust; its level in groundwater depends on the nature of the crust and the rocks in any given area. Accordingly, relatively high concentrations were detected in Makkah wells, though still below international and local standards. ${ }^{29}$ Different studies illustrated that $\mathrm{Cr}(\mathrm{vI})$ compounds can increase lung cancer risk, and that ingesting large amounts can cause ulcers, upset stomach, convulsions, and liver and kidney damage, and could even cause death.

\section{Traditional wastewater treatment technologies}

The main vulnerability of surface water is its ability to be contaminated by industrial and municipal emissions and runoff and soil erosion. Excessive turbidity and pollution cause numerous unwanted tastes, odors, and colors of water. ${ }^{30}$ Industries not only cause physical damage to river systems through direct water withdrawal and water infrastructure but also pollute the river qualitatively. ${ }^{31}$ Surface water is contaminated from industrial, agricultural, and domestic chemicals that enter from the surface by inorganic chemicals that are water soluble, such as acids, salts, and toxic metal compounds such as lead and mercury. These dissolved solids can render water undrinkable, affect fish and other aquatic life, diminish crop yields, and expedite corrosion of equipment that uses water. ${ }^{32}$ Many of these industries' factories are situated along the banks of rivers, such as steel and pulp and paper industries' factories, due to their requirement for huge amounts of water in their manufacturing processes. Their waste contains acid and alkali derivatives, dyestuffs, and other chemicals that are dumped into rivers as effluents. Chromium salts are used in industrial processes for the production of sodium dichromate and other compounds containing $\mathrm{Cr}(\mathrm{vI}) .^{33}$

Because of the undesirable inhibitory properties in terms of water pollution caused by dyes and heavy metals, elimination of these polluters from wastewater is key. Several methods including physical, mechanical, chemical, thermal, and biological methodologies are applied to remove these polluters from water systems. Ion exchange, ${ }^{34}$ precipitation, ${ }^{35}$ flocculation/ coagulation, ${ }^{36}$ photo oxidation, ${ }^{37}$ phytoextraction, ${ }^{38}$ electrocoagulation, ${ }^{39}$ electrodialysis, ${ }^{40}$ irradiation, ${ }^{41}$ membrane separation, ${ }^{42}$ ultrafiltration, ${ }^{43}$ forward osmosis, ${ }^{44}$ and microorganisms and plants ${ }^{45-47}$ are applied to remove dyes and heavy metals from water bodies. Generally, wastewater treatment scenarios can be categorized into mechanical, chemical, physical, thermal, and biological methods as displayed in Fig. 1.

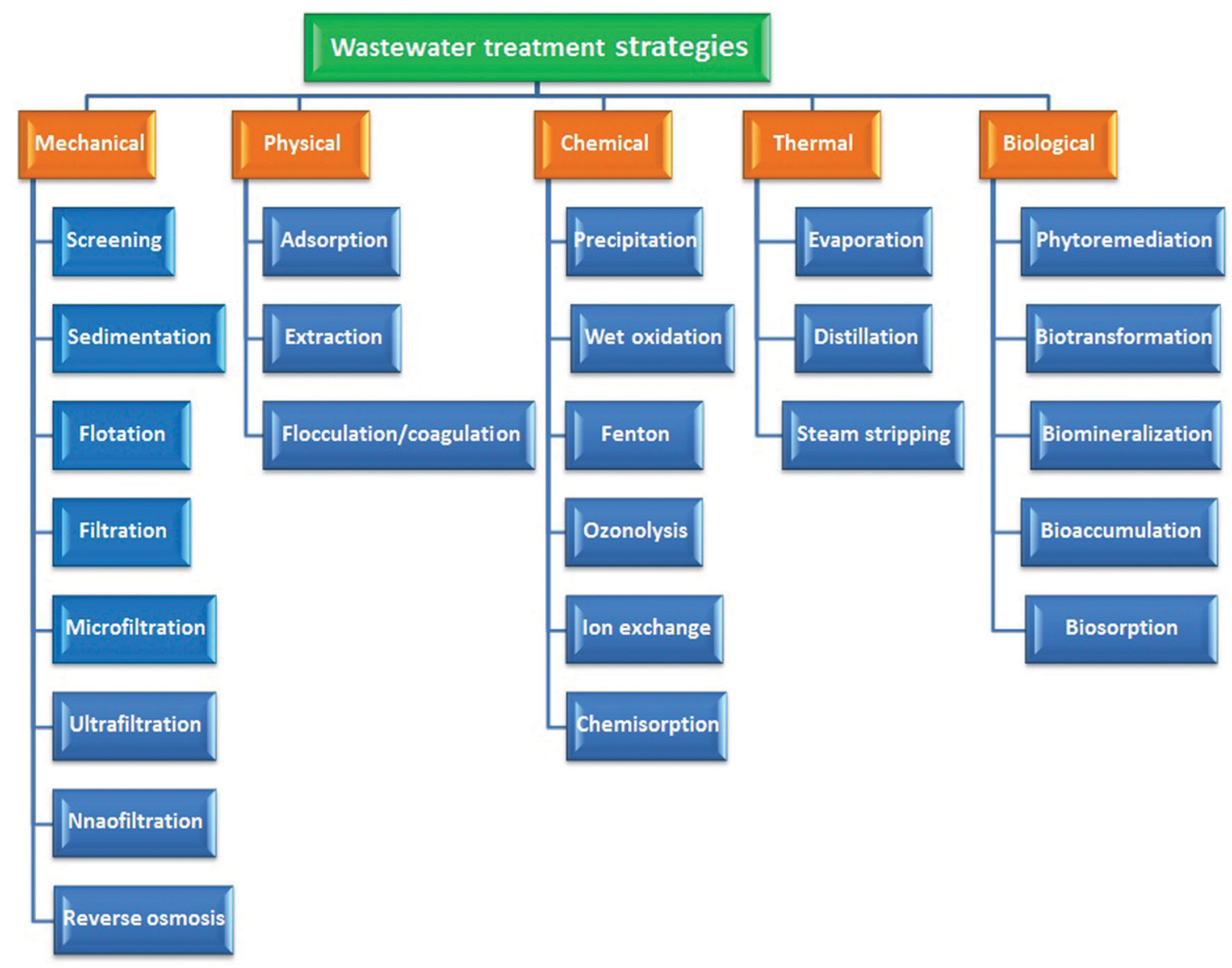

Fig. 1 Different strategies for water and wastewater treatment. 


\section{Adsorption}

Nowadays, the treatment of wastewater from different pollutants, such as heavy metals, is a worldwide necessity. Challenges related to pollution caused by heavy metals necessitate effective methods for their decontamination. Adsorption is an eco-friendly method to ameliorate this problem. It possesses a lot of potential in wastewater treatment as it is efficient and not costly. Yet, the majority of these complicated processes could introduce some challenges, e.g., high costs, inefficiency in low-concentration polluters, huge time consumption, reagents and energy, and formation of chemical sewage sludge. ${ }^{48,49}$ Based on the famous comment of Albert Einstein, "We can't solve our problems by using the same kind of thinking we used when we created them.", it is time to come up with alternative, greener, and cheaper technology for eliminating contaminants from water efficiently. The advantages of adsorption over other technologies can be summarized as:

- Extract a large number of pollutants over a wide $\mathrm{pH}$ range

- Fast kinetics

- Easy handling and low space

- Regenerability

- Low cost

- No chemical sludge

\subsection{Adsorption fundamentals}

Adsorption, as a practical application of sustainable development, is applied and considered as an economically efficient and ecofriendly technique for reducing various contaminant concentrations in different water resources, e.g., drinking water, to the optimal limits advised by various federal regulations all over the world. ${ }^{50-52}$ The green protocol conforms with green chemistry principles. The fundamentals involved in the adsorption process are related to its ingredients. Briefly, adsorption is a metabolism-independent process (passive uptake) utilizing nonliving biomass to get rid of various water polluters. In general, this process yields many benefits because of recycling biomass (biowaste). Application in the original and/or altered forms minimizes waste, rectifying various environmental and ecological issues. ${ }^{51}$ It also is characterized by exemplary merits, e.g., low operating and manufacturing costs, availability, flexibility, minimal energy requirements, easy operation, and high efficiency. Fig. 2 presents different water polluters' sorption on various low-cost biosorbents.

\subsection{Adsorption strategy}

Recently, the concept of adsorption as a multidimensional effective process has been evolving. It is considered as an admirable alternative to other orthodox technologies for wastewater decontamination. Sorption is a physicochemical phenomenon where gas or liquid molecules (the sorbate) concentrate on the surface of another substance (the sorbent). A sorbate is a material that gathers at the sorbent surface, while a sorbent is the substance whose surface hosts sorption, yielding highquality purified effluents. Despite the presence of "bio" as a prefix, adsorption simply defined is a physicochemical process where target sorbate molecules are captured from aqueous

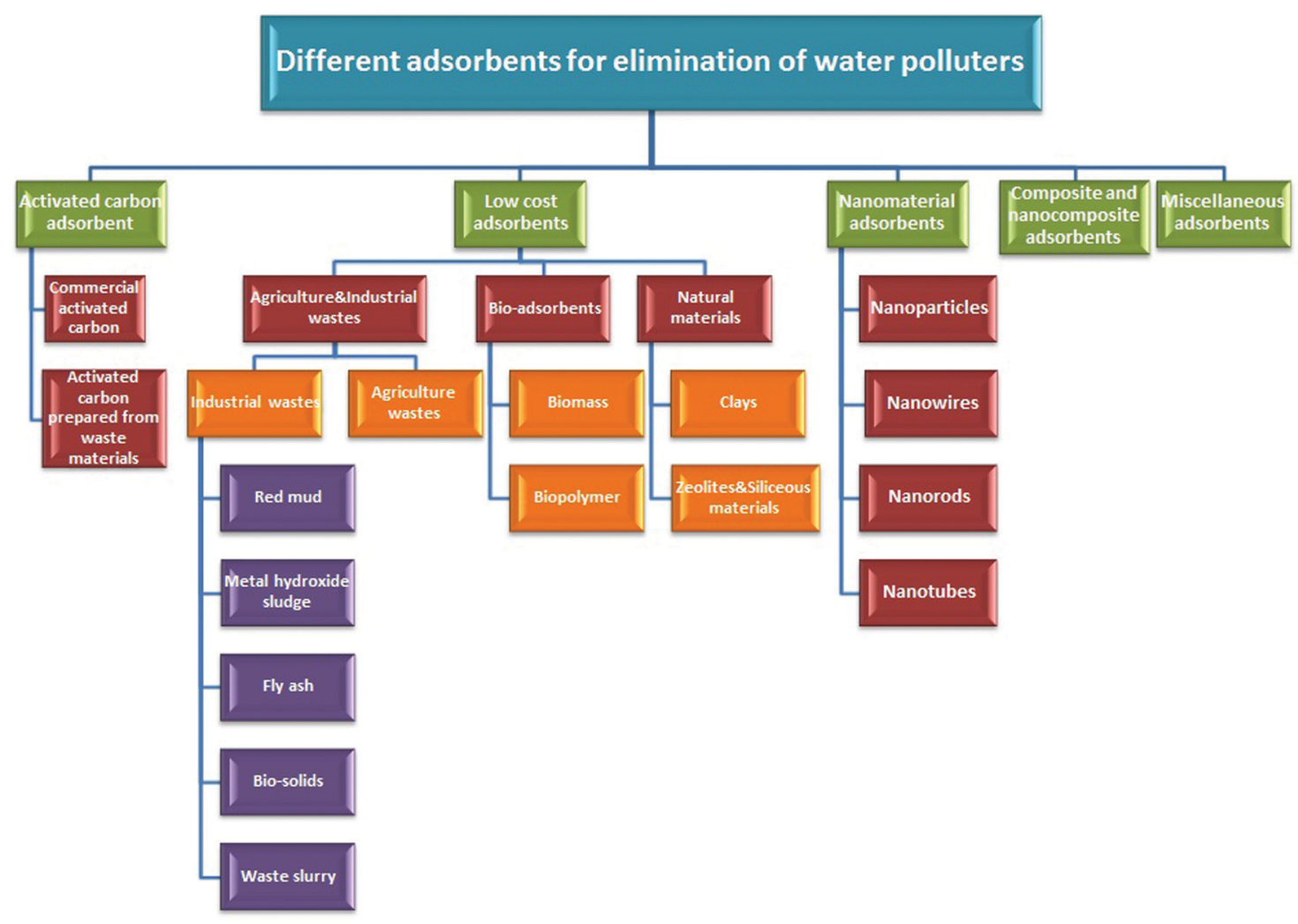

Fig. 2 Various types of water pollutant adsorbents. 
solutions via a biological matrix. Absorption is the incorporation of a substance from one state into another substance with a different state, i.e., gases absorbed by water or liquids absorbed by a solid, into a three-dimension matrix. Adsorption, on the other hand, is a physical attachment in which a sorbate, i.e. molecules and/or ions, interacts with a solid surface of another molecule (the sorbent), resulting in a sorbent-sorbate interface, i.e., into a two-dimensional surface. ${ }^{53}$

Adsorption can be described as a metabolically independent and passive process that covers all interactions between any sorbate and biological matrix (biosorbent). It is crucial to many naturally occurring processes in different scientific disciplines, e.g., biotechnology, life sciences, and medical approaches.

\subsection{Selection of adsorbents}

The adsorbent adequacy is known to be the most vital factor dictating the selection and preparation of a biosorbent. Considering cost and biomass origin as vital requirements as well, these two factors represent crucial criteria affecting the selection of the biosorbent. Dead biomass seizing priority over viable biomass stands out as a preferable technology applied for contending with various water polluters. Utilizing dead biomass possesses many advantages such as the following: (1) there is no need for nurture, i.e., nutrients and media, to be contained in the feed solution. (2) Toxicity is not a factor. (3) Saturated biosorbents and sorbed polluters can be reused and recovered, respectively. (4) It is easier to model, mathematically and statistically, the polluter uptake. To ensure the potential for a biosorbent to detoxify water polluters, the biosorbent should possess various parameters such as being ecofriendly, biocompatibility, availability, and cost efficiency. Other merits of biosorbents are high sorptive performance towards target polluters under different physicochemical parameters, i.e., temperature, $\mathrm{pH}$, etc., and good stability under acidic/alkaline conditions with capacity for sequential sorption of various polluters. Economically and environmentally, recyclability and adaptability to various designs, i.e., fixed-bed systems, batch, are crucial features for the established biosorbents. ${ }^{54}$ Some believe in waste as wealth-to be treated as a valuable resource; accordingly, this available waste should be treated with the utmost attention and care since utilizing it offers promising subject with a lot of benefits due to its environmentally benign nature. Reusing this waste is economically beneficial because it eliminates disposal problems while generating revenue for various industries. In reality, the plentiful biological materials structurally differ with the presence of various ligands such as amino, alcohol, aldehyde, hydroxyl, carboxylic, thiol, phosphate, ketone, phenolic and ether groups to different degrees with the capacity of interacting with target polluters through various mechanisms, hence enhancing their sorption processes. The adsorption capacities of different biosorbents towards multiple polluters were investigated and reported in thousands of articles researching their extent.

\subsection{Adsorption mechanism}

Adsorption mechanism studies of multiple water polluters allow the appraisal of their manipulation efficiency, which is crucial to and beneficial for optimization of the conditions of the removal process. Until now, a lot of studies have focused on assessing the possible interaction mechanism of different water polluters on as-used biosorbents. Efficiency in terms of high adsorption plays a vital role in characterizing a biosorbent for the elimination of different water polluters effectively. In general, the process of adsorption actualizes the physicochemical features of the biosorbent, i.e., molecular size, solubility, chemical composition, surface charge, reactivity, and hydrophobicity. The structural components' variable characters are attributed to the presence of many functional groups, with varying degrees, on its surface, i.e., amino, hydroxyl, carboxyl, thiol, phosphate, etc., which facilitates water polluter sorption onto the biosorbent via various sorption mechanisms. The interaction between contaminants and biosorbent surfaces, commonly, may occur through complexation/coordination, aggregation, electrostatic interaction, microprecipitation, ion exchange, oxidation, and reduction. Fig. 3 illustrates various mechanisms involved in the process of adsorption. The occurrence of precipitation, as well as crystallization, is possible and it cannot be ignored; thus, this complicates sorption and/or desorption processes.

To explore the main mechanism of adsorption, many strategies of characterization and theoretical calculation related to various models' assumptions in terms of kinetics, thermodynamics, and isotherms were carried out. The adsorption interaction between water contaminants and different biosorbents takes place in two different scenarios: surface and interstitial sorption. In surface sorption, sorbate molecules displace from the aqueous solution to the biosorbent surface. Once polluters (molecules and/or ions) pass the biosorbent's surrounding boundary layer, they attach to the active sites present on its surface, displacing themselves from aqueous solutions. Dipole interactions, hydrogen bonding, or van der Waals forces are usually the cause of this type of sorption. ${ }^{55}$ On the other hand, the interstitial sorption mechanism differs, where polluters (molecules and/or ions) diffuse towards the biosorbents, entering the biosorbent pores (macro, meso, and/or micropores),

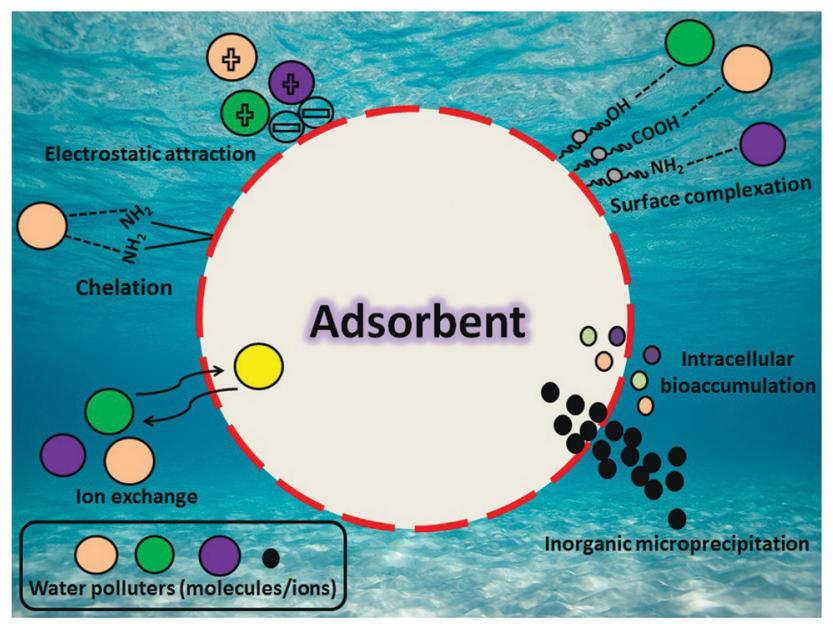

Fig. 3 Various mechanisms occurring in the adsorption process. 
and becoming biosorbed to the interior surface of the biosorbent. $^{56}$

Using biosorbents to tackle different polluters from water and wastewater can be explained via electrostatic interactions. They have been established as major contributors to water contaminant adsorption. The presence of a plethora of functional groups (active sites) on the surface of the biosorbent elects them for efficiently capturing polluters from various water systems. The capacity of these functional groups is significantly affected by the medium's $\mathrm{pH}$. The biosorbent surface charge and polluter's speciation are heavily reliant on the environmental $\mathrm{pH}$. Lower $\mathrm{pH}$ values lead to protonation of various functional groups, which results in maintaining a positive charge on the surface of the biosorbent. As a consequence, electrostatic repulsion takes place, diminishing and/or inhibiting positively charged polluter sorption, i.e., metal cations. Conversely, electrostatic repulsion diminishes with increasing the $\mathrm{pH}$ of the medium, causing an increase in their adsorption in terms of electrostatic attraction phenomena. For example, negative-function moieties such as carboxylate $\left(-\mathrm{COO}^{-}\right)$and hydroxyl $\left(-\mathrm{OH}^{-}\right)$on the biosorbent surface maintain its negative charge, hence facilitating the binding of positive-charge polluters (molecules and/or ions). Contrarily, the holding of positive functional groups such as amine sites $\left(-\mathrm{NH}_{2}\right)$ is considered as the main cause of the sorption of negative-charge water polluters.

The dissociation constant values $\left(\mathrm{p} K_{\mathrm{a}}\right)$ of biosorbent functional groups and their $\mathrm{pH}_{\mathrm{PZC}}$ values are relative to the solution's $\mathrm{pH}$, hence influencing the capacity of biosorbent sorption. The $\mathrm{p} K_{\mathrm{a}}$ values of various functional groups such as carboxylic and phenol groups range from 3.5 to 5.5. This implies that the majority of these groups deprotonate in this $\mathrm{pH}$ working range and that avails enhancement of negatively charged sorption sites for the adsorption process. ${ }^{57}$ Additionally, the biosorbent $\left(\mathrm{pH}_{\mathrm{PZC}}\right)$ value greatly affects the adsorption process. The charge of the surface of the biosorbent is positive ( $\mathrm{pH}$ of solution $<\mathrm{pH}_{\mathrm{PZC}}$ ), while its surface charge is negative ( $\mathrm{pH}$ of solution $>\mathrm{pH}_{\mathrm{PZC}}$ ). Therefore, the elimination of polluters (molecules and/or ions), particularly those possessing positive charges, i.e., metal cations, is decreased when their $\mathrm{pH}$ is lower than $\mathrm{pH}_{\mathrm{PZC}}$ and increases when their $\mathrm{pH}$ is greater than $\mathrm{pH}_{\mathrm{PZC}}$. This suggests the significant role of electrostatic forces during the process of adsorption. ${ }^{58}$

The adsorption process can be fathomed based on the ion exchange mechanism between the biosorbent and the studied polluters. Its contribution is illustrated through the replacement of protons from the exchangeable sites on the biosorbent surface with polluters, i.e., metal ions. Hydroxyl, carboxyl, and phenol groups facilitate the mechanism's operation, which can be attached to by polluter ions, i.e., divalent heavy metal ions, via two pairs of electrons and subsequently the release of two $\mathrm{H}^{+}$and/or $\mathrm{Na}^{+}$into the solution. ${ }^{59}$ The $\mathrm{pH}$ of the solution affects the ion exchange mechanism: in an acidic medium, the increase in the $\mathrm{H}^{+}$ions leads to a competition with positively charged polluters (molecules and/or ions) leading to them being sorbed onto the biosorbent. Meanwhile in a basic medium,
$\mathrm{OH}^{-}$ions' increase compels negatively charged polluters (molecules and/or ions) to be sorbed on the sorption sites. For example, the possible ion exchange mechanism between polluters such as metal cations and exchangeable protons from the adsorbent surface can be illustrated as shown in the following equations:

Adsorbent $\cdots \mathrm{H}^{+}+(\text {metal ion })^{+} \rightarrow$ Adsorbent $\cdots$ metal ion $^{+}+\mathrm{H}^{+}$

Adsorbent $\cdots \mathrm{Na}^{+}+(\text {metal ion })^{+} \rightarrow$ Adsorbent $\cdots$ metal ion ${ }^{+}+\mathrm{Na}^{+}$

Adsorbent $\cdots \mathrm{Ca}^{2+}+(\text { metal ion })^{+} \rightarrow$ Adsorbent $\cdots$ metal ion ${ }^{+}+\mathrm{Ca}^{2+}$.

Formation of surface complexes (complexation) involves the interaction of polluters, i.e., metal ions, with oxygen donor atoms from oxygen-containing functional groups (coordination) associated with the release of protons and formation of surface complexes. The ligand tendency for forming metal complexes significantly depends on the metal classification according to their chemical characters including the Hard-Soft-Acid-Base principle (HSAB). Metal ions (cations) can bind with the biosorbent surface through inner- or outer-sphere complex mechanisms by the covalent bond chemically established between the metal and the oxygen atom (electron donor) or by cations nearing the negative groups present on the surface (critical distance) linked to the presence of at least one water molecule between the cation and base, respectively. ${ }^{53}$

\subsection{Batch adsorption}

A batch adsorption scenario is a primitive step to assess the capability of the biosorbent of eliminating pollutants from their matrices. The influence of several operational parameters can be estimated during this strategy (Fig. 4).

\subsection{Adsorption isotherm modeling}

An adsorption isotherm is a curve relating the equilibrium concentration of a solute on the surface of an adsorbent, $q_{\mathrm{e}}$, to the concentration of the solute in the liquid, $C_{\mathrm{e}}$, with which it is in contact. The relationship between these $q_{\mathrm{e}}$ and $C_{\mathrm{e}}$ can normally be fitted to one or more equilibrium isotherm models. There are several isotherm equations available for analyzing experimental sorption equilibrium parameters. The most commonly used isotherms are reported in Table 1 . The availability of various models on the basis of parameter number whether two, three, four and five parameters are shown in Fig. 5.

3.6.1 Modeling of adsorptions kinetics. Kinetic studies grant insightful outcome data necessary for modeling and devising an adsorption operation system with high efficiency. Commonly, the time-dependent adsorption data are crosschecked with several kinetic models such as the Pseudo First-Order Rate Equation (PFORE), ${ }^{78}$ Pseudo-Second Order Rate Equation (PSORE), ${ }^{79}$ Weber and Morris model (W\&M), ${ }^{80}$ and Elovich model. ${ }^{81}$ Usually, linearized forms of the various previously mentioned models illustrate the sorption process, exhibited in Table 2. 
Table 1 Linearized and nonlinearized forms of some common isotherm models

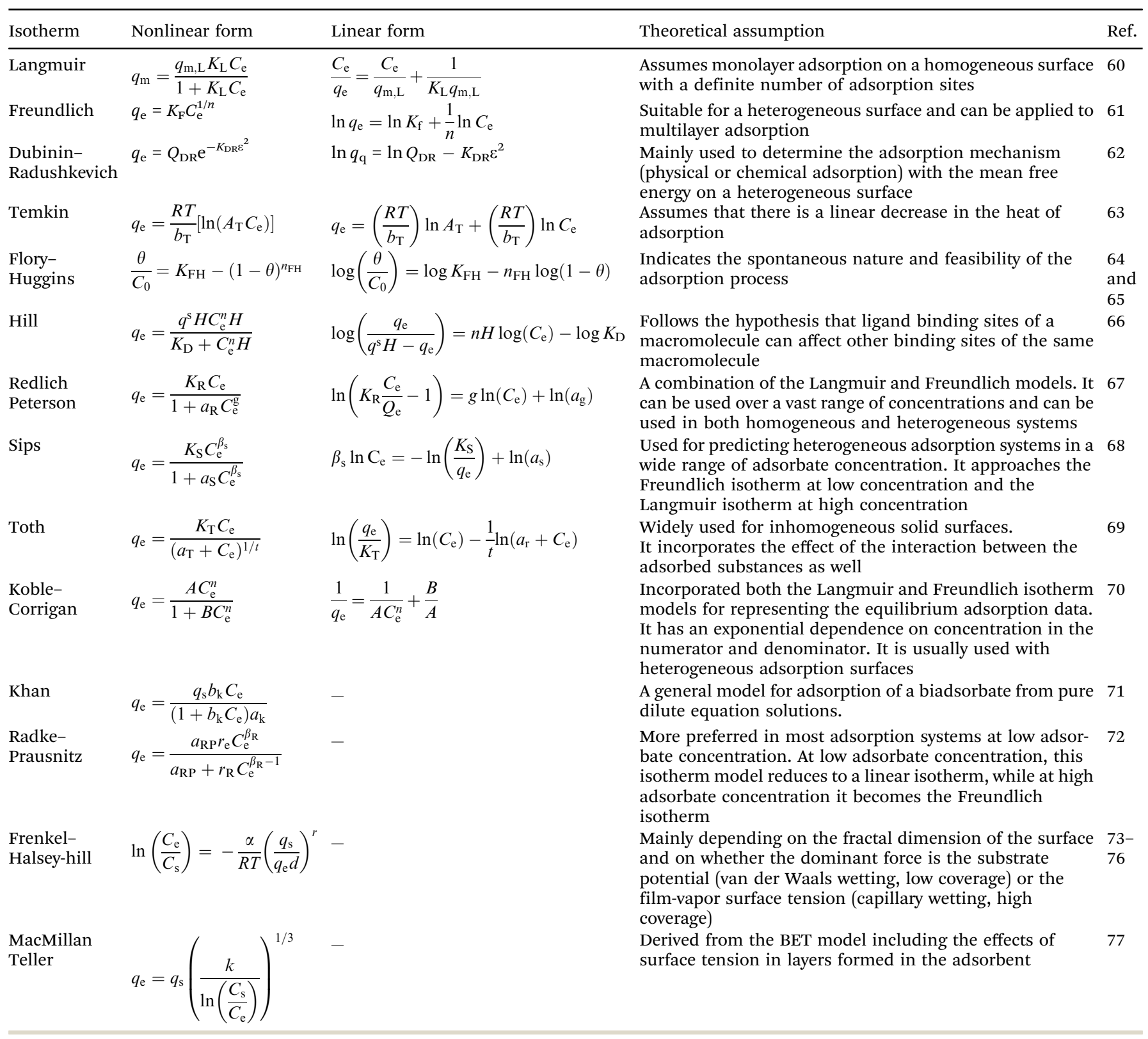

\subsection{The goodness of model fitting}

The goodness of fit of the used mathematical models to the experimental data can be evaluated via different statistical function errors as presented in Table 3. The following equations normally help to estimate the variances between the predicted and experimental data. The smaller the values of SSE, $X^{2}$, and CFEF, ARE, MPSD, and HYBRID, the closer the experimental data to the estimated data.

\section{Metals and adsorbents}

\subsection{Copper-incorporating adsorbents}

$\mathrm{CuO}$ nanostructures' various morphologies (leaves, clusters, ovals, small rods, and porous nano sheets) have been synthesized by a novel simple method applying microwave radiation. ${ }^{82}$ The produced $\mathrm{CuO}$ nanostructures were characterized by the $\mathrm{X}$-ray diffraction analysis technique (XRD), transmission electron microscopy (TEM), surface area analysis (BET), and energy-dispersive spectroscopy (EDS). CuO nanostructures' capacity as adsorbents was investigated for adsorptive removal of $\mathrm{Pb}$ (II) ions from aqueous solutions. Different physicochemical parameters such as the initial metal ion concentration, $\mathrm{pH}$, and equilibrium contact time were evaluated. The optimum $\mathrm{pH}$ value of the solution made for adsorption of $\mathrm{Pb}$ (II) from aqueous solutions was found to be 6.5 , while the optimum contact time was found to be four hours. The maximum capacity of oval, cluster, leaf, small rod, and porous nanosheet $\mathrm{CuO}$ nanostructures for $\mathrm{Pb}$ (II) was $125,116,117,120$, and $115 \mathrm{mg} \mathrm{g}^{-1}$. 


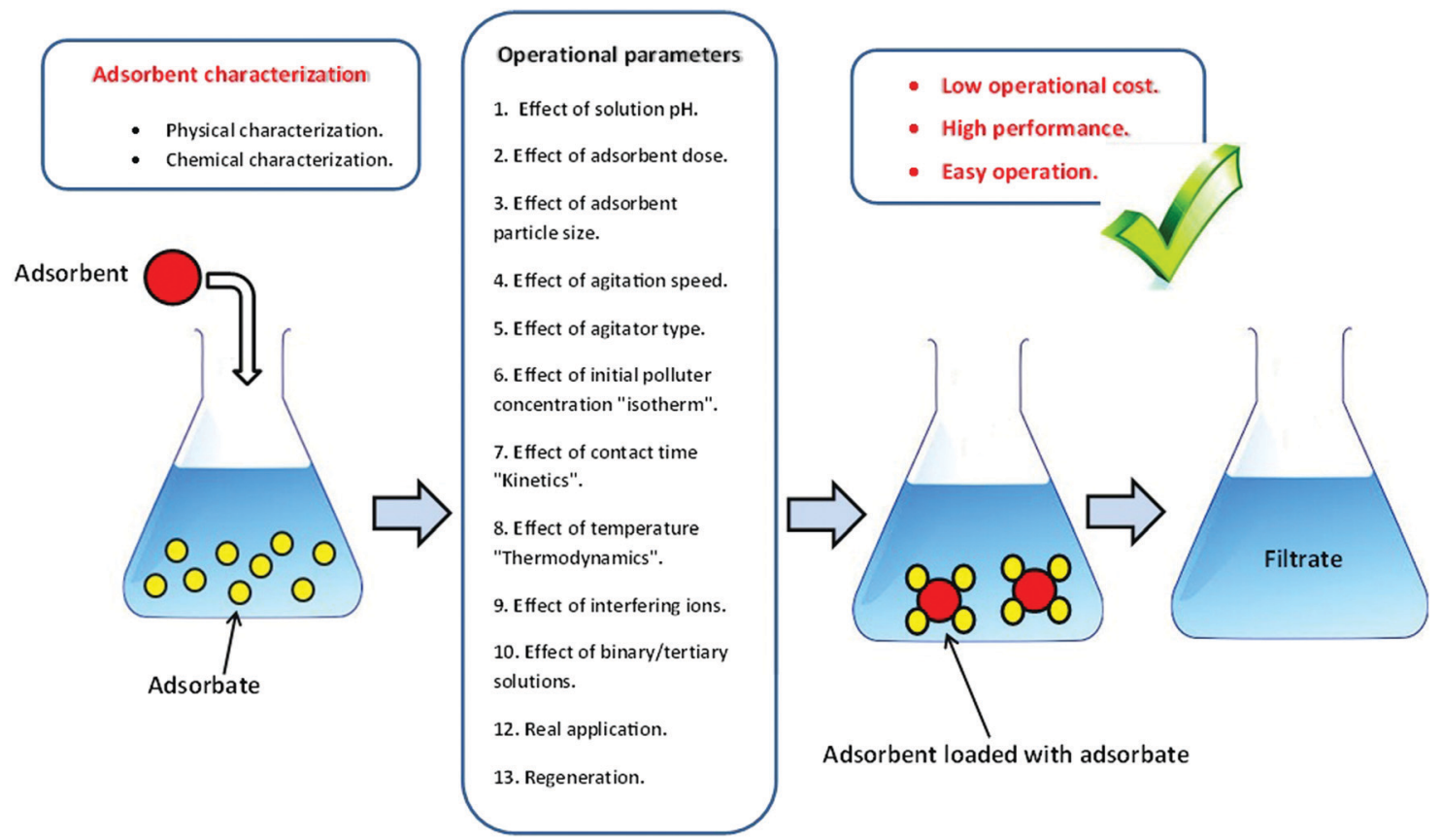

Fig. 4 Schematic diagram of batch adsorption.

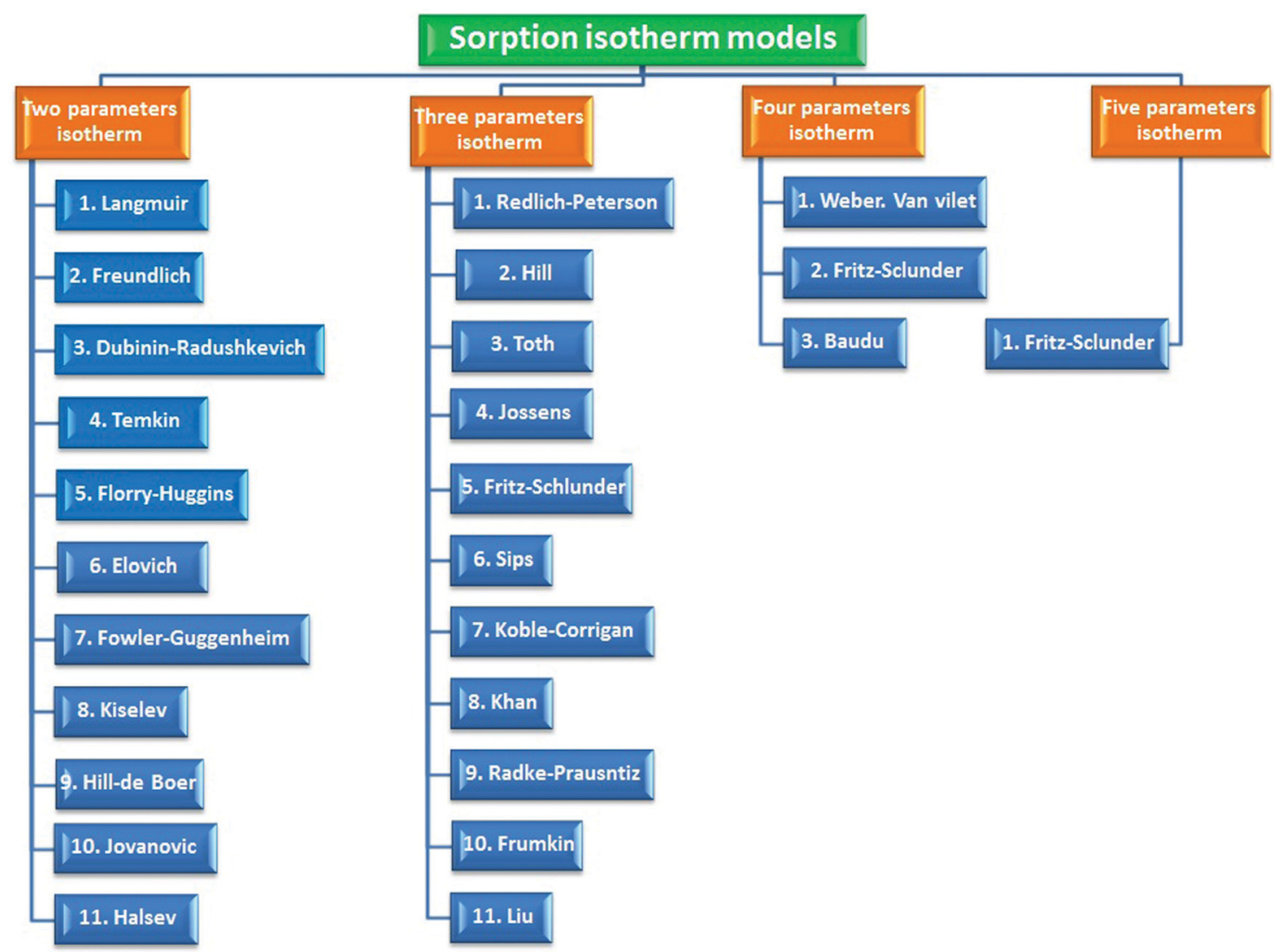

Fig. 5 Different isotherm models based on the number of parameters used.

To acquire a high-efficiency and low-cost adsorbent for arsenic removal from water, a nanostructured $\mathrm{Fe}(\mathrm{III})-\mathrm{Cu}$ (II) binary oxide was devised via the facile coprecipitation method. ${ }^{83}$ Various techniques including BET surface area measurement, 
Table 2 Linearized forms of some different kinetic models

\begin{tabular}{llll}
\hline $\begin{array}{l}\text { Kinetic } \\
\text { model }\end{array}$ & $\begin{array}{l}\text { Nonlinear } \\
\text { form }\end{array}$ & Linear form & Theoretical assumption \\
\hline $\begin{array}{l}\text { Pseudo-first } \\
\text { order }\end{array}$ & $\begin{array}{l}q_{t}= \\
q_{\mathrm{e}}\left[1-\mathrm{e}^{-k_{1} t}\right]\end{array}$ & $\log \left(q_{\mathrm{e}}-q_{t}\right)=\log q_{\mathrm{e}}-\left(\frac{k_{1}}{2.303}\right) t$ & $\begin{array}{l}\text { Based on the sorption capacity and removal rate change with time being } \\
\text { directly proportional to the difference in saturation concentrations (physical } \\
\text { sorption) } \\
\text { Investigates kinetic behavior in the case of a chemical reaction being the rate } \\
\text { controlling step (chemical sorption) }\end{array}$ \\
$\begin{array}{l}\text { Pseudo- } \\
\text { second order }\end{array}$ & $q_{t}=\frac{q_{\mathrm{e}}{ }^{2} k_{2} t}{1+k_{2} q_{\mathrm{e}} t}$ & $\frac{t}{q_{t}}=\frac{1}{k_{2} q_{\mathrm{e}}^{2}}+\left(\frac{1}{q_{\mathrm{e}}}\right) t$ & $\begin{array}{l}\text { Determines the rate controlling step of the sorption process (film diffusion } \\
\text { and/or intraparticle diffusion) }\end{array}$ \\
$\begin{array}{l}\text { Intraparticle } \\
\text { diffusion }\end{array}$ & - & $q_{t}=k_{\mathrm{i}} t^{0.5}+X$ & $\begin{array}{l}\text { Based on the difference in the sorption energies of sorbent active sites which } \\
\text { resulted from the heterogeneous nature of the binding sites }\end{array}$ \\
$\begin{array}{l}\text { Elovich } \\
\text { equation }\end{array}$ & $\frac{\mathrm{d} q_{t}}{\mathrm{~d} t}=\alpha \mathrm{e}^{-\beta q}$ & $q_{t}=\frac{1}{\beta} \ln \alpha \beta+\frac{1}{\beta} \ln t$ &
\end{tabular}

Table 3 Statistical functions used to investigate error deviation between experimental and calculated values

\begin{tabular}{|c|c|}
\hline Functions & Equation \\
\hline An error analysis of the sum of squared errors of prediction (SSE) & $\mathrm{SSE}=\sum_{n=1}^{n}\left(q_{\mathrm{cal}}-q_{\mathrm{exp}}\right)^{2}$ \\
\hline Chi-square statistic $\left(X^{2}\right)$ & $X^{2}=\sum_{n=1}^{n}\left[\frac{\left(q_{\mathrm{e}, \exp }-q_{\mathrm{e}, \mathrm{cal}}\right)^{2}}{q_{\mathrm{e}, \mathrm{cal}}}\right]$ \\
\hline The composite fraction error function (CFEF) & $\mathrm{CFEF}=\sum_{n=1}^{n}\left[\frac{\left(q_{\mathrm{e}, \exp }-q_{\mathrm{e}, \mathrm{cal}}\right)^{2}}{q_{\mathrm{e}, \exp }}\right]$ \\
\hline Average relative error (ARE) & $\mathrm{ARE}=\frac{1}{n} \sum\left(\frac{q_{\mathrm{e}, \mathrm{cal}}-q_{\mathrm{e}, \mathrm{exp}}}{q_{\mathrm{exp}}}\right) \times 100$ \\
\hline Marquardt's percentage standard deviation (MPSD) & $\operatorname{MPSD}=\sqrt{\frac{\sum\left(\frac{q_{\mathrm{e}, \mathrm{exp}}-q_{\mathrm{e}, \mathrm{cal}}}{q_{\mathrm{e}, \exp }}\right)^{2}}{n-P}}$ \\
\hline Hybrid fractional error function (HYBRID) & $\mathrm{HYBRID}=\frac{1}{n-p} \sum\left(\frac{q_{\mathrm{e}, \mathrm{exp}}-q_{\mathrm{e}, \mathrm{cal}}}{q_{\mathrm{e}, \mathrm{exp}}}\right) \times 100$ \\
\hline
\end{tabular}

Here $q_{\mathrm{e}, \exp }$ and $q_{\mathrm{e}, \mathrm{cal}}$ are the experimental and model calculated (predicted) sorption capacity values, respectively, and $n$ is the experimental sample number. $P$ is the number of parameters in each isotherm model.

powder XRD, SEM, and XPS were used to characterize the synthetic $\mathrm{Fe}(\mathrm{III})-\mathrm{Cu}$ (II) binary oxide. Adsorption experiments took place to assess the adsorption kinetics, isotherms, and $\mathrm{pH}$ edge and regeneration of spent adsorbent. The results indicated that the $\mathrm{Fe}(\mathrm{III})-\mathrm{Cu}(\mathrm{II})$ binary oxide with a $\mathrm{Cu}: \mathrm{Fe}$ molar ratio of $1: 2$ performed excellently in displacing $\mathrm{As}(\mathrm{v})$ and As(III) from water, and the maximal adsorption capacities for As(v) and As(III) were 82.7 and $122.3 \mathrm{mg} \mathrm{g}^{-1}$ at $\mathrm{pH} 7.0$, respectively.

It was attempted to synthesize cupric oxide nanoparticles (CuONPs) in a green effective way through utilizing lemon juice extract as a bioreductant. ${ }^{84}$ The CuONPs were applied for $\mathrm{Cr}(\mathrm{vI})$ displacement from water through the method of adsorption. The experimental parameters were optimized through the Box-Behnken Design (BBD) of response surface methodology for the optimum response. The adsorption equilibrium data were well fitted using the Freundlich isotherm model and the kinetics was explained through a pseudo-second-order kinetic model. The entire process proved to be cost effective, spontaneous, and exothermic. The linear approach for analyzing the isotherm as well as kinetic parameters was found to be more appropriate than the nonlinear approach. The experimental results showed that CuO nanoparticles can be good alternatives for the removal of $\mathrm{Cr}(\mathrm{vI})$ from aqueous solutions.
Another type of CuONPs has been effectively created via a green-effective route through employing lemon juice as a bioreductant. ${ }^{85}$ The green method for the synthesis of nanoparticles was cost effective, safe, and eco-friendly. The synthesized CuONPs were characterized by different analytical techniques, e.g., UV-visible, XRD, FTIR, SEM, and TEM analyses. This study revealed that the synthesized CuONPs were excellent solutions for detoxifying water of $\mathrm{Cr}(\mathrm{vI})$ through adsorption. The process of adsorption was found to be spontaneous and endothermic; the equilibrium during adsorption was well explained through pseudo-second-order kinetics.

Synthesizing copper oxide nanoparticles through the reactive magnetron sputtering technique and their adsorptive removal properties for $\mathrm{Pb}$ (II) ions from aqueous solution were investigated. ${ }^{86}$ Various adsorption parameters, e.g., the solution $\mathrm{pH}$, adsorbent dose, initial metal ion concentration, equilibrium contact time and temperature were evaluated for removing maximum $\mathrm{Pb}$ (II) ions. The optimal prerequisites were found to be, respectively, 6 , three hours, and $2 \mathrm{~g} \mathrm{~L}^{-1}$ for a $50 \mathrm{mg} \mathrm{L}^{-1}$ $\mathrm{Pb}$ (II) ion concentration. The adsorption kinetics followed the pseudo-second-order kinetic model, indicating that the adsorption was controlled through the chemisorption process. The adsorption isotherm follows a Langmuir isotherm with a maximum adsorption capacity of $37.03 \mathrm{mg} \mathrm{g}^{-1}$. The $\Delta S$ and 
$\Delta H$ values were found to be positive, indicating the endothermic nature of the adsorption process, while the negative value of the Gibbs free energy $(\Delta G)$ denotes that $\mathrm{Pb}$ (II) adsorption was spontaneous. The study revealed that the synthesized $\mathrm{CuO}$ nanoparticles may be a lucrative solution for removing $\mathrm{Pb}$ (II) ions from aqueous solutions.

A simple one-step approach for devising copper ferrocyanideembedded magnetic hydrogel beads (CuFC-MHBs) was designed, ${ }^{87}$ and the beads were applied to effectively remove Cs and then magnetically separate it from water. The resulting CuFC-MHBs illustrated the effectiveness of Cs removal performance with a high $K_{\mathrm{d}}$ value of $66780 \mathrm{~mL} \mathrm{~g}^{-1}$ and exemplary structural stability without the release of CuFC for at least one month; it was effectively separated from water by an external magnet. Additionally, the CuFC-MHBs selectively adsorbed Cs with high $K_{\mathrm{d}}$ values in the presence of different competing ions, such as in simulated groundwater $\left(24500 \mathrm{~mL} \mathrm{~g}^{-1}\right)$ and seawater $\left(8290 \mathrm{~mL} \mathrm{~g}^{-1}\right)$. Also, they maintained their Cs absorption capacity in a wide pH spectrum, from 3 to 11 . The convenient fabrication method and effective removal of Cs from various aqueous media showed that CuFC-MHBs show massive potential for practical application in the decontamination of Cs-contaminated water sources resulting from radioactive liquid waste and nuclear accidents in different nuclear industry fields.

\subsection{Zinc-incorporating adsorbents}

Efficient adsorbents made from $\mathrm{Mg}-\mathrm{Al}-\mathrm{Zn}$-mingled oxides were prepared by the coprecipitation method. ${ }^{88}$ The structure, composition, morphology, and thermal stability of the created $\mathrm{Mg}$-Al-Zn-mingled oxides were assessed by powder X-ray diffraction, Fourier-transform infrared spectrometry, $\mathrm{N}_{2}$ physisorption, scanning electron microscopy, differential scanning calorimetry, and thermogravimetry. The prepared $\mathrm{Mg}-\mathrm{Al}-$ Zn-mingled oxides can be used as a viable adsorbent for the removal of $\mathrm{Co}(\mathrm{II})$ and $\mathrm{Ni}(\mathrm{II})$ from their aqueous solutions. The maximum adsorption capacity was $116.7 \mathrm{mg} \mathrm{g}^{-1}$ and $70.4 \mathrm{mg} \mathrm{g}^{-1}$ for $\mathrm{Co}$ (II) and $\mathrm{Ni}$ (II), respectively. The adsorbed metal ion amount was found to differ with increasing the initial $\mathrm{pH}$ value of the solution up to a point where metal ions are precipitated out in the alkaline solution. The optimum $\mathrm{pH}$ was found to be 6 and 5.5 for $\mathrm{Co}(\mathrm{II})$ and $\mathrm{Ni}(\mathrm{II})$, respectively. The experimental data remained per the equation of the PSO rate. The equilibrium data of the metals were fitted optimally using the Langmuir isotherm and Freundlich isotherm models, and the maximum adsorption capacity values were $113.8 \mathrm{mg} \mathrm{g}^{-1}$ and $79.4 \mathrm{mg} \mathrm{g}^{-1}$ for $\mathrm{Co}(\mathrm{II})$ and Ni(II), respectively. The outcome denotes that the adsorbent provides a cost-effective method for removing heavy metal ions from contaminated wastewater.

The potential uses of $\mathrm{ZnO}$ and its microparticles and $\mathrm{TiO}_{2}$ nanoparticles to rid groundwater of arsenic were evaluated. ${ }^{89}$ The outcomes showed that the arsenic adsorption efficiency surged in proportion with the reduction of the adsorbents' particle size. Upon using $\mathrm{ZnO}$ and $\mathrm{TiO}_{2}$ nanoparticles, their adsorption capacities were 0.85 and $0.99 \mathrm{mg} \mathrm{g}^{-1}$, respectively. $\mathrm{TiO}_{2}$ nanoparticles showed better adsorption ability for arsenic than that of $\mathrm{ZnO}$ since the first had a smaller average particle size and larger surface area. In aqueous solution, metal oxide nanoparticles have a hydroxyl surface that allowed the physisorption of incoming $\mathrm{HAsO}_{4}{ }^{2-}$ ions via hydrogen bonding; this resulted in a better arsenic adsorptive capacity.

Meng et al. (2018) ${ }^{90}$ developed a one-pot method to remove $\mathrm{CrO}_{4}{ }^{2-}$ from wastewater by forming $\mathrm{Zn}$ Al-Layered Double Hydroxides (ZnAl-LDH). By this process, the efficiency of $\mathrm{Cr}(\mathrm{vI})$ removal was nearly $100 \%$ and reached the theoretical maximum of the ZnAl-LDH removal capacity. In addition, mixed contaminants of $\mathrm{Cr}(\mathrm{vI})$ and dyes in wastewater can be separated from each other by controlling the addition of $\mathrm{Zn} / \mathrm{Al}$ solution using this one-pot method.

A ZnO-tetrapod-activated carbon (ZnO-T/AC) nanocomposite was synthesized as an adsorbent for efficient decontamination of $\mathrm{Cr}(\mathrm{vI})$ from an aqueous medium. ${ }^{91}$ The reduction of $\mathrm{Cr}(\mathrm{vI})$ using the $\mathrm{ZnO}-\mathrm{AC}$ adsorbent was influenced by the $\mathrm{pH}$ value, contact time and dose of the adsorbent. The maximum reduction efficiency of $\mathrm{Cr}(\mathrm{VI})$ to $\mathrm{Cr}(\mathrm{III})$ by $\mathrm{AC}, \mathrm{ZnO}$, and $\mathrm{ZnO}-\mathrm{AC}$ adsorbents occurred at $\mathrm{pH}$ 2.0. At optimum $\mathrm{pH} 2$, AC, ZnO-T, and $\mathrm{ZnO}-\mathrm{T} / \mathrm{AC}$ showed $43 \%$, 55\%, and $97 \% \mathrm{Cr}(\mathrm{vI})$ reduction, respectively. The pseudo-second-order model and intraparticle diffusion and Elovich models were used to determine the adsorption capacity and the kinetic rate constant, and fitted well for all the adsorbents.

\subsection{Iron-incorporating adsorbents}

Nonmagnetic iron oxide-hydroxide nanoparticles of a spherical morphology and their application for defluorination of drinking water were reported. ${ }^{92}$ XRD, BET surface area, FTIR, Field Emission Scanning Electron Microscopy (FESEM), and Transmission Electron Microscopy (TEM) images were utilized to detect nanoscale iron oxide-hydroxide. TEM imagery revealed that the iron oxide-hydroxide nanoparticles were formed in a spherical morphology. These nanoparticles exhibited an exemplary capacity to displace fluoride from contaminated water within a wide range of $\mathrm{pH}$. The effects of temperature, $\mathrm{pH}$, stirring speed, the dose of adsorbent, and contact time were evaluated. The equilibrium data were verified with different isotherm models. Eventually, a calculation procedure was devised to determine the adsorbent requirement. The nanoparticles with adsorbed fluoride were regenerated up to $70 \%$ using sodium hydroxide or hydrochloric acid solution. The iron oxide-hydroxide nanoparticles can be employed as an effective and replicable adsorbent media for defluorination of water in the presence of competing anions like chloride, iodate, iodide, and sulfate.

Sulfidated zerovalent iron (S-ZVI) is garnering more attention owing to its easy-to-prepare and highly-reactive nature with contaminants. ${ }^{93}$ The results showed that sulfidation of zerovalent iron (ZVI) could significantly increase the $\mathrm{Cr}(\mathrm{vI})$ and $\mathrm{Sb}$ (III) sequestration simultaneously. During the sequestration of these pollutants, $\mathrm{Cr}(\mathrm{VI})$ was diminished into $\mathrm{Cr}$ (III) and $\mathrm{Sb}$ (III) was oxidized into $\mathrm{Sb}(\mathrm{v})$; both processes occurred simultaneously in this system. The sequestration rate of $\mathrm{Cr}(\mathrm{VI})$ and $\mathrm{Sb}(\mathrm{III})$ increased with the $\mathrm{pH}$ surging from 4.0 to 6.0 but diminished when the $\mathrm{pH}$ continued to rise to 8.0. More 
surface $\mathrm{Fe}(\mathrm{II})$ regenerated at $\mathrm{pH}$ 6.0, which significantly contributes to $\mathrm{Cr}(\mathrm{vI})$ sequestration.

Mubarak et al. $(2018)^{94}$ prepared $\mathrm{Mg} / \mathrm{Fe}$-layered double hydroxide (MF-LDH) hollow nanospheres by a simple thermal method. After calcination at $400{ }^{\circ} \mathrm{C}$, the MF-LDH hollow nanospheres were converted into the corresponding oxide. The nanospheres showed remarkable efficiency in removing $\mathrm{As}(\mathrm{v})$ and $\mathrm{Cr}(\mathrm{vI})$ ions, with maximum adsorption capacities of $178.6 \mathrm{mg} \mathrm{g}^{-1}$ for $\mathrm{As}(\mathrm{vI})$ and $148.7 \mathrm{mg} \mathrm{g}^{-1}$ for $\mathrm{Cr}(\mathrm{vI})$. Complete heavy metal removal $(\sim 99.9 \%)$ from wastewater up to the drinking water level (WHO standards) was achieved in $20 \mathrm{~min}$ and $10 \mathrm{~min}$ for $\mathrm{As}(\mathrm{vI})$ and $\mathrm{Cr}(\mathrm{vI})$, respectively. This material should facilitate practical applications in cost-effective wastewater purification.

Siderite $\left(\mathrm{FeCO}_{3}\right)$, an iron(II)-containing mineral, exists in many anaerobic sediments and groundwater systems. Siderite is an effective material for removing $\mathrm{Cr}(\mathrm{vI})$ in aqueous conditions with a maximum sorption of $81 \mathrm{mg} \mathrm{g}^{-1}$ at $\mathrm{pH} 5 .{ }^{95}$ The outcomes denote that within anoxic aqueous parameters, $\mathrm{Cr}(\mathrm{VI})$ can be detoxified by siderite provided that these coupled sorptions and redox reactions are being controlled by the initial $\mathrm{Cr}(\mathrm{vI})$ concentrations and $\mathrm{pH}$.

Graphene-coated iron oxide nanoparticles (GCIO) were devised via the microemulsion method for removing $\operatorname{Cr}(\mathrm{vI})$ ions from aqueous solutions. ${ }^{96}$ A swift and remarkable $\mathrm{Cr}(\mathrm{III})$ and $\mathrm{Cr}(\mathrm{vI})$ ion removal efficiency is exhibited by aqueous solutionprepared GCIO, which is $99.13 \%$ with $0.06 \mathrm{~g}$ GCIO in $100 \mathrm{ppm}$ adsorbate solution as confirmed by EDX analysis. The adsorption process follows pseudo-second-order kinetics with an $R^{2}$ value of 0.97 and the Freundlich model isotherm with a high adsorption capacity. $\operatorname{The} \mathrm{Cr}(\mathrm{vI})$ removal surges with the increase in temperature, revealing the endothermic nature of the process of adsorption. GCIO also shows a high intraparticle diffusion value with an $R^{2}$ value of 0.98 . GCIO maintains remarkable stability in an extremely acidic environment when treated with concentrated acid for 24 hours as well as a reusable nature to the same extent for adsorption of $\mathrm{Cr}(\mathrm{vI})$.

A multifunctional adsorbent was developed by preparing a composite of $\mathrm{Fe}_{2} \mathrm{O}_{3}$ and $\mathrm{ZnO} .{ }^{97}$ The prepared composite removed $\mathrm{Cr}(\mathrm{vI})$ efficiently. The data of adsorption corroborated well with the Freundlich isotherm model and pseudo-secondorder kinetic model with $R^{2}$ values close to 1 . The $1: 1$ ratio of $\mathrm{Fe}_{2} \mathrm{O}_{3}$ and $\mathrm{ZnO}$ provided the optimum sorption properties to the sorbent. At this ratio, the maximum adsorption capacity of the adsorbent was $36.50 \mathrm{mg} \mathrm{g}^{-1}$.

Mechano-chemically sulfidated microscale zerovalent iron (S-mZVIbm) is a potential remedy for groundwater for the removal of $\mathrm{Cr}(\mathrm{vI}){ }^{98}{ }^{98}$ Removing $\mathrm{Cr}(\mathrm{vI})$ by S-mZVIbm is mainly a process of a chemisorption nature and its kinetics was well fitted by a pseudo-second-order model. Alkaline $\mathrm{pH}$ halted the removal of $\mathrm{Cr}(\mathrm{vI})$ while dissolved oxygen slightly depressed the removal of $\operatorname{Cr}(\mathrm{vr})$. The high extent of removal of $\operatorname{Cr}(\mathrm{vI})$ by S-mZVIbm compared to its unsulfidated contemporary mZVIbm is a result of its enhanced surface area.

Another nanoscale zerovalent iron (nZVI) sorbent with a considerably high surface area $\left(182.97 \mathrm{~m}^{2} \mathrm{~g}^{-1}\right)$ with chain-structure morphology was synthesized and well characterized. ${ }^{99}$ The as-prepared nZVI can entirely displace $\mathrm{Cr}(\mathrm{vI})$ under anoxic conditions after a reaction of $20 \mathrm{~min}$; on the other hand, only $43 \%$ of $\mathrm{Cr}(\mathrm{vI})$ was removed after a reaction of 60 min under oxic conditions. Notably, nZVI demonstrates a remarkable removal capacity of $\operatorname{Cr}(\mathrm{vI})\left(123.85 \mathrm{mg} \mathrm{g}^{-1}\right)$ as well as a quick removal rate $\left(0.017 \mathrm{~g} \mathrm{mg}^{-1} \mathrm{~min}^{-1}\right)$. Moreover, the as-prepared nZVI exhibited swift displacement of traced $\mathrm{Cr}(\mathrm{vi})$ from Cr-spiked drinking water or actual Cr-contaminated lake water. $\mathrm{Cr}(\mathrm{vI})$ removal experimental results from simulated Cr-contaminated tap, drinking, and actual lake water show the effectiveness of the as-prepared nZVI as a potential material for the quick removal of traced $\mathrm{Cr}(\mathrm{vI})$ from Cr-spiked drinking water or actual Cr-contaminated lake water.

After being analyzed and characterized, nanoadsorbents of core-shell bimagnetic nanoparticles $\left(\mathrm{CoFe}_{2} \mathrm{O}_{4} @ \gamma-\mathrm{Fe}_{2} \mathrm{O}_{3}\right)$ with two different mean sizes were applied as potential sorbents for removing $\mathrm{Cr}(\mathrm{vI})$ from aqueous solutions via magnetic-assisted chemical separation. ${ }^{100}$ The adsorption data checked out with the Freundlich model, denoting that the $\mathrm{Cr}(\mathrm{vI})$ species create multilayers surrounding the nanoadsorbent surface. The utmost removal percentage was gauged at $\mathrm{pH}=2.5$ with an orbital shaking rate of $400 \mathrm{rpm}$, and the maximum adsorption capacities obtained were higher or close to those of other magnetic adsorbents dedicated to removing $\mathrm{Cr}(\mathrm{vI})$. The improved adsorption capacity of the sample according to smaller nanoparticles was related to its higher BET surfaces. The adsorption rapidly achieved equilibrium and the kinetic data adhered to the pseudo-second-order model, implying that the rate-controlling step of the process revolved around ionic interactions between the surface sites and the $\operatorname{Cr}(\mathrm{vI})$ species. The thermodynamic analysis yielded that the adsorption is endothermic and spontaneous. The process was found to be enhanced at higher temperatures and presented increased randomness at the surface/ solution interface. The magnetic nanoadsorbents also demonstrated a high selectivity towards $\mathrm{Cr}(\mathrm{VI})$ and good renewability for reuse, establishing them as a greener material. The adsorption capability remained high in simulated wastewater. This process can be efficiently applied to other related heavy metals such as molybdenum and arsenic.

Jain et al. $(2018)^{101}$ fabricated magnetite $\left(\mathrm{Fe}_{3} \mathrm{O}_{4}\right)$ and magnetite/activated-carbon $\left(\mathrm{Fe}_{3} \mathrm{O}_{4} / \mathrm{AC}\right)$ through the coprecipitation method for removing $\mathrm{Cr}(\mathrm{VI}), \mathrm{Cu}(\mathrm{II})$, and $\mathrm{Cd}(\mathrm{II})$ ions from aqueous solution in batch mode. The optimal conditions for the removal of ions were as follows: $\mathrm{pH}=2$ for $\mathrm{Cr}(\mathrm{vI})$ desorption studies with $0.1 \mathrm{M} \mathrm{HCl}$. It is stated that these nanoparticles can be regenerated effectively, allowing them to be reused for up to four adsorption-desorption cycles without any loss in mass.

A highly selective $\mathrm{Fe}_{3} \mathrm{O}_{4} @ A r g$-PPy adsorbent was effectively synthesized by a one-pot chemical polymerization of pyrrole with arginine and was made commercially available as $\mathrm{Fe}_{3} \mathrm{O}_{4}$ NPs. The FTIR, VSM, XRD, and TEM analyses of the $\mathrm{Fe}_{3} \mathrm{O}_{4}$ @ Arg-PPy nanocomposite imply the successful implementation of arginine and $\mathrm{Fe}_{3} \mathrm{O}_{4}$ into PPy. ${ }^{102}$ The batch experimental results showed a highly pH-dependent removal of $\mathrm{Cr}(\mathrm{vr})$ at the optimum $\mathrm{pH}$ value of 2 . The process of adsorption was 
Langmuir modeled with adsorption capacities of 294.11, $322.58,370.37$, and $416.67 \mathrm{mg} \mathrm{g}^{-1}$ at $15,25,35$, and $45{ }^{\circ} \mathrm{C}$, respectively. The $\mathrm{Cr}(\mathrm{vI})$ removal kinetics via $\mathrm{Fe}_{3} \mathrm{O}_{4} @ A r g-P P y$ conformed to the pseudo-second-order model, and the determined rate constant was $6.67 \times 10^{-3} \mathrm{~g} \mathrm{~m}^{-1} \mathrm{~min}^{-1}$ at room temperature for a solution of an initial $\mathrm{Cr}(\mathrm{vI})$ concentration of $50 \mathrm{mg} \mathrm{L}^{-1}$ and pH 2. The thermodynamic parameters that were calculated were as follows: $\Delta G^{\circ}-4.76 \mathrm{~kJ} \mathrm{~mol}^{-1}$ at $25{ }^{\circ} \mathrm{C}, \Delta H^{\circ}$ $+76.16 \mathrm{~kJ} \mathrm{~mol}^{-1}, \Delta S^{\circ}+0.27 \mathrm{~kJ} \mathrm{~mol}^{-1} \mathrm{~K}^{-1}$ and $E_{\mathrm{a}} 49.91 \mathrm{~kJ} \mathrm{~mol}^{-1}$, showing an endothermic, spontaneous, and chemisorption process.

A Microsized Granular Ferric Hydroxide (mGFH) adsorbent for chromate removal in competition with ions present in drinking water was elaborated. ${ }^{103}$ The results show a high dependency on the $\mathrm{pH}$ value with increasing adsorption in correspondence to decreasing $\mathrm{pH}$ values. Competing ions present in drinking water were tested for interfering effects on chromate adsorption. Bicarbonate was identified as the main inhibitor of chromate adsorption. Sulfate, silicate, and phosphate also decreased chromate loadings, while calcium enhanced chromate adsorption. The adsorption equilibrium was reached after $60 \mathrm{~min}$ for particles smaller than $63 \mathrm{~mm}$, while $240 \mathrm{~min}$ was required for particles from $125 \mathrm{~mm}$ to $300 \mathrm{~mm}$. The adsorption kinetics in single-solute systems could be modeled using the Homogeneous Surface Diffusion Model (HSDM) with a surface diffusion coefficient of $4 \times 10^{-14} \mathrm{~m}^{2} \mathrm{~s}^{-1}$.

Wen et al. $(2019)^{104}$ successfully synthesized nanosized ordered Magnetic Mesoporous Fe-Ce bimetal oxides (nanosizedMMIC) with a highly well-ordered interconnected mesostructure. This nanosized-MMIC exhibited remarkable adsorption capabilities for $\mathrm{As}(\mathrm{v}), \mathrm{Cr}(\mathrm{vI})$, and acid orange $7\left(\mathrm{AO}_{7}\right)$ and the corresponding calculated maximum adsorption capacities of the materials were $111.17,125.28$, and $156.52 \mathrm{mg} \mathrm{g}^{-1}$, respectively. The removal of $\mathrm{As}(\mathrm{v})$ and $\mathrm{Cr}(\mathrm{vI})$ by nanosized-MMIC was slightly dependent on the ionic strength, yet it was highly solution-pH dependent; the coexistent silicate and phosphate ions competed excellently with $\mathrm{As}(\mathrm{v})$ and $\mathrm{Cr}(\mathrm{vI})$ for the adsorption active sites. The mechanisms implied that $\mathrm{As}(\mathrm{v})$ and $\mathrm{Cr}(\mathrm{vI})$ formed inner-sphere complexes on the nanosized-MMIC interface through surface complexation and electrostatic interaction. Nanosized-MMIC is anticipated to be a potential excellent nano-adsorbent with high potential for application for removing coexisting organic dyes and toxic heavy metals in specific wastewater treatment. The adsorption capacity of some selected iron incorporating adsorbents are reported in Table 4.

\subsection{Other metallic adsorbents}

The aluminum oxide hydroxide efficiency to displace trivalent chromium from aqueous solutions through batch mode experiments was assessed. ${ }^{163}$ The effects of the contact time, $\mathrm{pH}$, initial concentration, and dosage on $\mathrm{Cr}(\mathrm{III})$ adsorption were evaluated. This study divulged that more than $99 \%$ of $\mathrm{Cr}(\mathrm{III})$ was removed over a wide range of initial pH (3-10). The optimal parameters for removing $\mathrm{Cr}$ (III) were established to be at $\mathrm{pH} 4-6$ with a $40 \mathrm{~g} \mathrm{~L}^{-1}$ adsorbent dose within a contact time of $60 \mathrm{~min}$. The capacity of adsorption was evaluated via Langmuir and
Freundlich isotherms. The equilibrium data at varying adsorbent dosage crosscheck with the two isotherms. The adsorbent was found to be optimal for removing Cr(III) from waste effluent from a tannery.

Mikhaylov et al. (2018) ${ }^{164}$ synthesized Al/Fe oxide-oxyhydroxide composite powders through a hydrothermal method applying metal sulfate solutions and urea as precursors. The maximum specific surface area $\left(190 \mathrm{~m}^{2} \mathrm{~g}^{-1}\right)$ is reached for the synthesized samples synthesized from solutions with $\left[\mathrm{Al}^{3+}\right]:\left[\mathrm{Fe}^{3+}\right]=1: 0$ and $1: 1$. However, sulfate ions present on the surface of Al-containing samples inhibit the adsorption of $\mathrm{Cr}(\mathrm{vI})$. The maximum capacity for adsorption in the batch regime $\left(3.66 \mathrm{mg} \mathrm{g}^{-1}\right)$ was for a sample synthesized from solutions with $\left[\mathrm{Al}^{3+}\right]:\left[\mathrm{Fe}^{3+}\right]=1: 6$, which had a high (though not maximal) surface area $\left(102 \mathrm{~m}^{2} \mathrm{~g}^{-1}\right)$, a low-sulfate content, and maximum zeta potential. Sorption experiments illustrated that the mean free adsorption energy was lower than $8 \mathrm{~kJ} \mathrm{~mol}^{-1}$ for the entirety of the samples; this indicates that the process of adsorption was physical and the possibility of $\mathrm{Cr}(\mathrm{vi})$ desorption and adsorbent regeneration.

Another type of metallic adsorbent based on Apatitic Tricalcium Phosphate powder (ATrPh-105) was devised and analyzed by different techniques of characterization. ${ }^{165}$ At $60{ }^{\circ} \mathrm{C}$ and under acidic conditions, a higher adsorption capacity $\left(527.19 \mathrm{mg} \mathrm{g}^{-1}\right)$ towards $\mathrm{Cr}(\mathrm{vI})$ was recorded. The kinetic data of the adsorption of $\mathrm{Cr}(\mathrm{vI})$ onto ATrPh-105 adhered to pseudo-second-order kinetics. The results of isotherms and thermodynamics studies affirmed that $\mathrm{Cr}(\mathrm{vI})$ adsorption onto ATrPh-105 is endothermic, which happens to fit the Langmuir isotherm as well. According to the thermodynamic results of the sorption of $\mathrm{Cr}(\mathrm{vI})$ onto ATrPh-105, the process was controlled by a chemical reaction. Additionally, ATrPh-105 illustrated $\mathrm{Cr}(\mathrm{vI})$ high sorption efficiency (90.22\%) following three cycles of adsorption-regeneration. This finding confirms the potential of ATrPh-105 as an efficient adsorbent with room for utilization in various environmental applications.

\subsection{Silica-based adsorbents}

Corn cob silica-supported nanoscale zerovalent iron (MCCS) is a nano biocomposite that was developed by a facile technique, and its efficiency for removal of $\mathrm{Cr}(\mathrm{vI})$ from aqueous solution was evaluated. ${ }^{166}$ The adsorption data illustrated that the extent of fitting with models is higher in the pseudo-second-order kinetics as compared with the pseudo-first-order kinetics model. Corn cob silica is a cost-effective material. From the studied results, it is divulged that the efficiency of the removal is correlated to the $\mathrm{pH}$ value of the solution and temperature and the sorption kinetics. Moreover, thanks to its magnetic property, this material is potent in overcoming the separation problems concerning adsorption-based treatment techniques, alongside other advantages such as being environmentally friendly and highly efficient, and its high capacity. Thus, MCCS can also be utilized for removing other toxic elements present in wastewater.

Dutta and Nath (2018) ${ }^{167}$ synthesized a $\mathrm{SiO}_{2} /$ carbon nanocomposite $\left(\mathrm{SiO}_{2} / \mathrm{CCNC}\right)$ and nanoporous carbon (CCNC) from a simple, low-cost, and industry-scalable method from corn cob 
Table 4 Adsorption capacity of some selected iron incorporating adsorbents

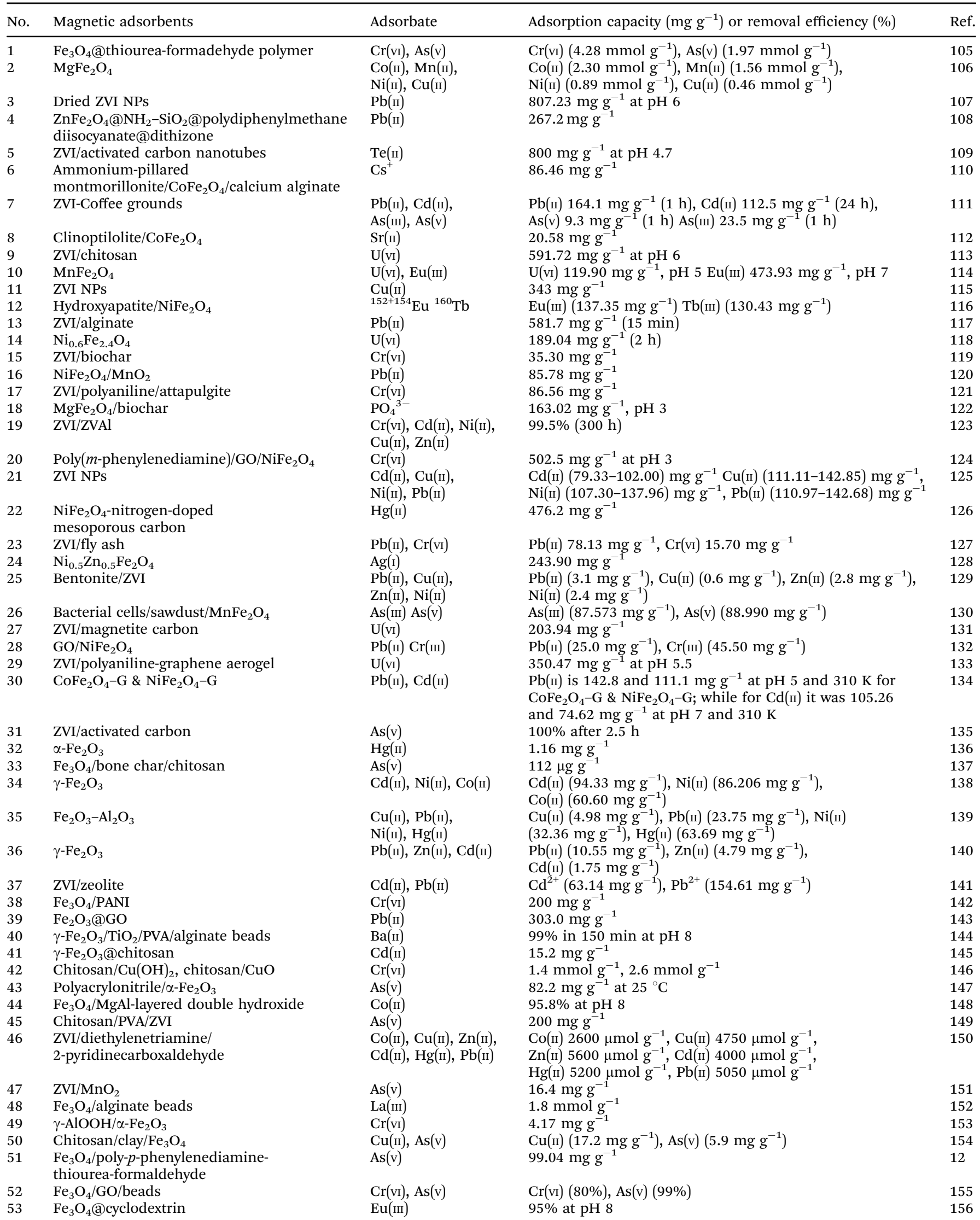


Table 4 (continued)

\begin{tabular}{|c|c|c|c|c|}
\hline No. & Magnetic adsorbents & Adsorbate & Adsorption capacity $\left(\mathrm{mg} \mathrm{g}^{-1}\right)$ or removal efficiency (\%) & Ref. \\
\hline 55 & Functionalized nanosilica & $\mathrm{Cu}(\mathrm{II})$ & $386.4 \mathrm{mg} \mathrm{g}^{-1}$ & 157 \\
\hline 58 & $\begin{array}{l}\text { Zeolitic imidazolate frameworks } \\
\text { confined in polystyrene }\end{array}$ & Benzotriazole & $210.4 \mathrm{mg} \mathrm{g}^{-1}$ & 160 \\
\hline 60 & $\begin{array}{l}\text { Aromatic ring-functionalized } \\
\text { chitosan magnetic composite }\end{array}$ & $\begin{array}{l}\text { Norfloxacin, tylosin, } \\
\text { diclofenac sodium }\end{array}$ & $327.5 \mathrm{mg} \mathrm{g}^{-1}, 843.5 \mathrm{mg} \mathrm{g}^{-1}, 438.6 \mathrm{mg} \mathrm{g}^{-1}$ & 162 \\
\hline
\end{tabular}

biowaste. The higher BET specific surface area of $\mathrm{SiO}_{2} / \mathrm{CCNC}$ $\left(715.22 \mathrm{~m}^{2} \mathrm{~g}^{-1}\right)$ compared with CCNC $\left(430.17 \mathrm{~m}^{2} \mathrm{~g}^{-1}\right)$ allows for enhanced adsorption efficiency. The uptake of $\mathrm{Cr}(\mathrm{vI})$ ions was also tested in the presence of interfering salts such as $\mathrm{NaCl} /$ $\mathrm{Na}_{2} \mathrm{SO}_{4}$. The effects of temperature, $\mathrm{pH}$, and concentration of the dye on the efficiency of sorption of the $\mathrm{SiO}_{2} / \mathrm{CCNC}$ nanocomposite and CCNC for MB dye were evaluated. The adsorption process kinetics adhered to the pseudo-first-order model for CCNC and a pseudo-second-order model for the $\mathrm{SiO}_{2} / \mathrm{CCNC}$ nanocomposite. The experimental data acquired for $\mathrm{SiO}_{2} / \mathrm{CCNC}$ and CCNC adhere to Bangham's pore diffusion model, indicating pore diffusion as the rate-controlling step during MB adsorption. The isotherm data match the Freundlich model for $\mathrm{SiO}_{2} / \mathrm{CCNC}$ and CCNC, which is a telltale of multilayer sorption. Hence, it can be deduced that $\mathrm{SiO}_{2} / \mathrm{CCNC}$ is a potential low-cost adsorbent compared with commercial activated carbon for removing pollutants like $\mathrm{MB}$ dye and $\mathrm{U}(\mathrm{vI}) / \mathrm{Cr}(\mathrm{vI})$ ions from water and wastewater.

Carboxyl-group-functionalized mesoporous silica (CFMS) prepared by a one-pot cocondensation method was employed for the Solid Phase Extraction (SPE) of chromium species. ${ }^{168}$ The captured $\mathrm{Cr}(\mathrm{III})$ can be eluted by using $\mathrm{HNO}_{3}$ and detected by ICP-MS, and the concentration of $\mathrm{Cr}(\mathrm{VI})$ was the difference between the total chromium and $\mathrm{Cr}(\mathrm{III})$. This protocol has been successfully applied to detect inorganic chromium species in environmental water (rain and lake and river water) with recoveries between $91.9 \%$ and $103 \%$. Therefore, this developed method exhibited good potential for the speciation of chromium in environmental water samples.

\subsection{Zeolite-based adsorbents}

Adsorptive $\mathrm{Cr}(\mathrm{vI})$ removal from an aqueous solution was evaluated using a natural zeolite, clinoptilolite, in the shape of a Hollow Fiber Ceramic Membrane (HFCM). ${ }^{169}$ The performance of the HFCM in adsorption/filtration was $44 \% \mathrm{Cr}(\mathrm{vI})$ removal at a concentration of $40 \mathrm{mg} \mathrm{L}^{-1}$ and $\mathrm{pH}$. The natural zeolitebased HFCM has potential as a single-step removal-byadsorption process for $\mathrm{Cr}(\mathrm{vI})$ for treating wastewater. The slightly low removal could be a result of the high feed concentration and the HFCM's morphology. This performance can be further increased by maintaining the particle size of the natural zeolite and the sintering temperature and preconditioning the feed before the adsorption and filtration processes. The HFCM also exhibited self-accelerating adsorption behavior, which was translated from some mechanisms and models. The membrane can be potentially developed in different separation systems such as membrane contact and membrane distillation.

Elwakeel et al. $(2018)^{170}$ prepared a composite material (PAN-Na-Y-zeolite) through the polymerization of acrylonitrile in the presence of Na-Y-zeolite. The composite was made usable through amidoximation as a result of the reaction of hydroxylamine on nitrile groups of the composite. The adsorbent (APNa-Y-zeolite) was characterized by FTIR spectrometry, XRD diffraction, SEM, TGA, zetametry, and BET analysis. The adsorption properties of APNa-Y-zeolite were evaluated for the recovery of $\mathrm{Cu}(\mathrm{II}), \mathrm{Cd}(\mathrm{II})$, and $\mathrm{Pb}$ (II) from synthetic solutions prior to being tested for purity standards of drinking water. The properties of adsorption were profiled through the study of the effect of $\mathrm{pH}$, adsorption isotherms, and uptake kinetics. The PSORE adhered to the kinetic profiles. Langmuir, Freundlich, and Sips equations were used to model adsorption. Variation of temperature was used as a benchmark to evaluate thermodynamic parameters. While the adsorption of $\mathrm{Cu}(\mathrm{II})$ and $\mathrm{Cd}(\mathrm{II})$ was endothermic, $\mathrm{Pb}$ (II) recovery was exothermic. Metal ions were effectively desorbed using $5 \mathrm{M} \mathrm{HCl}$ solutions. High concentrations of $\mathrm{NaCl}$ scarcely affect the sorption performance.

\section{Biosorbents}

The utility of a bacteria (Nitrosomonas)-modified zirconium Metal-Organic Framework (MOF) was tested for the remediation of toxic $\mathrm{Cr}(\mathrm{vI}){ }^{171}$ The proposed MOF-Nitrosomonas combination emphasized the crucial impact and convergence of biotechnology and porous materials to detoxify $\mathrm{Cr}(\mathrm{vI})$. Supported by composite analytical characterization techniques, chromium interaction with the biosorbent was well established. The porosity of the metal-organic framework in conjunction with the functional groups $\left(\mathrm{NH}_{2}, \mathrm{COOH}\right.$, and $\left.\mathrm{OH}\right)$ on the bacterial cell surface enhances the affinity between the hydrochlorate anion and the biosorbent through an electrostatic interaction mechanism. With a Langmuir adsorption capacity of $23.69 \mathrm{mg} \mathrm{g}^{-1}$, facile 
adsorption-desorption kinetics and favorable thermodynamics, a removal efficiency exceeding 95\% was attained with this biosorbent. The proof of concept was verified in removing chromium in a certified rock phosphate sample with utmost efficiency. The biosorbent reusability was confirmed via facile desorption employing $\mathrm{NaOH}$ for three adsorption-desorption cycles. In principle, the microbe-modified MOF represents an interesting confluence of biotechnology and materials science towards the development of sustainable methods for removing various pollutants from the environment.

Spent C. monacanthastem (CS) is a copiously available agrowaste material that was experimented upon for adsorbing noxious pollutants from water systems. Toxic $\mathrm{Cr}(\mathrm{vI})$ adsorption has been verified by EDX and FTIR techniques. The adsorption behavior of the adsorbates was highly correlated with the $\mathrm{pH}$ of the solution. ${ }^{172}$ The maximum adsorption of $\mathrm{Cr}(\mathrm{vI})$ was recorded at 2.0, and the maximum monolayer adsorption capacity $\left(Q_{\mathrm{m}}: \mathrm{mg}^{-1}\right)$ of $\mathrm{Cr}(\mathrm{vI})$ was recorded to be $67.88 \mathrm{mg} \mathrm{g}^{-1}$. The thermodynamic evaluation confirmed the endothermic and spontaneous displacement of adsorbate ions from the aqueous phase. On the other hand, the desorption assessment showed that the adsorbate was efficiently removed from the adsorbent's surface with greater adsorption uptake (\%) after five cycles. The use of CS-AC as an adsorbent for $\mathrm{Cr}(\mathrm{vI})$ was highly economic and competent, indicating potential use for detoxification of water.

The utilization of magnetic activated carbon modified with Poly Amidoxime (PAMC) as a potent methodology for chromium and thallium adsorption was studied. ${ }^{173}$ Activated carbon was devised from waste rubber tires, subsequently altered with magnetic properties, and then changed with poly amidoxime to provide more functional groups and thus improve the sorption efficiency. Tests were also carried out on real wastewater. With easy separation and high efficiency of removing chromium and thallium from water, besides reliable regeneration without significant loss in the capacity of adsorption, even after multiple cycles, the material exhibited encouraging potential as an adsorbent for treating water. The obtained result showed that the adsorbent works in a broad spectrum of $\mathrm{pH}$ from 3 to 11 and at an initial concentration of 1 to $20 \mathrm{ppm}$ with an optimal shaking speed of $200 \mathrm{rpm}$. Adsorbents were easily displaced from the liquid after adsorption of the toxic pollutants from water; this indicates that PAMC has a promising method as an adsorbent for treating water.

Electrospinning allowed the facile synthesis of a mechanically stable nanofiber network, while hydrothermal treatment attained an $\alpha-\mathrm{Fe}_{2} \mathrm{O}_{3}$ nanostructure surface coating that expanded the reactive surface area allocated for the uptake of dissolved metals. ${ }^{174}$ Composite nanofibers of polyacrylonitrile (PAN) with embedded hematite $\left(\alpha-\mathrm{Fe}_{2} \mathrm{O}_{3}\right)$ nanoparticles were synthesized via a single-pot electrospinning synthesis. A coreshell nanofiber composite was also prepared through the subsequent hydrothermal growth of $\alpha-\mathrm{Fe}_{2} \mathrm{O}_{3}$ nanostructures on embedded hematite composites. These materials were tested for $\mathrm{Cu}(\mathrm{II}), \mathrm{Pb}(\mathrm{II}), \mathrm{Cr}(\mathrm{VI})$, and $\mathrm{As}(\mathrm{v})$ sorption. Although the uptake of $\mathrm{Cu}(\mathrm{II}), \mathrm{Pb}(\mathrm{II}), \mathrm{Cr}(\mathrm{VI})$, and $\mathrm{As}(\mathrm{V})$ was largely independent of the core-shell variables explored, metal uptake on embedded nanofibers was increased with $\alpha-\mathrm{Fe}_{2} \mathrm{O}_{3}$ loading. Fig. 6 summarizes the incorporation of different metals into biosorbents.

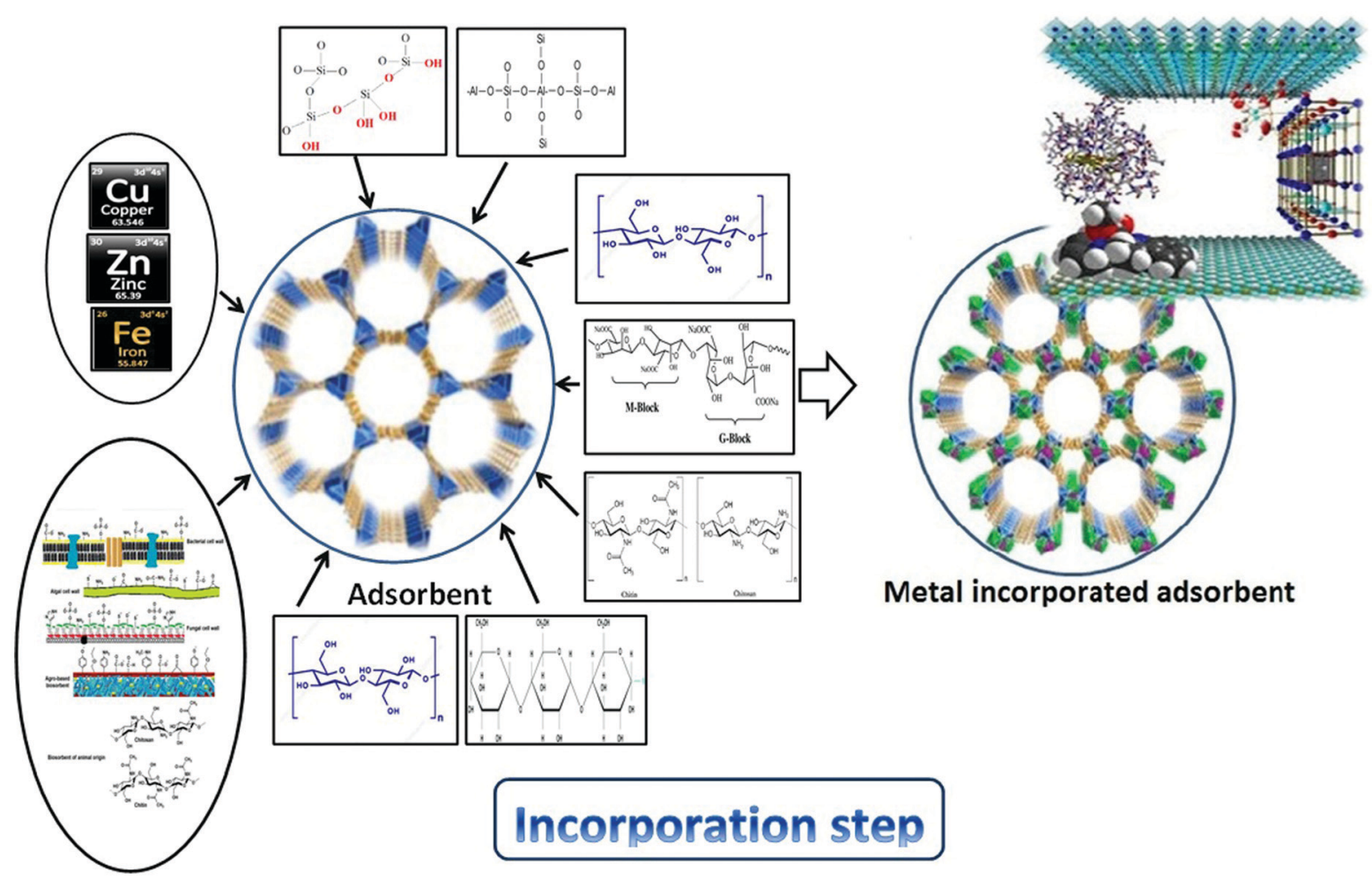

Fig. 6 Incorporation process using different adsorbents. 


\subsection{Biochar-incorporating metals}

Metal oxide/carbon composites have harnessed great interest towards the removal of certain anionic contaminants from the polluted environment. A surface-enhanced MgO-coated biochar adsorbent from sugarcane harvest residue pretreated with dilute sulfuric acid was effectively devised and maintained significantly improved removal of $\mathrm{Cr}(\mathrm{vI}) .{ }^{175}$ It was surmised that sulfuric acid hydrolysis and the MgO coating simultaneously allowed the ease of removal of $\mathrm{Cr}(\mathrm{vI})$ by biochars and the maximum sorption capacities reached $62.89 \mathrm{mg} \mathrm{g}^{-1}$. The chemical interactions between $\mathrm{MgO}$ and $\mathrm{Cr}(\mathrm{vI})$, as well as acid-enhanced carbon structural characteristics, elevated the sorption of $\mathrm{Cr}(\mathrm{VI})$ on the MgO-coated biochars.

Nanomineral-modified biochars show potential capacity for adsorbing and thus removing pollutants through combining the advantages of the porous structure of biochar and nanominerals' unique properties. ${ }^{176}$ Therefore, nano $\mathrm{ZnO} / \mathrm{ZnS}$ modified biochar was created from the slow pyrolysis of zinc-contaminated corn stover resulting from the process of adsorption. Consequently, the nano $\mathrm{ZnO} / \mathrm{ZnS}$-modified biochar exhibited far better sorption capacity in terms of $\mathrm{Pb}(\mathrm{II}), \mathrm{Cu}(\mathrm{II})$, and $\mathrm{Cr}(\mathrm{vI})$ compared with the common biochar. The adsorption pattern complied with heterogeneous adsorbents, reflected by adhering to the Freundlich model. The thermodynamic outcomes implied that the adsorption process was spontaneous and endothermic. The method could be a dependable and highly lucrative approach to transforming heavy metal-polluted biomass to highly efficient nanomineral-modified biochar.

Biochar that was derived from Enteromorpha prolifera and magnetically modified was evaluated for its sorption properties towards $\mathrm{Cr}(\mathrm{vI}){ }^{177}$ The $\mathrm{pH}$ and background ion intensity of the solution exhibited significant effects on $\mathrm{Cr}(\mathrm{vI})$ adsorption. Besides, the magnetic Enteromorpha prolifera derived biochar could be effectively recovered magnetically and regenerated with an alkaline solution. Therefore, this magnetic biochar derived from Enteromorpha prolifera has the potential to serve as a highly efficient adsorbent for water pollution control.

Biochar has redox activity that can be involved in environmentally relevant redox reactions. The electron transfer for the reduction transformation of $\mathrm{Cr}(\mathrm{vI})$ during its sorption by biochar was evaluated. Biochar extracted from peanut shells at $350{ }^{\circ} \mathrm{C}$ could impeccably displace $\mathrm{Cr}(\mathrm{vI})$ from solution, paired with reducing $\mathrm{Cr}(\mathrm{VI})$ to $\mathrm{Cr}(\mathrm{III})$, which was more apparent at strong acidity $(\mathrm{pH} 2) .{ }^{178}$ As a result of electron acceptance from lactate and/or biochar, $\mathrm{Cr}(\mathrm{vI})$ was reduced into $\mathrm{CrOOH}$, which was verified by X-ray diffraction analysis. The outcome implies that biochar possesses potential for acting as an electron donor and shuttle for reducing $\mathrm{Cr}(\mathrm{vI})$ during the process of sorption, posing it as an alternative for detoxifying $\mathrm{Cr}(\mathrm{vI})$ from wastewater.

Conversion of carcinogenic $\mathrm{Cr}(\mathrm{vI})$ to less toxic $\mathrm{Cr}(\mathrm{III})$ has always been deemed an effective method to decontaminate $\mathrm{Cr}(\mathrm{vI})$-contaminated water. However, the commonly utilized reducing agents such as nano zerovalent iron (nZVI) and its derivatives usually are unstable and pose the threat of yielding secondary contamination. ${ }^{179}$ To focus on these, nZVI was loaded on sludge-derived biochar to create a nZVI-BC composite for removing $\mathrm{Cr}(\mathrm{vI})$. Re-pyrolysis thus can be applied as an effective technology to diminish the environmental risks of exhausted adsorbent biochar for safe disposal. The adsorbent characterization showed that most Cr adsorbed on nZVI-BC was in the form of $\mathrm{Cr}$ (III) hydroxides or iron chromium hydroxides. The process of removal was extremely $\mathrm{pH}$ dependent. The adsorption kinetics was well modeled by the pseudo-secondorder model and the intraparticle diffusion model. The Langmuir model illustrated the isotherms well and the maximum $\mathrm{Cr}(\mathrm{vI})$ removal capacity of nZVI-BC was $31.53 \mathrm{mg} \mathrm{g}^{-1}$ at $\mathrm{pH} 4$ and $25{ }^{\circ} \mathrm{C}$. The thermodynamic analysis yielded that the process of sorption was deemed spontaneous. Results from the risk analysis postulate that direct disposal of the postadsorption biochar threatens the environment. Re-pyrolysis of the exhausted adsorbent biochar, however, can optimally eliminate the bioavailable content of $\mathrm{Cr}$ and reduce its latent negative impact.

Biochar-supported nano-scale zerovalent iron (biochar-CMCnZVI) stabilized by carboxymethyl cellulose (CMC) was devised and utilized for removing $\mathrm{Cr}(\mathrm{vI})$ from an aqueous solution. ${ }^{180}$ The outcome showed that $100 \mathrm{mg} \mathrm{L}^{-1} \mathrm{Cr}(\mathrm{vI})$ could be displaced entirely by biochar-CMC-nZVI within 18 hours, at a dosage of $1.25 \mathrm{~g} \mathrm{~L}^{-1}$, and an initial $\mathrm{pH}$ value of 5.6.Cr(vI). Using biocharCMC-nZVI to remove contamination is favored when lower $\mathrm{pH}$ is present. Sorption kinetics and isotherm results confirmed that the adsorption progress of $\mathrm{Cr}(\mathrm{vI})$ by biochar-CMC-nZVI is chemisorption of monolayers under optimal conditions. The $\mathrm{pH}$ value contributed immensely to $\mathrm{Cr}(\mathrm{vI})$ removal as the hydrogen ion could elevate the reduction of $\mathrm{Cr}(\mathrm{VI})$ to $\mathrm{Cr}(\mathrm{III})$ and thusly facilitate Cr(III) precipitation. These results showcase the biochar-CMCnZVI composite potential as a green-effective, low-cost sorbent for removing $\mathrm{Cr}(\mathrm{vI})$ in the environment.

Kumarathilaka et al. $(2016)^{181}$ evaluated the $\mathrm{Cr}(\mathrm{vI})$ reduction ability and removal using a stabilized nanozerovalent irongraphene composite (NZVI-Gn). The composite was characterized by XRD, SEM, FTIR, BET, and pHpzc and NZVI was found to be homogeneously impregnated onto graphene sheets with a high surface area. The results revealed that the NZVI-Gn composite achieved excellent efficiency of removal within acidic conditions. It was suggested by the kinetic study that PSORE could illustrate the adsorption behavior of the NZVIGn composite so that the rate-limiting factor could be a chemisorption process. The Langmuir isotherm model provided a better correlation of the experimental equilibrium data, hinting that $\mathrm{Cr}(\mathrm{vI})$ adsorption onto a composite of NZVI-Gn could involve a process of a monolayer nature. Moreover, dual sorption and reduction followed by the immobilization process could elevate the removal of $\mathrm{Cr}(\mathrm{vI})$ immensely. Therefore, the preset NZVI-Gn composites are considered an admirable and efficient alternative and magnetically separable adsorbent for removing $\mathrm{Cr}(\mathrm{vI})$ from the environment.

A hierarchical porous carbon monolith with a 3D-interconnected structure was derived via resorcinol/melamine/ formaldehyde as precursors. ${ }^{182}$ This hierarchical porous carbon maintains a high specific surface area of $1808 \mathrm{~m}^{2} \mathrm{~g}^{-1}$ and a 
well-developed porous structure, proved to be beneficial for removing $\mathrm{Cr}(\mathrm{vI})$. The experiments of adsorption show that the hierarchical porous carbon is an exemplary $\mathrm{Cr}(\mathrm{vI})$ adsorbent with an adsorption aptitude of $463 \mathrm{mg} \mathrm{g}^{-1}$ at $\mathrm{pH} 1$. The developed porous carbon monolith maintains high selectivity for $\mathrm{Cr}(\mathrm{VI})$ ions in a coexisting system of $\mathrm{Ni}(\mathrm{II}), \mathrm{Zn}$ (II), and $\mathrm{Cu}(\mathrm{II})$. Therefore, this novel hierarchical porous carbon with controllable hierarchical porosity possesses good potential for water treatment application. Monolith strength improvement, adjustment of the carbon surface chemistry, and the performance in a more realistic water treatment system will be studied in our future work.

\subsection{Cellulose-incorporating metals}

Merging the advantages of both cellulose and an ionic liquid, Ionic Liquid-Functionalized Cellulose (ILFC) acting as an adsorbent was devised through radiation-grafting glycidyl methacrylate onto cellulose microspheres followed by reaction with ionic liquid 1-aminopropyl-3-methyl imidazolium nitrate. ${ }^{183}$ The adsorption characteristics of removing $\mathrm{Cr}(\mathrm{vI})$ were evaluated in batch and column experiments. Taking other adsorbents into consideration, ILFC maintained quick and efficient adsorption properties with an adsorption capacity of $181.0 \mathrm{mg} \mathrm{g}^{-1}$. The test in simulated chrome-plating wastewater revealed that ILFC can selectively remove and separate $\mathrm{Cr}(\mathrm{vI})$ from the solution even when the concentrations of $\mathrm{Cu}$ (II), $\mathrm{Zn}$ (II), and $\mathrm{Ni}$ (II) are higher than that of $\mathrm{Cr}(\mathrm{vI})$ by ten times. Moreover, ILFC can be regenerated and reused six times without any apparent decrease in the adsorbed amount. Therefore, ILFC has reusability, practicality, and selectivity for the removal of $\mathrm{Cr}(\mathrm{vI})$, and is set to be a potential adsorbent for actual environmental wastewater.

Hydroxyethyl cellulose and $\mathrm{CuO}$ nanoparticles making up a clay-alumina ceramic composite membrane (CuO/HEC) were fabricated for separation of $\mathrm{Cr}(\mathrm{VI})$ and $\mathrm{Pb}$ (II) from contaminated water. ${ }^{184}$ They were prepared by a slurry-casting method over a low-cost clay alumina ceramic substrate. It is believed that these $\mathrm{CuO}$ nanoparticle-containing clay-alumina ceramic composite membranes will be an effective solution for removing heavy metals from contaminated water. The prepared composite represents a reasonably high-performance novel ceramic UF membrane for the separation of toxic metal ions from mixed-salt solution. However, future study related to the use of the developed membrane for the treatment of real wastewater is necessary before implementation on a pilot scale.

Cellulose Aerogels (CA) and Zeolitic Imidazolate Framework-8 (ZIF-8) are combined into one highly functional aerogel for removing $\mathrm{Cr}(\mathrm{vi})$ from water through adsorptive means as a facile method of combining two emerging materials, by entrapping ZIF-8 particles into a flexible and porous CA (ZIF-8@CA). ${ }^{185}$ The adsorption capacity of the cellulose aerogel for $\mathrm{Cr}(\mathrm{vI})$ was significantly increased when ZIF-8 was added, and the Langmuir maximum adsorption capacity reaches up to $41.84 \mathrm{mg} \mathrm{g}^{-1}$. This kind of material may also be extended to be used as air filters and sensors, and for substrate-supported catalysis.

An efficient adsorbent of bacterial cellulose/poly( $m$-phenylenediamine) (BC/PmPD) was prepared for removing $\mathrm{Cr}(\mathrm{vI})$ through merging the merits of PmPD's high adsorption capacity and BC's ease of reclamation. ${ }^{186}$ The $\mathrm{Cr}(\mathrm{vI})$ BC/PmPD adsorption was ascribed to the $\mathrm{Cr}(\mathrm{vI})$ adsorption on protonated $-\mathrm{NH}-$ and $-\mathrm{NH}_{2}$ groups and the redox reaction of $\mathrm{Cr}(\mathrm{VI})$ to $\mathrm{Cr}(\mathrm{III})$ by the reduction of amine. Afterward, Cr(III) chelation on imino groups of PmPD took place. The calculated adsorption capacity of BC/PmPD for $\mathrm{Cr}(\mathrm{vI})$ was as high as $434.78 \mathrm{mg} \mathrm{g}^{-1}$. The $\mathrm{Cr}(\mathrm{vI})$ adsorption kinetics on $\mathrm{BC} / \mathrm{PmPD}$ can be properly modeled by the pseudo-second-order kinetic model, placing the rate-controlling step as the chemical reaction. The findings in that study showed that BC/PmPD can be deemed as a potential adsorbent for removing $\mathrm{Cr}(\mathrm{vI})$ thanks to its efficient reclamation, high adsorption capacity, and good regeneration aptitude.

A composite adsorbent (PCA@AC) was successfully devised via cellulose (AC) as a substrate and poly(catechol tetraethylenepentamine- $p$-phenylenediamine) as a coating layer under a multitude of technical conditions. ${ }^{187}$ This composite maintains a remarkable performance for removing $\mathrm{Cr}(\mathrm{vI})$ from aqueous solutions, surpassing pure AC. The PCA@AC maximum adsorption capacity for $\mathrm{Cr}(\mathrm{vI})$ is obtained as $507.61 \mathrm{mg} \mathrm{g}^{-1}$ at $30{ }^{\circ} \mathrm{C}$ using the Langmuir model, surpassing pure AC. The removal ability of PCA@AC is attributed to the electrostatic interaction and reduction reaction of $\mathrm{Cr}(\mathrm{VI})$ to $\mathrm{Cr}$ (III) within the adsorption process. The composite adsorbent (PCA@AC) has great potential for $\mathrm{Cr}(\mathrm{vI})$-wastewater purification with excellent chelating ability.

\subsection{Starch-incorporating metals}

The adsorption capacity of chemically modified potato starch (CPS) for $\mathrm{Cr}(\mathrm{vi})$ from an aqueous solution was simulated. ${ }^{188}$ The material at hand is biodegradable and considered environmentally acceptable and safe. The hydroxyl, carbonyl, and carboxyl groups are responsible for the process of adsorption. The influence of different vital criteria, e.g., time, $\mathrm{pH}$, dose, and $\mathrm{Cr}(\mathrm{vI})$ 's initial concentration, on the adsorption capacity was evaluated. The Freundlich and the Redlich-Peterson isotherms well fitted the adsorption of $\mathrm{Cr}(\mathrm{vI})$ with chemically modified potato starch. The $\mathrm{Cr}(\mathrm{vI})$ removal kinetics using chemically modified potato starch were well explained by the secondorder kinetic model. The thermodynamic prerequisites were also evaluated from the adsorption measurements. Among the different desorbing agents tested, $98.2 \%$ chromium recovery was achieved with $0.1 \mathrm{~mol} \mathrm{~L}^{-1} \mathrm{NaOH}$.

Singh et al. (2014) ${ }^{189}$ evaluated the effect of starch functionalization of iron oxide nanoparticles on their adsorption of $\mathrm{Cr}$ (vi) from aqueous solutions. Starch-Functionalized (SIONPs) as well as nonfunctionalized Iron Oxide Nanoparticles (IONPs) have been synthesized under different rates of addition of the base $\mathrm{NaOH}$. The efficiency of SIONPs and IONPs for removal of hexavalent chromium from aqueous medium has been studied. The variation of the adsorption capacity with $\mathrm{pH}$ depends on the nanoparticle phase composition as well as its starch functionalization. $\mathrm{Cr}(\mathrm{vI})$ removal by SIONPs and IONPs follows a Langmuir adsorption isotherm. The highest monolayer saturation adsorption capacity as obtained from the Langmuir adsorption isotherm for SIONPs is $9.02 \mathrm{mg} \mathrm{g}^{-1}$. 
Sodium carboxymethyl cellulose and starch coated with nanoscale zerovalent iron-nickel (SS-nZVI-Ni) were devised and their $\mathrm{Cr}(\mathrm{vI})$ removal extent was analyzed and crosschecked. ${ }^{190}$ The results showed that SS-nZVI-Ni has high $\mathrm{Cr}(\mathrm{vI})$ removal aptitude. Cr(vi) removal by SS-nzvi-Ni while being affected by acidic conditions revealed that the $\mathrm{Cr}(\mathrm{vI})$ removal efficiency by SS-nZVI-Ni reached a maximum of $95.70 \%$ at $\mathrm{pH} 2$. Different initial $\mathrm{Cr}(\mathrm{vI})$ concentrations showed that SS-nZVI-Ni performed well at a high $\mathrm{Cr}(\mathrm{vI})$ concentration. Meanwhile, SEM images showed that SS-nZVI-Ni maintained a larger surface area, solving aggregation problems.

\subsection{Alginate-incorporating metals}

Alginate-based sorbents are commonly applied to remove chromium from aqueous medium, but they possess downsides such as a poor capacity for sorption and instability. To overcome the limitations of biopolymers and to enhance their properties, Gopalakannan and Viswanathan, in 2016, ${ }^{191}$ devised a novel sorbent with enhanced capacity for chromium sorption and improved stability by synthesizing metal ion cross-linked binary biocomposites using biopolymers like alginate and gelatin cross-linked with $\mathrm{Ca}(\mathrm{II})$, $\mathrm{Ce}(\mathrm{III})$, and $\mathrm{Zr}$ (Iv) ions, namely Ca@AlgGel, Ce@AlgGel, and Zr@AlgGel composites (Gopalakannan \&Viswanathan, 2016). The optimum dosage for all the three composites was stabilized as $0.1 \mathrm{~g}$ and the capacity of sorption was affected by the $\mathrm{pH}$ value of the medium. The detection of competing ions does not show a notable influence on the capacity of sorption of composites except the bicarbonate ion, which inhibits the sorption capacity by a considerable amount. The process of sorption was explained by Freundlich, Langmuir, and D-R isotherms; the Langmuir isothermal model was the best fit amongst them. Thermodynamic studies imply that the process of sorption was spontaneous and endothermic. The sorption mechanism was mainly controlled by electrostatic attraction.

Greenly synthesized alginate nanoparticles stabilized by honey were prepared by cross-linking an aqueous solution of alginate with calcium ions. The potential of applying these nanoparticles for removing $\mathrm{Cr}(\mathrm{vI})$ was studied, where a maximum efficiency of removal of $93.5 \%$ was obtained. ${ }^{192}$ The method reported in that study affords the synthesis of many different protein and polysaccharide nanoparticles like chitosan, casein, and albumin. Since the materials used are all nontoxic and biocompatible, this method can also be used in the synthesis of nanoparticles for biomedical applications. Alginate nanoparticles synthesized using honey were highly stable. Even though they showed slight aggregation on drying, they can be redispersed in water by mild sonication. Various microscopic analyses confirmed the formation of stable nanoparticles. The presence of honey prevented the stickiness and aggregation of nanoalginate particles on centrifugation. The high adsorption capacity of the synthesized nanoparticles explores the possibility of removing toxic metal ions from contaminated water.

Sodium alginate was used to encapsulate magnetite graphene oxide to create $\mathrm{mGO} /$ alginate beads. $\mathrm{Cr}(\mathrm{vI})$ and $\mathrm{As}(\mathrm{v})$ adsorption by the mGO/alginate beads agreed with pseudo-second-order kinetics. ${ }^{155}$ The overall ranking for fit isotherm models is Freundlich $>$ Langmuir for $\mathrm{Cr}(\mathrm{vI})$ and Langmuir $>$ Freundlich for As(v). Core material (mGO) aggregation and leaching were avoided; thus, the adsorption capacity was enhanced compared with other adsorbent materials. By applying various cross-linking cations, the $\mathrm{pH}$ at the interface could be controlled at the optimal conditions for removing $\mathrm{Cr}(\mathrm{vI})$ and $\mathrm{As}(\mathrm{v})$. The $\mathrm{mGO} /$ alginate beads possess the potential to optimally displace heavy metals from a multicomponent system and contaminated wastewater. Moreover, mGO/alginate beads could be easily separated from aqueous solutions due to their superparamagnetic nature, thus avoiding secondary pollution. With all the advantages mentioned beforehand, the mGO/alginate beads are anticipated to be a diverse material in the treatment of water.

Auricularia auricula spent substrate altered by cetyltrimethyl ammonium bromide (CTAB) and stabilized on sodium alginate was tested as a novel biosorbent (MIAASS) for removing $\mathrm{Cr}(\mathrm{vI})$ in a fixed-bed column. ${ }^{193}$ The Thomas model was more reasonably accurate in predicting the experimental column capacity than the Adams-Bohart model. Following three cycles of the adsorption-desorption process, the regeneration efficiency of MIAASS was $52.48 \%$.

Omer et al. (2019) ${ }^{194}$ developed an efficient adsorbent based on tetraethylenepentamine (TEPA)-functionalized alginate (Alg) beads (TEPA-Alg) for the adsorptive removal of $\mathrm{Cr}(\mathrm{vI})$ from aqueous solutions. The alginate surface's chemical modification was performed via $p$-benzoquinone (PBQ) as a coupling agent followed by functionalization with TEPA. The concentration of amine groups in TEPA-Alg surged with the increase of the TEPA concentration up to $0.05 \mathrm{M}$. The functionalized beads illustrated a higher affinity towards the adsorption of $\mathrm{Cr}(\mathrm{vI})$ compared with native alginate beads. The maximum $\mathrm{Cr}(\mathrm{vI})$ removal percentage was $100 \%$ and was obtained using $0.2 \mathrm{~g}$ of adsorbent, contact time $180 \mathrm{~min}, \mathrm{pH} \mathrm{2,} \mathrm{room} \mathrm{temperature,}$ and $50 \mathrm{rpm}$. Moreover, the experimental data were best fit to the pseudo-first-order model while the adsorption equilibrium adhered to a Langmuir adsorption isotherm, i.e., maximum adsorption capacity $\sim 77 \mathrm{mg} \mathrm{g}^{-1}$. Additionally, the study of reusability showed good adsorption traits after five cycles in a row. Therefore, the prepared functionalized TEPA-Alg beads could be optimally used for removing $\mathrm{Cr}(\mathrm{vI})$ ions from their aqueous solutions.

Another type of chemically modified alginate beads for removing heavy metals were synthesized via polyethylenimine (PEI) as a modification reagent, with high-density active sites introduced favorably onto the surface by a cross-linking reaction; this led to designing a flexible core-shell/bead-like alginate@PEI sorbent which was employed for Cr(vi) adsorption from aqueous solutions. ${ }^{195}$ The maximum adsorption extent of $\mathrm{Cr}(\mathrm{vI})$ on the typical alginate@PEI-1.5 was $431.6 \mathrm{mg} \mathrm{g}^{-1}$, surpassing most reported sorbents for $\mathrm{Cr}(\mathrm{vI})$ removal from aqueous solutions. The adsorption kinetics followed the pseudo-secondorder kinetic equation while the Freundlich model optimally described the equilibrium data of adsorption of $\mathrm{Cr}(\mathrm{vI})$. The alginate@PEI adsorption capacity only had a slight loss after ten cycles of adsorption-desorption studies. Compared with 
other reported adsorptive materials, this core-shell/bead-like composite promises advantages of low cost, ultra-high adsorption capacity, environmental friendliness, and exemplary recycling performance.

Alginate can be made into various usable forms like membranes, beads, and candles for water remediation. To prepare alginate in a usable bead form, magnetic nano-hydroxyapatite encapsulated alginate beads $\left(\mathrm{Fe}_{3} \mathrm{O}_{4} @ \mathrm{n}-\mathrm{HApAlg}\right)$ were devised by a hydrothermal method for selective removal of chromium. ${ }^{196}$ The thermodynamic studies imply the spontaneous and endothermic nature of the sorption of $\mathrm{Cr}(\mathrm{vI}) \cdot \mathrm{Fe}_{3} \mathrm{O}_{4} @$ @n-HApAlg beads were made usable by using $\mathrm{NaOH}$ eluent, up to five cycles. The magnetic alginate hybrid beads showed promising results against chromium-contaminated groundwater by removing $\mathrm{Cr}(\mathrm{vI})$ ions below the tolerance limit. Regeneration and reusability assessments were successfully conducted, and the hybrid beads can be reused for up to five successive cycles. The synthesized $\mathrm{Fe}_{3} \mathrm{O}_{4} @$ @n-HApAlg beads were an optimal material for the treatment of $\mathrm{Cr}(\mathrm{vI})$-contaminated field water.

Removing Cr(vI) using NZVI immobilized in alginate beads (NZVI beads) and a bacterial consortium immobilized in alginate beads (bio beads) in a sequence process was performed. ${ }^{197}$ The process utilizing the NZVI beads and bio beads was successfully analyzed with a $\mathrm{Cr}(\mathrm{vI})$-spiked groundwater sample. The efficiency of removing $\mathrm{Cr}(\mathrm{vI})$ was observed to upscale (more than $90 \pm 5.96 \%$ at $381 \pm 17.1 \mathrm{mg} \mathrm{g}^{-1}$ capacity for a $10 \mathrm{mg} \mathrm{L}^{-1}$ influent concentration) using NZVI beads and microbial consortium immobilized beads in sequence. The system was successfully assessed with real water systems, having direct field applicability for that process.

The suitability of the Ca-alginate immobilized consortium SFC 500-1 for simultaneous removal of $\mathrm{Cr}(\mathrm{vI})$ and phenol was demonstrated. ${ }^{198}$ Immobilization was a successful strategy to enhance the removal of $\mathrm{Cr}(\mathrm{vI})$, mostly associated with enzymatic reduction through the synthesis of $\mathrm{Cr}(\mathrm{III})$. The immobilized SFC 500-1 showed great prowess in degrading phenol in a short time, probably due to the protective impact of the alginate matrix against the toxicity of phenol concentrations over $1000 \mathrm{mg} \mathrm{L}^{-1}$. Complete phenol oxidation to catechol and cismuconate was verified through the detection of these intermediates in the reaction medium during the co-remediation process. The optimum long-term storage, removal potential, and reusability make SFC 500-1 entrapped cells an interesting system for the removal of $\mathrm{Cr}(\mathrm{vI})$ and phenol in media of lowconcentration organic matter. The low-cost and high-resistance alginate matrix exhibits more merits when possible applications for the decontamination of real effluents are considered.

\subsection{Chitin and chitosan incorporating metals}

Sargin et al. (2019) ${ }^{199}$ produced three-dimensional chitinous microcages and their iron-based magnetic particle loaded counterparts from ephippial resting eggs of a cladoceran species (D. longispina). FTIR spectra analysis revealed that the microcages produced from ephippial resting eggs consisted of $\alpha$-chitin. SEM-EDX analysis confirmed the incorporation of the magnetic particles into the chitinous microcages. The findings of heavy metal sorption experiments demonstrated that the magnetic particles enhanced the affinity of the chitinous-microcages for $\mathrm{Cd}(\mathrm{II}), \mathrm{Cu}(\mathrm{II})$, and $\mathrm{Ni}(\mathrm{II})$ ions. In conclusion, it was revealed that these biological materials are optimal sorbents for heavy metal ions. These newly produced materials also can possess the potential for biotechnological applications in various areas in further studies.

Ali $(2018)^{200}$ prepared chitosan-1,2-cyclohexylenedinitrilotetraacetic acid/graphene oxide (chitosan/CDTA/GO) nanocomposite in the presence of glutaraldehyde as a cross-linker. The removal efficiency and adsorption of $\mathrm{Cr}(\mathrm{vI})$ utilizing the chitosan/CDTA/GO adsorbent were investigated at various adsorption conditions. The prepared adsorbent at hand was characterized by SEM and FTIR. The effects of the adsorbent chemical composition, CDTA/GO concentration, adsorbent dose, $\mathrm{pH}$, temperature, time of contact, and initial metal ion concentration on $\mathrm{Cr}(\mathrm{vI})$ sorption were investigated. The results showed that the optimum adsorbent dose was $2 \mathrm{~g} \mathrm{~L}^{-1}$ at a $\mathrm{pH}$ value of 3.5 and an equilibrium time of $60 \mathrm{~min}$. Besides, the temperature and $\mathrm{pH}$ immensely influenced the adsorption process. The $\mathrm{Cr}(\mathrm{VI})$ adsorption kinetics onto Cs/CDTA/GO followed the pseudo-second-order model and the adsorption isotherm adhered to the Langmuir model. The maximum adsorption capacity of the adsorbent was $166.98 \mathrm{mg} \mathrm{g}^{-1}$, and the equilibrium parameter $\left(R_{\mathrm{L}}\right)$ at different concentrations was less than unity, indicating that $\mathrm{Cr}(\mathrm{vI})$ ion adsorption onto chitosan/CDTA/GO is favorable. The chitosan/CDTA/GO adsorbent could be regenerated more than three times according to its adsorption-desorption cycles.

Chitosan and alginate nanocomposites were evaluated for chromium(vi) removal from wastewater. ${ }^{201}$ The sorbent was characterized by XRD, FT-IR, SEM, DLS, and DSC. Batch adsorption experiments were carried out to evaluate the removal process under various factors like the effects of the initial concentration, dose of adsorbent, $\mathrm{pH}$ value, and agitation time. The $\mathrm{pH}$-dependent metal ion removal reached the optimum at $\mathrm{pH}$ 5.0. The experimental data were analyzed by the Freundlich and Langmuir isotherms. The isotherm study revealed that the adsorption equilibrium is adherent to the Freundlich isotherm and the sorption extent of alginate and chitosan nanocomposites is very high, and the adsorbent favors multilayer adsorption. Pseudo-first and second-order kinetics models were used to illustrate the kinetic data. It was determined that removing $\mathrm{Cr}(\mathrm{vI})$ adhered to second-order reaction kinetics. It is concluded that alginate and chitosan nanocomposites are exemplary biosorbents material for adsorping $\mathrm{Cr}(\mathrm{vi})$ from waterwaste.

Zirconium(Iv) cross-linked chitosan magnetic microspheres ( $\mathrm{Fe}_{3} \mathrm{O}_{4} @ \mathrm{Zr}$-chitosan) as a recoverable adsorbent were fabricated through the coordination reaction between zirconium oxychloride and a chitosan biopolymeric matrix for efficient adsorption and simultaneous detoxification of $\mathrm{Cr}(\mathrm{vI})$ in aqueous solutions. ${ }^{202} \mathrm{XRD}$ and SEM verified the formation of core@shell magnetite microspheres. XPS and FT-IR confirmed Zr(Iv)'s cross-linking with chitosan on the microspheres. The batch $\mathrm{Cr}(\mathrm{vI})$ adsorption performances of the resultant $\mathrm{Fe}_{3} \mathrm{O}_{4} @ \mathrm{Zr}$-chitosan microspheres 
showed that a maximum adsorption capacity of $280.97 \mathrm{mg} \mathrm{g}^{-1}$ was achieved under $\mathrm{pH} 4.0$ at $298 \mathrm{~K}$. The XPS analyses indicated that $61.1 \%$ of the adsorbed $\mathrm{Cr}(\mathrm{VI})$ was reduced to $\mathrm{Cr}(\mathrm{III})$ because of the oxidization of alcoholic groups on C-6 in chitosan serving as electron donors to carbonyl groups. The adsorbent showed preferential $\mathrm{Cr}(\mathrm{vI})$ adsorption with the existence of coexisting cations $\left(\mathrm{K}^{+}, \mathrm{Na}^{+}, \mathrm{Cu}^{2+}, \mathrm{Zn}^{2+}, \mathrm{Ca}^{2+}\right.$, and $\left.\mathrm{Mg}^{2+}\right)$ and anions $\left(\mathrm{NO}_{3}{ }^{-}\right.$, $\mathrm{Cl}^{-}, \mathrm{SO}_{4}{ }^{-2}$, and $\mathrm{CO}_{3}{ }^{-2}$ ). The adsorbent maintained excellent reusability and lowered the effluent $\mathrm{Cr}(\mathrm{vI})$ contents down to the ppb level, reaching the drinking water standard recommended by the World Health Organization, and was a potential option for water purification.

Chitosan- $\mathrm{Fe}(\mathrm{OH})_{3}$ beads were one-step synthesized without using acid solvents, which could be used as effective adsorbents for anionic dye removal. The preparation process was simple and green. ${ }^{203}$ The prepared beads were characterized by morphological and structural analyses in detail using several techniques, e.g., SRD, SEM, XRD, TGA, and XPS. The $\mathrm{Fe}(\mathrm{OH})_{3}$ content in the chitosan- $\mathrm{Fe}(\mathrm{OH})_{3}$ beads was $54.64 \mathrm{wt} \%$. The removal efficiencies towards anionic dyes, Congo Red (CR) and Methyl Orange (MO), by the chitosan- $\mathrm{Fe}(\mathrm{OH})_{3}$ beads surpassed the pure chitosan beads. Moreover, incorporating $\mathrm{Fe}(\mathrm{OH})_{3}$ into chitosan beads could overcome the shortcoming that powdery $\mathrm{Fe}(\mathrm{OH})_{3}$ particles are not easy to separate from adsorption solutions. The maximum adsorption capacities from the Langmuir model for CR and MO by the chitosan- $\mathrm{Fe}(\mathrm{OH})_{3}$ beads were 445.32 and $314.45 \mathrm{mg} \mathrm{g}^{-1}$, respectively. The calculated thermodynamic parameters, namely $\Delta G^{\circ}, \Delta H^{\circ}$, and $\Delta S^{\circ}$, suggest that adsorption of $\mathrm{CR}$ and MO was endothermic and spontaneous in the temperature range 293-353 K. More importantly, the chitosan-Fe(OH $)_{3}$ beads can be regenerated and the adsorption properties reset after $\mathrm{NaOH}$ treatment. The desorption results showed that the adsorption capacity can remain up to $95 \%$ after being used five times. Moreover, the chitosan- $\mathrm{Fe}(\mathrm{OH})_{3}$ beads additionally exhibited good reusability and the efficiencies for the removal of both dyes surpassed 95\% after five cycles. From this work, it is suggested that chitosan$\mathrm{Fe}(\mathrm{OH})_{3}$ beads have great potential as effective and low-cost adsorbents for removing anionic dyes.

Bimetallic $\mathrm{Fe} / \mathrm{Cu}$ nanoparticles were successfully stabilized by chitosan and then used for remediating $\mathrm{Cr}(\mathrm{vI})$-contaminated wasterwater. $^{204}$ However, the overloaded chitosan on the surface of $\mathrm{Fe} / \mathrm{Cu}$ particles limited the reduction of $\mathrm{Cr}(\mathrm{vI})$ due to the occupation of the surface reactive sites. Most importantly, the contribution of chitosan and $\mathrm{Cu}$ in the removal mechanism was studied by reduction experiments and XPS analysis. On one hand, chitosan could effectively combine with $\mathrm{Cr}(\mathrm{vI})$ due to chelation; on the other hand, Cu played an important role in the precipitation and coprecipitation phenomena. These findings dictate that $\mathrm{CS}-\mathrm{Fe} / \mathrm{Cu}$ has the potential to be a promising material for wastewater treatment.

The preparation of $\mathrm{Cu}_{2} \mathrm{~S}$-chitosan nanocomposites for removing $\mathrm{Cr}(\mathrm{vI})$ ions from wastewater samples was achieved. ${ }^{205}$ Structural studies of the particles were carried out using TEM and XRD. The XRD patterns presented the cubic $\mathrm{Cu}_{1.8} \mathrm{~S}$ phase for all the synthesized copper sulfide nanoparticles. TEM images showed spherical shape particles which became agglomerated when the stabilizers were introduced into the nanomaterial. The adsorption studies proved that the $\mathrm{pH}$ value, dosage, and time of contact play an important part during the water treatment.

Guo et al. (2018) ${ }^{206}$ synthesized polydopamine-modifiedchitosan (CS-PDA) aerogels through dopamine self-polymerization and glutaraldehyde cross-linking reactions to increase the capacity of adsorption and acid resistance of chitosan. CS-PDA were applied in the adsorption of $\mathrm{Cr}(\mathrm{VI})$ and $\mathrm{Pb}(\mathrm{II})$. CS-PDA exhibited superior adsorption performances in removing $\mathrm{Cr}(\mathrm{VI})$ and $\mathrm{Pb}(\mathrm{II})$. The adsorption isotherms and kinetic data were adherent to the Langmuir and pseudo-second-order kinetic models. The maximum adsorption capacities of CS-PDA for $\mathrm{Cr}(\mathrm{VI})$ and $\mathrm{Pb}$ (II) were 374.4 and $441.2 \mathrm{mg} \mathrm{g}^{-1}$, respectively. After eight cycles, the CS-PDA adsorption capacity showed no obvious decline. These superiorities make CS-PDA a promising multifunctional adsorbent for the purification of metal ions and dyes.

A chitosan-grafted graphene oxide (CS-GO) nanocomposite was tested for the adsorption of $\mathrm{Cr}(\mathrm{vI})$ in batch mode. ${ }^{207}$ The CS-GO nanocomposite material was prepared by the ultrasonic irradiation technique. The CS-GO adsorbent was characterized by XRD, FTIR spectroscopy, SEM, and TEM. An adsorption capacity of $104.16 \mathrm{mg} \mathrm{g}^{-1}$ was achieved at $\mathrm{pH} 2.0$, at a contact time of $420 \mathrm{~min}$. The adsorption process was confirmed by the pseudo-second-order kinetic and Langmuir isotherm models. The nano-microstructural investigation validates the successful $\mathrm{Cr}(\mathrm{vI})$ adsorption on the CS-GO nanocomposite. The CS-GO material is recyclable for up to ten cycles with a minimum loss in adsorption capacity.

Thiosemicarbazide-modified chitosan (TSFCS) was fabricated and characterized by SEM, FTIR, and TGA techniques and its application as an adsorbent for the displacement of $\mathrm{Pb}$ (II) and methyl red (MR) was evaluated. ${ }^{208}$ Some adsorption parameters, e.g., the dose of sorbent, $\mathrm{pH}$ value, and initial concentration of solutions, were evaluated alongside their effects. The maximum removal percentages for $\mathrm{MR}$ and $\mathrm{Pb}$ (II) were found to be about $91 \%$ and $85.6 \%$ at $\mathrm{pH}$ values 8 and 5 and sorbent dosages of $3.33 \mathrm{~g} \mathrm{~L}^{-1}$ and $1.33 \mathrm{~g} \mathrm{~L}^{-1}$, respectively. Langmuir, Freundlich, and Temkin isotherms were evaluated and the maximum adsorption extents for $\mathrm{Pb}$ (II) and MR were found to be $56.89 \mathrm{mg} \mathrm{g}^{-1}$ and $17.31 \mathrm{mg} \mathrm{g}^{-1}$ at $55{ }^{\circ} \mathrm{C}$ and $25{ }^{\circ} \mathrm{C}$, respectively. Isotherm studies indicate that $\mathrm{Pb}$ (II) and $\mathrm{MR}$ adsorption adhere to the Freundlich and Langmuir models, respectively. The kinetics of adsorption was more accurately adherent to the PSORE. Thermodynamic parameters including $\Delta G^{\circ}, \Delta H^{\circ}$, and $\Delta S^{\circ}$ were gauged over the temperature range of $25-55{ }^{\circ} \mathrm{C}$. The sorption process was endothermic and spontaneous.

Neto et al. (2019) ${ }^{209}$ prepared an adsorbent in the form of an iron oxide/carbon nanotube/chitosan magnetic composite film (CLCh/MWCNT/Fe). CLCh/MWCNT/Fe was characterized by Inductively Coupled Plasma Mass Spectrometry (ICP-MS), nitrogen adsorption/desorption, SEM, XRD, Energy-Dispersive Spectrometry (EDS), Raman spectroscopy, and IR. The CLCh/MWCNT/Fe film presented a maximum adsorption capacity of $449.30 \mathrm{mg} \mathrm{g}^{-1}$ for $\mathrm{Cr}(\mathrm{vI})(60 \mathrm{~min})$ at $25^{\circ} \mathrm{C}$. In ten consecutive reutilization adsorption 
cycles, the CLCh/MWCNT/Fe film suffered efficiency losses of only $12 \%$ and $6 \%$ for the removal of $\mathrm{Cr}(\mathrm{III})$ and $\mathrm{Cr}(\mathrm{VI})$, respectively.

\section{Adsorbent regeneration}

A suitable adsorbent for metal ion removal should not only have high sorption capacity and feasibility but should also be amenable to easy desorption of the sorbed metal ion as well, to be efficiently regenerated and reusable for a long time. Desorption of metal ions is done by leaching of sorbed metal ions using bases, acids, and salts and chelating agents. In some cases, desorption may be done using a combination of salts and bases. High concentrations of bases and acids do not suit certain sorbents (oxides such as $\mathrm{Si}, \mathrm{Fe}$, and $\mathrm{Al}$ and carbonates of $\mathrm{Ca}$ and $\mathrm{Mg}$ ) because they can dissolve or corrode parts of the sorbents, structurally changing or damaging them; this negatively affects regeneration and reuse of the sorbents. The search for a suitable eluent for the new prepared materials needs further investigation; the eluent type, volume, concentration, and regeneration kinetics needs further investigations. The stability of the adsorbent incorporating metal or mineral should be investigated using FTIR, SEM, TEM and XRD during successive desorption cycles along with the analysis of the released metals during desorption cycles.

\section{Prospects for future research}

Incorporation of metals/minerals can enhance their sorption behavior compared with metal/mineral free materials; however, the risk of release of the incorporated metals under different adsorption conditions such as $\mathrm{pH}$ and time needs further investigation. Also the release of these metals during successive adsorption/desorption cycles is an important issue. Also the authors propose a detailed desorption study to optimize the desorption conditions (i.e. optimum $\mathrm{pH}$, eluent concentration, desorption kinetics, equilibrium parameters, desorption temperature and thermodynamics). Moreover the effect of several industrial factors such as microwave radiation and ultrasonic power on the sorption/desorption behavior of these materials needs to be investigated. Eventually, a multiply reused sorbent resin can no longer be regenerated and will require disposal. It is very important to dispose of the spent sorbents in an environmentally friendly way. If this waste is not managed and destroyed in a proper manner it can create health and environmental risks. Only limited studies are available in the literature about the safe disposal of the spent sorbents. The disposal options and costs of the spent material will generally depend on whether or not the materials are hazardous. Several options are available such as (i) converting the adsorbent to energy this is the process of generating energy in the form of electricity and/or heat from the primary treatment of the exhausted sorbent. (ii) Incineration of the adsorbent, converting it to a char based adsorbent, and then reuse. (iii) Landfill - for landfilling, the toxicity characteristic leaching procedure determines the toxic hazards of a spent adsorbent. Additional studies may be needed to adequately predict any environmental or health threat from landfilling for the spent adsorbent.

\section{Conclusion}

The current immobilization methods of metals/minerals onto sorbents mainly include adsorption, crosslinking, and embedding methods. Among them, embedding is the most used method. The cross-linking method is usually used in combination with the sorption and embedding methods. This review investigates the use of metal/mineral-incorporating sorbents and biosorbents for water pollutant removal with a special focus on $\mathrm{Cr}(\mathrm{vI})$. It was illustrated from this article that the incorporation of metals/minerals with several sorbents and biosorbents elevates the sorption potential of these materials alongside the separation ease of suspending adsorbents in the case of magnetite incorporation. Moreover, the sorption process kinetics depends on several factors such as the surface properties and operational factors such as $\mathrm{pH}$, sorbent dose, temperature, and the initial concentration of pollutants. Secondly, biosorbents have an advantage over other sorbents in being naturally available with high abundance and renewability. Incorporation of metals/minerals can enhance their sorption behavior compared with metal/mineral free materials; however, this may increase the remediation expenses and introduce new materials into the environment. Furthermore, the risk of release of the incorporated metals during sorption needs further investigation. Finally, it is very important to dispose of the spent sorbents in an environmentally friendly way. Only limited studies are available in the literature about the safe disposal of the spent sorbents. Eventually, a multiply reused sorbent resin can no longer be regenerated and will require disposal. The disposal options and costs of the spent material will generally depend on whether or not the materials are hazardous.

\section{Nomenclature}

$\begin{array}{ll}C_{0} & \text { Sorbate initial concentration }\left(\mathrm{mol} \mathrm{L}^{-1}\right) \\ C_{\mathrm{e}} & \text { The equilibrium concentration }\left(\mathrm{mol} \mathrm{L}^{-1}\right) \\ q_{\mathrm{e}} & \text { The amount of sorbate sorbed in the absorbent at } \\ & \text { equilibrium }\left(\mathrm{mol} \mathrm{g}^{-1}\right) \\ q_{\mathrm{m}, \mathrm{L}} & \text { The capacity of maximum monolayer }\left(\mathrm{mol} \mathrm{g}^{-1}\right) \\ K_{\mathrm{L}} & \text { Langmuir isotherm constant }\left(\mathrm{L} \mathrm{mol}^{-1}\right) \\ K_{\mathrm{F}} & \text { Freundlich constant relative sorption capacity } \\ & \left.\left(\mathrm{mol} \mathrm{g}^{-1}\right)(\mathrm{L} \mathrm{mol})^{-1}\right)^{1 / n} \\ n & \text { Sorption intensity } \\ R & \text { Universal gas constant }\left(8.314 \mathrm{~J} \mathrm{~mol}^{-1} \mathrm{~K}^{-1}\right) \\ T & \text { Temperature }(\mathrm{K}) \\ A_{\mathrm{T}} & \text { Temkin isotherm equilibrium constant }\left(\mathrm{L} \mathrm{g} \mathrm{g}^{-1}\right) \\ b_{\mathrm{T}} & \text { Temkin isotherm constant }\left(\mathrm{J} \mathrm{mol}^{-1}\right) \\ \varepsilon & \text { The Polanyi potential }\left(\mathrm{J}^{2} \text { mol }^{-2}\right) \\ q_{\mathrm{s}} & \text { Theoretical isotherm saturation capacity } \\ & \left(\text { mol } \mathrm{g}^{-1}\right)\end{array}$


$\beta \quad$ Dubinin-Radushkevich isotherm constant $\left(\mathrm{mol}^{2} \mathrm{~kJ}^{-2}\right)$

$\theta \quad$ Degree of surface coverage

$K_{\mathrm{FH}} \quad$ Flory-Huggins isotherm equilibrium constant $\left(\mathrm{L} \mathrm{g}^{-1}\right)$

$K_{\mathrm{D}} \quad$ Hill constant

$n_{\mathrm{H}} \quad$ Hill cooperativity coefficient of the binding interaction

$q_{\mathrm{sH}} \quad$ Hill isotherm maximum uptake saturation $\left(\mathrm{mol} \mathrm{L}^{-1}\right)$

$K_{\mathrm{R}} \quad$ Redlich-Peterson isotherm constant $\left(\mathrm{L} \mathrm{g}^{-1}\right)$

$a_{\mathrm{R}} \quad$ Redlich-Peterson isotherm constant $\left(\mathrm{L} \mathrm{mol}{ }^{-1}\right)$

$g \quad$ Redlich-Peterson isotherm exponent

$K_{\mathrm{S}} \quad$ Sips isotherm model constant $\left(\mathrm{L} \mathrm{mg}^{-1}\right)$

$\beta_{\mathrm{S}} \quad$ Sips isotherm model exponent

$K_{\mathrm{T}} \quad$ Toth isotherm constant $\left(\mathrm{mol} \mathrm{g}^{-1}\right)$

$B \quad$ Koble-Corrigan isotherm constant $\left(\mathrm{L} \mathrm{mol}^{-1}\right)^{n}$

A Koble-Corrigan isotherm constant

$\left(\mathrm{L}^{n} \mathrm{~mol}^{1-n} \mathrm{~g}^{-1}\right)$

$b_{\mathrm{k}} \quad$ Khan isotherm model constant

$\alpha_{\mathrm{k}} \quad$ Khan isotherm model exponent

$\alpha_{\mathrm{RP}} \quad$ Radke-Prausnitz isotherm model constant

$\beta_{\mathrm{R}} \quad$ Radke-Prausnitz isotherm model exponent

$\gamma_{\mathrm{R}} \quad$ Radke-Prausnitz isotherm model constant

$\alpha \quad$ Frenkel-Halsey-Hill isotherm constant $\left(\mathrm{J} \mathrm{mol}^{-1}\right)$

$r \quad$ Sign of inverse power of distance from the surface

$d \quad$ Interlayer spacing $(\mathrm{m})$

$k \quad$ MacMillan-Teller (MET) isotherm constant

$q_{t} \quad$ Amount of metal ions sorbed at time $t\left(\mathrm{mmol} \mathrm{g}^{-1}\right)$

$K_{1} \quad$ Pseudo-first-order rate constant of adsorption $\left(\min ^{-1}\right)$

$K_{2} \quad$ Pseudo-second-order rate constant of adsorption (g mmol ${ }^{-1} \min ^{-1}$ )

$K_{\mathrm{i}} \quad$ The intra-particle diffusion rate $\left(\mathrm{mmol} \mathrm{g}^{-1} \mathrm{~min}^{-0.5}\right)$

$X \quad$ The boundary layer diffusion effects $\left(\mathrm{mmol} \mathrm{g}^{-1}\right)$

$\alpha \quad$ The initial sorption rate $\left(\mathrm{mmol} \mathrm{g}^{-1} \mathrm{~min}^{-1}\right)$

$\beta \quad$ The desorption constant $\left(\mathrm{g} \mathrm{mmol}^{-1}\right)$

\section{Conflicts of interest}

The authors declare that they have no known competing financial interests or personal relationships that could have influenced the work reported in this paper.

\section{References}

1 P. K. Roy, S. Ray and A. Majumder, Bottled and Packaged Water: The Science of Beverages, Elsevier, 1st edn, 2019, ch. 3, pp. 63-82.

2 P. K. Sengupta, Industrial Water Resource Management: Challenges and Opportunities for Corporate Water Stewardship, Wiley, 2017, ch. 6, pp. 195-245.

3 A. L. Cukierman and P. R. Bonelli, Nanotechnology for Sustainable Water Resources, Wiley, 2018, ch. 8, pp. 227-276.
4 X. Fan, B. A. Niemira, C. J. Doona, F. E. Feeherry and R. B. Gravani, Microbial Safety of Fresh Produce, Wiley, 2009, ch. 7, pp. 129-142.

5 E. R. P. Farr and P. Piroozfar, Water Efficiency in Buildings: Theory and Practice, Wiley, 2013, ch. 2, pp. 24-41.

6 L. Schweitzer and J. Noblet, Green Chemistry: An Inclusive Approach, Elsevier, 2018, ch. 3, pp. 261-290.

7 D. Li and S. Liu, Water Quality Monitoring and Management Basis, Technology and Case Studies, Elsevier, 2019, ch. 9, pp. 233-249.

8 R. Weiner and R. Matthews, Environmental Engineering, Elsevier, 4th edn, 2003, ch. 4, pp. 51-79.

9 K. Z. Elwakeel, Environmental application of chitosan resins for the treatment of water and wastewater: a review, J. Dispersion Sci. Technol., 2010, 31, 273-288.

10 S. Ibrahim, M. A. El-Liethy, K. Z. Elwakeel, H. M. Abd ElGabbar, A. M. Al Zanaty and M. M. Kamel, Role of identified bacterial consortium in treatment of Quhafa Wastewater Treatment Plant influent in Fayuom, Egypt, Environ. Monit. Assess., 2020, 192, 161.

11 H. S. Ibrahim, M. A. Ibrahim and F. A. Samhan, Distribution and bacterial bioavailability of selected metals in sediments of Ismailia Canal, Egypt, J. Hazard. Mater., 2009, 168, 1012-1016.

12 K. Z. Elwakeel and A. S. Al-Bogami, Influence of Mo(vi) immobilization and temperature on $\mathrm{As}(\mathrm{V})$ sorption onto magnetic separable poly p-phenylenediamine-thiourea-formaldehyde polymer, J. Hazard. Mater., 2018, 342, 335-346.

13 K. Z. Elwakeel, A. S. Al-Bogami and A. M. Elgarahy, Efficient retention of chromate from industrial wastewater by a green magnetic polymer based on shrimp peels, J. Polym. Environ., 2018, 26, 2018-2029.

14 W. Song, B. Gao, T. Zhang, X. Xu, X. Huang, H. Yu and Q. Yue, High-capacity adsorption of dissolved hexavalent chromium using amine-functionalized magnetic corn stalk composites, Bioresour. Technol., 2015, 190, 550-557.

15 World Health Organization, Guidelines for Drinking-Water Quality: Incorporating the First Addendum, WHO, Geneva, 4th edn, 2017.

16 EU, Council Directive, 98/83/EC, 3 November, Off. J. Eur. Communities: Legis., 1998, L330, 32-54.

17 USEPA, Drinking Water Standards and Health Advisories, 2000.

18 O. Çimen, A. Ö. Önaol and E. A. Akyol, Assessment of pollution potential of the Hasangazi chromite pit (Tunceli, Turkey): implications for the natural environment, Environ. Earth Sci., 2018, 77, 199.

19 N. Ferronato and V. Torretta, Waste mismanagement in developing countries: A Review of Global Issues, Int. J. Environ. Res. Public Health, 2019, 16, 1060.

20 Y. Xie, S. Holmgren, D. M. K. Andrews and M. S. Wolfe, Evaluating the Impact of the U.S. National Toxicology Program: A Case Study on Hexavalent Chromium, Environ. Health Perspect., 2017, 125, 81-188.

21 E. M. Hamilton, R. M. Lark, S. D. Young, E. H. Bailey, G. M. Sakala, K. K. Maseka and M. J. Watts, Reconnaissance 
sampling and determination of hexavalent chromium in potentially-contaminated agricultural soils in Copper belt Province, Zambia, Chemosphere, 2020, 247, 125984.

22 J. Lach, E. Okoniewska, E. Neczaj and M. Kacprzak, Removal of $\mathrm{Cr}(\mathrm{III})$ cations and $\mathrm{Cr}(\mathrm{VI})$ anions on activated carbons oxidized by $\mathrm{CO}_{2}$, Desalination, 2007, 206, 259-269.

23 D. Homa, E. Haile and A. P. Washe, Determination of Spatial Chromium Contamination of the Environment around Industrial Zones, Int. J. Anal. Chem., 2016, 7214932.

24 M. D. Cohen, Environmental Toxicants: Human Exposures and Their Health Effects, Wiley, 3rd edn, 2008, ch. 15, pp. 529-550.

25 D. Paustenbach, B. Finley, F. Mowat and B. Kerger, Human Health Risk and Exposure Assessment of chromium(vI) in Tap Water, J. Toxicol. Environ. Health, Part A, 2003, 66, 1295-1339.

26 M. Stiborova, Metabolism of Drugs and Other Xenobiotics, Wiley, 2012, ch. 23, pp. 637-670.

27 M. M. Nasr, M. A. Gondal and Z. S. Seddigi, Detection of hazardous pollutants in chrome-tanned leather using locally developed laser-induced breakdown spectrometer, Environ. Monit. Assess., 2011, 175, 387-395.

28 M. P. Karuppasamy, M. A. Qurban, P. K. Krishnakumar, S. A. Mushir and N. Abuzaid, Evaluation of toxic elements As, $\mathrm{Cd}, \mathrm{Cr}, \mathrm{Cu}, \mathrm{Ni}, \mathrm{Pb}$ and $\mathrm{Zn}$ in the surficial sediments of the Red Sea (Saudi Arabia), Mar. Pollut. Bull., 2017, 119, 181-190.

29 N. H. M. Khdary and A. E. H. Gassim, The Distribution and Accretion of Some Heavy Metals in Makkah Wells, J. Water Resour. Prot., 2014, 6, 998-1010.

30 Y. Posudin, Methods of Measuring Environmental Parameters, Wiley, 2014, ch. 19, pp. 247-252.

31 P. K. Sengupta, Industrial Water Resource Management: Challenges and Opportunities for Corporate Water Stewardship, Wiley, 2017, ch. 3, pp. 61-108.

32 A. R. Mareddy, Environmental Impact Assessment Theory and Practice, Elsevier, 2017, ch. 6, pp. 217-248.

33 J. G. Speight, Natural Water Remediation Chemistry and Technology, Elsevier, 2020, ch. 5, pp. 165-198.

34 Y. Feng, S. Yang, L. Xia, Z. Wang, N. Suo, H. Chen, Y. Long, B. Zhou and Y. Yu, In-situ ion exchange electrocatalysis biological coupling (i-IEEBC) for simultaneously enhanced degradation of organic pollutants and heavy metals in electroplating wastewater, J. Hazard. Mater., 2019, 364, 562-570.

35 Q. Chen, Y. Yao, X. Li, J. Lu, J. Zhou and Z. Huang, Comparison of heavy metal removals from aqueous solutions by chemical precipitation and characteristics of precipitates, J. Water Process Eng., 2018, 26, 289-300.

36 H. I. Hamoud, G. Finqueneisel and B. Azambre, Removal of binary dyes mixtures with opposite and similar charges by adsorption, coagulation/flocculation and catalytic oxidation in the presence of $\mathrm{CeO}_{2} / \mathrm{H}_{2} \mathrm{O}_{2}$ Fenton-like system, J. Environ. Manage., 2017, 195, 195-207.

37 W. N. Du and S. T. Chen, Photo- and chemocatalytic oxidation of dyes in water, J. Environ. Manage., 2018, 206, 507-515.
38 M. Napoli, S. Cecchi, C. Grassi, A. Baldi, C. A. Zanchi and S. Orlandini, Phytoextraction of copper from a contaminated soil using arable and vegetable crops, Chemosphere, 2019, 219, 122-129.

39 A. Doggaz, A. Attour, M. L. Mostefa, K. Côme, M. Tlili and F. Lapicque, Removal of heavy metals by electrocoagulation from hydrogenocarbonate-containing waters: Compared cases of divalent iron and zinc cations, J. Water Process Eng., 2019, 29, 100796.

40 M. Nemati, S. M. Hosseini and M. Shabanian, Novel electrodialysis cation exchange membrane prepared by 2-acrylamido-2-methylpropane sulfonic acid; heavy metal ions removal, J. Hazard. Mater., 2017, 337, 90-104.

41 M. M. Ghobashy and M. A. Elhady, pH-sensitive wax emulsion copolymerization with acrylamide hydrogel using gamma irradiation for dye remova, Radiat. Phys. Chem., 2017, 134, 47-55.

42 S. A. Hosseini, M. Vossoughi, N. M. Mahmoodi and M. Sadrzadeh, Efficient dye removal from aqueous solution by high-performance electrospun nanofibrous membranes through incorporation of $\mathrm{SiO}_{2}$ nanoparticles, J. Cleaner Prod., 2018, 183, 1197-1206.

43 E. Kavitha, A. Sowmya, S. Prabhakar, P. Jain, R. Surya and M. P. Rajesh, Removal and recovery of heavy metals through size enhanced ultrafiltration using chitosan derivatives and optimization with response surface modeling, Int. J. Biol. Macromol., 2019, 132, 278-288.

44 M. Qiu and C. He, Efficient removal of heavy metal ions by forward osmosis membrane with a polydopamine modified zeolitic imidazolate framework incorporated selective layer, J. Hazard. Mater., 2019, 367, 339-347.

45 J. M. Jacob, C. Karthik, R. G. Saratale, S. S. Kumar, D. Prabakar, K. Kadirvelu and A. Pugazhendhi, Biological approaches to tackle heavy metal pollution: A survey of literature, J. Environ. Manage., 2018, 217, 56-70.

46 Z. Huang, K. He, Z. Song, G. Zeng, A. Chen, L. Yuan, H. Li and G. Chen, Alleviation of heavy metal and silver nanoparticle toxicity and enhancement of their removal by hydrogen sulfide in Phanerochaete chrysosporium, Chemosphere, 2019, 224, 554-561.

47 X. Zhao, J. C. Joo, J. K. Lee and J. Y. Kim, Mathematical estimation of heavy metal accumulations in Helianthus annuus L. with a sigmoid heavy metal uptake model, Chemosphere, 2019, 220, 965-973.

48 I. P. S. S. Fernando, K. K. A. Sanjeewa, S. Y. Kim, J. S. Lee and J. Y. Jeon, Reduction of heavy metal $\left(\mathrm{Pb}^{2+}\right)$ biosorption in zebrafish model using alginic acid purified from Ecklonia cava and two of its synthetic derivatives, Int. J. Biol. Macromol., 2018, 106, 330-337.

49 M. R. Hadiani, K. K. Darani and N. Rahimifard, Optimization of $\mathrm{As}(\mathrm{III})$ and $\mathrm{As}(\mathrm{V})$ removal by Saccharomyces cerevisiae biomass for biosorption of critical levels in the food and water resources, J. Environ. Chem. Eng., 2019, 7, 102949.

50 V. Krstić, T. Urošević and B. Pešovski, A review on adsorbents for treatment of water and wastewaters containing copper ions, Chem. Eng. Sci., 2018, 192, 273-287. 
51 V. K. Gupta, Experimental design, modeling and mechanism of cationic dyes biosorption on to magnetic chitosanglutaraldehyde composite, Int. J. Biol. Macromol., 2019, 131, 633-645.

52 A. Işıldar, E. D. Hullebusch, M. Lenz, G. D. Laing, A. Marra, A. Cesaro, S. Panda, A. Akcil, M. A. Kucuker and K. Kuchta, Biotechnological strategies for the recovery of valuable and critical raw materials from waste electrical and electronic equipment (WEEE) - A review, J. Hazard. Mater., 2019, 362, 467-481.

53 M. Fomina and G. M. Gadd, Biosorption: current perspectives on concept, definition and application, Bioresour. Technol., 2014, 160, 3-14.

54 N. B. Singh, G. Nagpal, S. Agrawal and Rachna, Water purification by using Adsorbents: A Review, Environ. Technol. Innov., 2018, 11, 187-240.

55 M. Sulyman, J. Namiesnik and A. Gierak, Low-cost adsorbents derived from agricultural by-products/wastes for enhancing contaminant uptakes from wastewater: $A$ review, Pol. J. Environ. Stud., 2017, 26, 479-510.

56 L. Joseph, B. Jun, J. Flora, C. M. Park and Y. Yoon, Removal of heavy metals from water sources in the developing world using low-cost materials: A review, Chemosphere, 2019, 229, 142-159.

57 M. Torab-Mostaedi, M. Asadollahzadeh, A. Hemmati and A. Khosravi, Equilibrium, kinetic, and thermodynamic studies for biosorption of cadmium and nickel on grapefruit peel, J. Taiwan Inst. Chem. Eng., 2013, 44, 295-302.

58 A. Ghazali, M. Shirani, A. Semnani, V. Zare-Shahabadi and M. Nekoeinia, Optimization of crystal violet adsorption onto Date palm leaves as a potent biosorbent from aqueous solutions using response surface methodology and ant colony, J. Environ. Chem. Eng., 2018, 6, 3942-3950.

59 V. R. Moreira, Y. A. Lebron, S. J. Freire, L. V. Santos, F. Palladino and R. S. Jacob, Biosorption of copper ions from aqueous solution using Chlorella pyrenoidosa: Optimization, equilibrium and kinetics studies, Microchem. J., 2019, 145, 119-129.

60 I. Langmuir, The adsorption of gases on plane surfaces of glass, mica and platinum, J. Am. Chem. Soc., 1918, 40, 1361-1403.

61 H. M. F. Freundlich, Uber die adsorption in lasungen, J. Phys. Chem., 1906, 57, 385-470.

62 M. M. Dubinin, E. D. Zaverina and L. V. Radushkevich, Sorption and structure of active carbons. I. Adsorption of organic vapors, Zh. Fiz. Khim., 1947, 21, 1351-1362.

63 M. I. Temkin and V. Pyzhev, Kinetics of ammonia synthesis on promoted iron catalysts, Acta Physicochim. URSS, 1940, 12, 217-222.

64 P. J. Flory, Themodynamics of high polymer solutions, J. Chem. Phys., 1942, 10(1), 51-61.

65 M. L. Huggins, Some properties of solutions of long-chain compounds, J. Phys. Chem., 1942, 46(1), 151-158.

66 T. L. Hill, Statistical mechanics of multimolecular adsorption II. Localized and mobile adsorption and absorption, J. Chem. Phys., 1946, 7, 441-453.
67 O. Redlich and D. L. Peterson, A useful adsorption isotherm, J. Phys. Chem., 1959, 63, 1024-1026.

68 R. Sips, On the structure of a catalyst surface, J. Chem. Phys., 1948, 16, 490-495.

$69 \mathrm{~J}$. Toth, State equation of the solid gas interface layer, Acta Chim. Acad. Sci. Hung., 1971, 69, 311-317.

70 R. A. Koble and T. E. Corrigan, Adsorption isotherms for pure hydrocarbons, Ind. Eng. Chem., 1952, 44(2), 383-387.

71 A. R. Khan, R. Ataullah and A. Al-Haddad, Equilibrium adsorption studies of some aromatic pollutants from dilute aqueous solutions on activated carbon at different temperatures, J. Colloid Interface Sci., 1997, 194, 154-165.

72 C. J. Radke and J. M. Prausnitz, Adsorption of organic solutes from dilute aqueous solution on activated carbon, Ind. Eng. Chem. Fundam., 1972, 11, 445-451.

73 J. Frenkel, Kinetic Theory of Liquids, Oxford University Press, Oxford, International Series of Monographs on Physics, 1946.

74 G. D. Halsey, Physical Adsorption on Non-Uniform Surfaces, J. Chem. Phys., 1948, 16, 931.

75 T. L. Hill, Advances in Catalysis, IV, Academic Press, New York, NY, 1952.

76 P. J. M. Carrott, A. I. Mcleod and K. S. W. Sing, Application of the Frenkel-Halsey-Hill equation to multilayer isotherms of nitrogen on oxides at 77 K, Stud. Surf. Sci. Catal., 1982, 10, 403-410.

77 W. G. McMillan and E. Teller, The assumptions of the B.E.T. theory, J. Phys. Colloid Chem., 1951, 55(1), 17-20.

78 S. Lagergren, About the theory of so-called adsorption of soluble substances, K. Sven. Vetenskapsakad. Handl., 1898, 24, 1-39.

79 Y. S. Ho and G. McKay, Pseudo-second order model for sorption processes, Process Biochem., 1999, 34, 451-465.

80 W. J. Weber and J. C. Morris, Kinetics of adsorption on carbon from solutions, J. Sanit. Eng. Div., Am. Soc. Civ. Eng., 1963, 89, 31-60.

$81 \mathrm{~J}$. Zeldowitsch, The catalytic oxidation of carbon monoxide on manganese dioxide, Acta Physicochim. URSS, 1934, 1, 364-449.

82 A. A. Farghali, M. Bahgat, A. Enaiet Allah and M. H. Khedr, Adsorption of $\mathrm{Pb}$ (II) ions from aqueous solutions using copper oxide nanostructures, Beni-Suef Univ., J. Basic Appl. Sci., 2013, 2, 61-71.

83 G. Zhang, Z. Ren, X. Zhang and J. Chen, Nanostructured iron(III)-copper(II) binary oxide: A novel adsorbent for enhanced arsenic removal from aqueous solutions, Water Res., 2013, 47, 4022-4031.

84 S. Dubey and Y. C. Sharma, Calotropis procera mediated one pot green synthesis of Cupric oxide nanoparticles (CuO-NPs) for adsorptive removal of $\mathrm{Cr}(\mathrm{VI})$ from aqueous solutions, Appl. Organomet. Chem., 2017, 31, 3849.

85 S. Mohan, Y. Sing, D. K. Verma and S. H. Hasan, Synthesis of $\mathrm{CuO}$ nanoparticles through green route using Citrus limon juice and its application as nanosorbent for $\mathrm{Cr}(\mathrm{vI})$ remediation: Process optimization with RSM and ANN-GA based model, Process Saf. Environ. Prot., 2015, 96, 156-166. 
86 M. Verma, I. Tyagi, R. Chandra and V. K. Gupta, Adsorptive removal of $\mathrm{Pb}$ (II) ions from aqueous solution using $\mathrm{CuO}$ nanoparticles synthesized by sputtering method, J. Mol. Liq., 2017, 225, 936-944.

87 I. Lee, C. W. Park, S. S. Yoon and H. M. Yang, Facile synthesis of copper ferrocyanide embedded magnetic hydrogel beads for the enhanced removal of cesium from water, Chemosphere, 2019, 224, 776-785.

88 M. El-Sayed, G. Eshaq and A. E. ElMetwally, Adsorption of heavy metals from aqueous solutions by $\mathrm{Mg}-\mathrm{Al}-\mathrm{Zn}$ mingled oxides adsorbent, Water Sci. Technol., 2016, 74, 1644-1657.

89 P. Muensri and S. Danwittayakul, Removal of Arsenic from Groundwater Using Nano-Metal Oxide Adsorbents, Key Eng. Mater., 2017, 751, 766-772.

90 Z. Meng, M. Wu, Y. Yu, F. Meng, A. Liua, S. Komarneni and Q. Zhang, Selective removal of methyl orange and $\mathrm{Cr}$ anionic contaminants from mixed wastewater by in situ formation of $\mathrm{Zn}-\mathrm{Al}$ layered double hydroxides, Appl. Clay Sci., 2018, 161, 1-5.

91 M. Sharma, M. Joshi, S. Nigam, S. Shree, D. K. Avasthi, R. Adelung, S. K. Srivastava and Y. K. Mishra, ZnO tetrapods and activated carbon based hybrid composite: Adsorbents for enhanced decontamination of hexavalent chromium from aqueous solution, Chem. Eng. J., 2019, 358, 540-551.

92 P. K. Raul, R. R. Devi, I. M. Umlong, S. Banerjee, L. Singh and M. Purkait, Removal of Fluoride from Water Using Iron Oxide-Hydroxide Nanoparticles, J. Nanosci. Nanotechnol., 2012, 12, 3922-3930.

93 Y. Wang, Q. Shao, S. Huang, B. Zhang and C. Xu, High performance and simultaneous sequestration of $\mathrm{Cr}(\mathrm{vI})$ and Sb(III) by sulfidated zerovalent iron, J. Cleaner Prod., 2018, 191, 436-444.

94 M. Mubarak, H. Jeon, Md. S. Islam, C. Yoon, J. S. Bae, S. J. Hwang, W. S. Choi and H. J. Lee, One-pot synthesis of layered double hydroxide hollow nanospheres with ultrafast removal efficiency for heavy metal ions and organic contaminants, Chemosphere, 2018, 201, 676-686.

95 I. Bibi, N. K. Niazi, G. Choppala and E. D. Burton, Chromium(vi) removal by siderite $\left(\mathrm{FeCO}_{3}\right)$ in anoxic aqueous solutions: An X-ray absorption spectroscopy investigation, Sci. Total Environ, 2018, 640-641, 1424-1431.

96 N. Khare, J. Bajpai and A. K. Bajpai, Graphene coated iron oxide (GCIO) nanoparticles as efficient adsorbent for removal of chromium ions: Preparation, characterization and batch adsorption studies, Environ. Nanotechnol. Monit. Manag., 2018, 10, 148-162.

97 S. Olivera, C. Hu, G. S. Nagananda, N. Reddy, K. Venkatesh, H. B. Muralidhara, Inamuddin and A. M. Asiri, The adsorptive removal of $\mathrm{Cr}(\mathrm{vI})$ ions and antibacterial activity studies on hydrothermally synthesized iron oxide and zinc oxide nanocomposite, J. Taiwan Inst. Chem. Eng., 2018, 93, 342-349.

98 H. Zou, E. Hu, S. Yang, L. Gong and F. He, Chromium(vi) removal by mechanochemically sulfidated zero valent iron and its effect on dechlorination of trichloroethene as a co-contaminant, Sci. Total Environ, 2019, 650, 419-426.

99 S. H. Zhang, M. F. Wu, T. T. Tang, Q. J. Xing, C. Q. Peng, F. Li, H. Liu, X. B. Luo, J. P. Zou, X. B. Minc and J. M. Luo, Mechanism investigation of anoxic $\mathrm{Cr}(\mathrm{vI})$ removal by nano zero-valent iron based on XPS analysis in time scale, Chem. Eng. J., 2018, 335, 945-953.

100 A. F. C. Campos, H. A. L. de Oliveira, F. N. da Silva, F. G. da Silva, P. Coppola, R. Aquino, A. Mezzi and J. Depeyrot, Core-Shell Bimagnetic Nanoadsorbents for Hexavalent Chromium Removal from Aqueous Solutions, J. Hazard. Mater., 2019, 362, 82-91.

101 M. Jain, M. Yadav, T. Kohout, M. Lahtinen, V. K. Garg and M. Sillanpää, Development of iron oxide/activated carbon nanoparticle composite for the removal of $\mathrm{Cr}(\mathrm{VI}), \mathrm{Cu}(\mathrm{II})$ and Cd(II) ions from aqueous solution, Water Resour. Ind., 2018, 20, 54-74.

102 M. Chigondo, H. K. Paumo, M. Bhaumik, K. Pillay and A. Maity, Magnetic arginine-functionalized polypyrrole with improved and selective chromium(vi) ions removal from water, J. Mol. Liq., 2019, 275, 778-791.

103 I. Hilbrandt, A. S. Ruhl, F. Zietzschmann, M. Molkenthin and M. Jekel, Competition in chromate adsorption onto micro-sized granular ferric hydroxide, Chemosphere, 2019, 218, 749-757.

104 Z. Wen, Y. Zhang, G. Cheng, Y. Wang and R. Chen, Simultaneous removal of $\mathrm{As}(\mathrm{v}) / \mathrm{Cr}(\mathrm{vI})$ and acid orange 7 (AO7) by nanosized ordered magnetic mesoporous Fe-Ce bimetal oxides: Behavior and mechanism, Chemosphere, 2019, 218, 1002-1013.

105 K. Z. Elwakeel, A. Shahat, A. S. Al-Bogami, B. Wijesiri and A. Goonetillekee, The synergistic effect of ultrasound power and magnetite incorporation on the sorption/ desorption behavior of $\mathrm{Cr}(\mathrm{vI})$ and $\operatorname{As}(\mathrm{v})$ oxoanions in an aqueous system, J. Colloid Interface Sci., 2020, 569, 76-88.

106 A. I. Ivanets, V. Srivastava, M. Y. Roshchina, M. Sillanpää, V. G. Prozorovich and V. V. Pankov, Magnesium ferrite nanoparticles as a magnetic sorbent for the removal of $\mathrm{Mn}^{2+}, \mathrm{Co}^{2+}, \mathrm{Ni}^{2+}$ and $\mathrm{Cu}^{2+}$ from aqueous solution, Ceram. Int., 2018, 44, 9097-9104.

107 Z. Dongsheng, G. Wenqiang, C. Guozhang, L. Shuai, J. Weizhou and L. Youzhi, Removal of heavy metal lead(II) using nanoscale zero-valent iron with different preservation methods, Adv. Powder Technol., 2019, 30, 581-589.

108 J. Ma, Y. Zeng, M. Sun, M. Zhang, W. Zheng, C. Zhang, Q. Wang, Y. Xiao and S. Zhang, A superparamagnetic $\mathrm{ZnFe}_{2} \mathrm{O}_{4} @ \mathrm{NH}_{2}-\mathrm{SiO}_{2} @ \mathrm{PMDI} @$ dithizone microspheres as an effective selective adsorbent for $\mathrm{Pb}^{2+}$ from wastewater, J. Environ. Chem. Eng., 2019, 7, 102874.

109 H. Yu, T. Zhang, Z. Jing, J. Xu, F. Qiu, D. Yang and L. Yu, In situ fabrication of dynamic nano zero-valent iron/activated carbon nanotubes membranes for tellurium separation, Chem. Eng. Sci., 2019, 205, 278-286.

110 X.-M. Zheng, J.-F. Dou, M. Xia and A.-Z. Ding, Ammoniumpillared montmorillonite- $\mathrm{CoFe}_{2} \mathrm{O}_{4}$ composite caged in calcium alginate beads for the removal of $\mathrm{Cs}^{+}$from wastewater, Carbohydr. Polym., 2017, 167, 306-316. 
111 M. H. Park, S. Jeong, G. Lee, H. Park and J. Y. Kim, Removal of aqueous-phase $\mathrm{Pb}(\mathrm{II}), \mathrm{Cd}(\mathrm{II}), \mathrm{As}(\mathrm{III})$, and $\mathrm{As}(\mathrm{V})$ by nanoscale zero-valent iron supported on exhausted coffee grounds, Waste Manage., 2019, 92, 49-58.

112 Y. Huang, W. Wang, Q. Feng and F. Dong, Preparation of magnetic clinoptilolite/ $\mathrm{CoFe}_{2} \mathrm{O}_{4}$ composites for removal of $\mathrm{Sr}^{2+}$ from aqueous solutions: Kinetic, equilibrium, and thermodynamic studies, J. Saudi Chem. Soc., 2017, 21, 58-66.

113 Q. Zhang, D. Zhao, S. Feng, Y. Wang, J. Jin, A. Alsaedi, T. Hayat and C. Chen, Synthesis of nanoscale zero-valent iron loaded chitosan for synergistically enhanced removal of $\mathrm{U}(\mathrm{vI})$ based on adsorption and reduction, J. Colloid Interface Sci., 2019, 552, 735-743.

114 Y. Hu, C. Zhao, L. Yin, T. Wen, Y. Yang, Y. Ai and X. Wang, Combining batch technique with theoretical calculation studies to analyze the highly efficient enrichment of $\mathrm{U}(\mathrm{vI})$ and $\mathrm{Eu}(\mathrm{III})$ on magnetic $\mathrm{MnFe}_{2} \mathrm{O}_{4}$ nanocubes, Chem. Eng. J., 2018, 349, 347-357.

115 S. Li, W. Wang, W. Yan and W.-X. Zhang, Nanoscale zerovalent iron (nZVI) for the treatment of concentrated $\mathrm{Cu}$ (II) wastewater: A field demonstration, Environ. Sci.: Processes Impacts, 2014, 16, 524-533.

116 M. A. Attia, S. I. Moussa, R. R. Sheha, H. H. Someda and E. A. Saad, Hydroxyapatite/ $\mathrm{NiFe}_{2} \mathrm{O}_{4}$ superparamagnetic composite: Facile synthesis and adsorption of rare elements, Appl. Radiat. Isot., 2019, 145, 85-94.

117 S. Luo, T. Lu, L. Peng, J. Shao, Q. Zeng and J.-D. Gu, Synthesis of nanoscale zero-valent iron immobilized in alginate microcapsules for removal of $\mathrm{Pb}$ (II) from aqueous solution, J. Mater. Chem. A, 2014, 2, 15463-15472.

118 S. Duan, X. Liu, Y. Wang, D. Shao, N. S. Alharbi, A. Alsaedi and J. Li, Highly efficient entrapment of U(vI) by using porous magnetic $\mathrm{Ni}_{0.6} \mathrm{Fe}_{2.4} \mathrm{O}_{4}$ micro-particles as the adsorbent, J. Taiwan Inst. Chem. Eng., 2016, 65, 367-377.

119 S. Li, T. You, Y. Guo, S. Yao, S. Zang, M. Xiao, Z. Zhang and Y. Shen, High dispersions of nano zero valent iron supported on biochar by one-step carbothermal synthesis and its application in chromate removal, $R S C A d v ., 2019, \mathbf{9}$, 12428-12435.

120 B. Xiang, D. Ling, H. Lou and H. Gu, 3D hierarchical flower-like nickel ferrite/manganese dioxide toward lead(II) removal from aqueous water, J. Hazard. Mater., 2017, 325, 178-188.

121 H. Lu, H. Xu, Y. Chen, J. Zhang and J. Zhuang, ZVI/PANI/ ATP composite by static polymerization as adsorbent for removal of $\mathrm{Cr}(\mathrm{vI}), \mathrm{RSC} A d v ., 2014,4,5873-5879$.

122 K.-W. Jung, S. Lee and Y. J. Lee, Synthesis of novel magnesium ferrite $\left(\mathrm{MgFe}_{2} \mathrm{O}_{4}\right) /$ biochar magnetic composites and its adsorption behavior for phosphate in aqueous solutions, Bioresour. Technol., 2017, 245, 751-759.

123 W. Han, F. Fu, Z. Cheng, B. Tang and S. Wu, Studies on the optimum conditions using acid-washed zero-valent iron/ aluminum mixtures in permeable reactive barriers for the removal of different heavy metal ions from wastewater, J. Hazard. Mater., 2016, 302, 437-446.
124 W. Wang, K. Cai, X. Wu, X. Shao and X. Yang, A novel $\operatorname{poly}(m$-phenylenediamine $) /$ reduced graphene oxide/nickel ferrite magnetic adsorbent with excellent removal ability of dyes and $\mathrm{Cr}(\mathrm{vI})$, J. Alloys Compd., 2017, 722, 532-543.

125 V. Danila, S. Vasarevicius and V. Valskys, Batch removal of $\mathrm{Cd}(\mathrm{II}), \mathrm{Cu}(\mathrm{II}), \mathrm{Ni}(\mathrm{II})$, and $\mathrm{Pb}$ (II) ions using stabilized zerovalent iron nanoparticles, Energy Procedia, 2018, 147, 214-219.

126 M. Naushad, T. Ahamad, B. M. Al-Maswari, A. A. Alqadami and S. M. Alshehri, Nickel ferrite bearing nitrogen-doped mesoporous carbon as efficient adsorbent for the removal of highly toxic metal ion from aqueous medium, Chem. Eng. J., 2017, 330, 1351-1360.

127 J. Liu, T. Mwamulima, Y. Wang, Y. Fang, S. Song and C. Peng, Removal of $\mathrm{Pb}(\mathrm{II})$ and $\mathrm{Cr}(\mathrm{vI})$ from aqueous solutions using the fly ash-based adsorbent material-supported zero-valent iron, J. Mol. Liq., 2017, 243, 205-211.

128 P. Beigzadeh and F. Moeinpour, Fast and efficient removal of silver(I) from aqueous solutions using aloe vera shell ash supported $\mathrm{Ni}_{0 \cdot 5} \mathrm{Zn}_{0.5} \mathrm{Fe}_{2} \mathrm{O}_{4}$ magnetic nanoparticles, Trans. Nonferrous Met. Soc. China, 2016, 26, 2238-2246.

129 L.-N. Shi, Y. Zhou, Z. Chen, M. Megharaj and R. Naidu, Simultaneous adsorption and degradation of $\mathrm{Zn}^{2+}$ and $\mathrm{Cu}^{2+}$ from wastewaters using nanoscale zero-valent iron impregnated with clays, Environ. Sci. Pollut. Res., 2013, 20, 3639-3648.

130 M. S. Podder and C. B. Majumder, Fixed-bed column study for $\mathrm{As}(\mathrm{III})$ and $\mathrm{As}(\mathrm{v})$ removal and recovery by bacterial cells immobilized on Sawdust/ $\mathrm{MnFe}_{2} \mathrm{O}_{4}$ composite, Biochem. Eng. J., 2016, 105, 114-135.

131 Z. Lv, S. Yang, L. Chen, A. Alsaedi, T. Hayat and C. Chen, Nanoscale zero-valent iron/magnetite carbon composites for highly efficient immobilization of U(vi), J. Environ. Sci., 2019, 76, 377-387.

132 L. P. Lingamdinne, J. R. Koduru, Y.-L. Choi, Y.-Y. Chang and J.-K. Yang, Studies on removal of $\mathrm{Pb}$ (II) and $\mathrm{Cr}$ (III) using graphene oxide based inverse spinel. nickel ferrite nanocomposite as sorbent, Hydrometallurgy, 2016, 165, 64-72.

133 L. Chen, S. Feng, D. Zhao, S. Chen, F. Li and C. Chen, Efficient sorption and reduction of $\mathrm{U}(\mathrm{vI})$ on zero-valent iron-polyaniline-graphene aerogel ternary composite, J. Colloid Interface Sci., 2017, 490, 197-206.

134 C. Santhosh, P. Kollu, S. Felix, V. Velmurugan, S. K. Jeong and A. N. Grace, $\mathrm{CoFe}_{2} \mathrm{O}_{4}$ and $\mathrm{NiFe}_{2} \mathrm{O}_{4} @$ graphene adsorbents for heavy metal ions - kinetic and thermodynamic analysis, RSC Adv., 2015, 5, 28965-28972.

135 X. Dou, R. Li, B. Zhao and W. Liang, Arsenate removal from water by zero-valent iron/activated carbon galvanic couples, J. Hazard. Mater., 2010, 182, 108-114.

136 Z. Zhang, H. Liu, P. Lu, T. Chen and W. Ma, Nanostructured $\alpha-\mathrm{Fe}_{2} \mathrm{O}_{3}$ derived from siderite as an effective $\mathrm{Hg}$ (II) adsorbent: Performance and mechanism, Appl. Geochem., 2018, 96, 92-99.

137 R. D. C. Soltani, M. Safari, A. Maleki, R. Rezaee, B. Shahmoradi, S. Shahmohammadi and E. Ghahramani, Decontamination of arsenic(v)-contained liquid phase 
utilizing $\mathrm{Fe}_{3} \mathrm{O}_{4}$ /bone char nanocomposite encapsulated in chitosan biopolymer, Environ. Sci. Pollut. Res., 2017, 24, 15157-15166.

138 A. Roy and J. Bhattacharya, A binary and ternary adsorption study of wastewater $\mathrm{Cd}(\mathrm{II}), \mathrm{Ni}(\mathrm{II})$ and $\mathrm{Co}(\mathrm{II})$ by $\gamma-\mathrm{Fe}_{2} \mathrm{O}_{3}$ nanotubes, Sep. Purif. Technol., 2013, 115, 172-179.

139 A. Mahapatra, B. G. Mishra and G. Hota, Electrospun $\mathrm{Fe}_{2} \mathrm{O}_{3}-\mathrm{Al}_{2} \mathrm{O}_{3}$ nanocomposite fibers as efficient adsorbent for removal of heavy metal ions from aqueous solution, J. Hazard. Mater., 2013, 258-259, 116-123.

140 A. Ahmadi, S. Heidarzadeh, A. R. Mokhtari, E. Darezereshki and H. A. Harouni, Optimization of heavy metal removal from aqueous solutions by maghemite $(\gamma$ $\mathrm{Fe}_{2} \mathrm{O}_{3}$ ) nanoparticles using response surface methodology, J. Geochem. Explor., 2014, 147, 151-158.

141 X. Kong, G. Huang, Z. Han, Y. Xu, M. Zhu and Z. Zhang, Evaluation of zeolite-supported microscale zero-valent iron as a potential adsorbent for $\mathrm{Cd}^{2+}$ and $\mathrm{Pb}^{2+}$ removal in permeable reactive barriers, Environ. Sci. Pollut. Res., 2017, 24, 13837-13844.

142 X. Han, L. Gai, H. Jiang, L. Zhao, H. Liu and W. Zhang, Core-shell structured $\mathrm{Fe}_{3} \mathrm{O}_{4} /$ PANI microspheres and their Cr(vi) ion removal properties, Synth. Met., 2013, 171, 1-6.

143 J. K. Grewal and M. Kaur, Effect of core-shell reversal on the structural, magnetic and adsorptive properties of $\mathrm{Fe}_{2} \mathrm{O}_{3}-$ GO nanocomposites, Ceram. Int., 2017, 43, 16611-16621.

144 Z. Majidnia, A. Idris, M. Majid, R. Zin and M. Ponraj, Efficiency of barium removal from radioactive waste water using the combination of maghemite and titania nanoparticles in PVA and alginate beads, Appl. Radiat. Isot., 2015, 105, 105-113.

145 M. Ahmadi, M. H. Niari and B. Kakavandi, Development of maghemite nanoparticles supported on cross-linked chitosan $\left(\gamma-\mathrm{Fe}_{2} \mathrm{O}_{3} @ \mathrm{CS}\right)$ as a recoverable mesoporous magnetic composite for effective heavy metals removal, J. Mol. Liq., 2017, 248, 184-196.

146 M. S. Almughamisi, Z. A. Khan, W. Alshitari and K. Z. Elwakeel, Recovery of chromium(vi) oxyanions from aqueous solution using $\mathrm{Cu}(\mathrm{OH})_{2}$ and $\mathrm{CuO}$ embedded chitosan adsorbents, J. Polym. Environ., 2020, 28, 47-60.

147 P. Bahmani, A. Maleki, H. Daraei, R. Rezaee, M. Khamforoush, S. D. Athar, F. Gharibi, A. H. Ziaee and G. McKay, Application of modified electrospun nanofiber membranes with $\alpha-\mathrm{Fe}_{2} \mathrm{O}_{3}$ nanoparticles in arsenate removal from aqueous media, Environ. Sci. Pollut. Res., 2019, 26, 21993-22009.

148 J. Shou, C. Jiang, F. Wang, M. Qiu and Q. Xu, Fabrication of $\mathrm{Fe}_{3} \mathrm{O}_{4} / \mathrm{MgAl}$-layered double hydroxide magnetic composites for the effective decontamination of $\mathrm{Co}$ (II) from synthetic wastewater, J. Mol. Liq., 2015, 207, 216-223.

149 D. Chauhan, J. Dwivedi and N. Sankararamakrishnan, Novel chitosan/PVA/zerovalent iron biopolymeric nanofibers with enhanced arsenic removal applications, Environ. Sci. Pollut. Res., 2014, 21, 9430-9442.

150 M. E. Mahmoud, E. A. Saad, M. A. Soliman and M. S. Abdelwahab, Removal of radioactive cobalt/zinc and some heavy metals from water using diethylenetriamine/ 2-pyridinecarboxaldehyde supported on NZVI, Microchem. J., 2019, 145, 1102-1111.

151 T. H. Bui, C. Kim, S. P. Hong and J. Yoon, Effective adsorbent for arsenic removal: core/shell structural nano zero-valent iron/manganese oxide, Environ. Sci. Pollut. Res., 2017, 24, 24235-24242.

152 K. Z. Elwakeel, A. M. Daher, A. I. L. Abd El-Fatah, H. Abd El Monem and M. M. H. Khalil, Biosorption of lanthanum from aqueous solutions using magnetic alginate beads, J. Dispersion Sci. Technol., 2017, 38, 145-151.

153 V. I. Mikhaylov, T. P. Maslennikova and P. V. Krivoshapkin, Characterization and sorption properties of $\gamma-\mathrm{AlOOH} /$ $\alpha-\mathrm{Fe}_{2} \mathrm{O}_{3}$ composite powders prepared via hydrothermal method, Mater. Chem. Phys., 2017, 186, 612-619.

154 D.-W. Cho, B.-H. Jeon, C.-M. Chon, Y. Kim, F. W. Schwartz, E.-S. Lee and H. Song, A novel chitosan/clay/magnetite composite for adsorption of $\mathrm{Cu}(\mathrm{II})$ and $\mathrm{As}(\mathrm{v})$, Chem. Eng. J., 2012, 200-202, 654-662.

155 H. C. Vu, A. D. Dwivedi, T. T. Le, S. H. Seo, E. J. Kim and Y. S. Chang, Magnetite graphene oxide encapsulated in alginate beads for enhanced adsorption of $\mathrm{Cr}(\mathrm{vI})$ and $\mathrm{As}(\mathrm{v})$ from aqueous solutions: Role of crosslinking metal cations in pH control, Chem. Eng. J., 2017, 307, 220-229.

156 Z. Guo, Y. Li, S. Pan and J. Xu, Fabrication of $\mathrm{Fe}_{3} \mathrm{O}_{4} @$ cyclodextrin magnetic composite for the high-efficient removal of Eu(III), J. Mol. Liq., 2015, 206, 272-277.

157 A. A. Yakout, M. A. Shaker, K. Z. Elwakeel and W. Alshitari, Response surface methodological optimization of batch $\mathrm{Cu}$ (II) sorption onto succinic acid functionalized $\mathrm{SiO}_{2}$ nanoparticles, Can. J. Chem., 2019, 97(4), 277-286.

158 D. Zhao, X. Gao, C. Wu, R. Xie, S. Feng and C. Chen, Facile preparation of amino functionalized graphene oxide decorated with $\mathrm{Fe}_{3} \mathrm{O}_{4}$ nanoparticles for the adsorption of $\mathrm{Cr}(\mathrm{vI})$, Appl. Surf. Sci., 2016, 384, 1-9.

159 S. Zhang, Y. Dong, Z. Yang, W. Yang, J. Wu and C. Dong, Adsorption of pharmaceuticals on chitosan-based magnetic composite particles with core-brush topology, Chem. Eng. J., 2016, 304, 325-334.

160 X. Wang, N. Zhuo, C. Fu, Z. Tian, H. Li, J. Zhang, W. Wu, Z. Yang and W. Yang, Enhanced selective adsorption of benzotriazole onto nanosized zeolitic imidazolate frameworks confined in polystyrene anion exchanger, Chem. Eng. J., 2017, 328, 816-824.

161 Z. Yang, N. Zhuo, S. Zhang, Y. Dong, X. Zhang, J. Shen, W. Yang, Y. Wang and J. Chen, A pH- and Temperatureresponsive Magnetic Composite Adsorbent for Targeted Removal of Nonylphenol, ACS Appl. Mater. Interfaces, 2015, 7, 24446-24457.

162 X. Zhou, C. Dong, Z. Yang, Z. Tian, L. Lu, W. Yang, Y. Wang, L. Zhang, A. Li and J. Chen, Enhanced adsorption of pharmaceuticals onto core-brush shaped aromatic rings-functionalized chitosan magnetic composite particles: Effects of structural characteristics of both pharmaceuticals and brushes, J. Cleaner Prod., 2018, 172, 1025-1034. 
163 A. Bedemo, B. S. Chandravanshi and F. Zewge, Removal of trivalent chromium from aqueous solution using aluminum oxide hydroxide, SpringerPlus, 2016, 5, 128.

164 V. I. Mikhaylov, T. P. Maslennikova, E. F. Krivoshapkina, E. M. Tropnikov and P. V. Krivoshapkin, Express Al/Fe oxide-oxyhydroxide sorbent systems for $\mathrm{Cr}(\mathrm{vI})$ removal from aqueous solutions, Chem. Eng. J., 2018, 350, 344-355.

165 A. Elouahli, M. Zbair, Z. Anfar, H. A. Ahsaine, H. Khallok, R. Chourak and Z. Hatim, Apatitic tricalcium phosphate powder: High sorption capacity of hexavalent chromium removal, Surf. Interfaces, 2018, 13, 139-147.

166 D. Kumari, R. Goswami, M. Kumar, P. mazumder, R. Kataki and J. Shim, Removal of $\mathrm{Cr}(\mathrm{vI})$ ions from the aqueous solution through nanoscale zerovalent iron (nZVI) Magnetite Corn Cob Silica (MCCS): A bio-waste based water purification perspective, Groundw. Sustain. Dev., 2018, 7, 470-476.

167 D. P. Dutta and S. Nath, Low cost synthesis of $\mathrm{SiO}_{2} / \mathrm{C}$ nanocomposite from corn cobs and its adsorption of uranium(vi), chromium(vi) and cationic dyes from wastewater, J. Mol. Liq., 2018, 269, 140-151.

168 Q. Zhu, L. Zhao, D. Sheng, Y. Chen, X. Hu, H. Lian, L. Maob and X. Cui, Speciation analysis of chromium by carboxylic group functionalized mesoporous silica with inductively coupled plasma mass spectrometry, Talanta, 2019, 195, 173-180.

169 M. R. Adam, N. M. Salleh, M. H. D. Othman, T. Matsuura, M. H. Ali, M. H. Puteh, A. F. Ismail, M. A. Rahman and J. Jaafar, The adsorptive removal of chromium(vI) in aqueous solution by novel natural zeolite based hollow fibre ceramic membrane, J. Environ. Manage., 2018, 224, 252-262.

170 K. Z. Elwakeel, A. A. El-Bindary, E. Y. Kouta and E. Guibal, Functionalization of polyacrylonitrile/Na-Y-zeolite composite with amidoxime groups for the sorption of $\mathrm{Cu}(\mathrm{II}), \mathrm{Cd}(\mathrm{II})$ and $\mathrm{Pb}$ (II) metal ions, Chem. Eng. J., 2018, 332, 727-736.

171 T. Sathvika, S. Balaji, M. Chandra, A. Soni, V. Rajesh and N. Rajesh, A co-operative endeavor by nitrifying bacteria Nitrosomonas and Zirconium based Metal Organic Framework to remove hexavalent chromium, Chem. Eng. J., 2019, 360, 879-889.

172 A. Sharma, K. K. Thakur, P. Mehta and D. Pathania, Efficient adsorption of chlorpheniramine and hexavalent chromium (Cr(vi)) from water system using agronomic waste material, Sustainable Chem. Pharm., 2018, 9, 1-11.

173 S. O. Adio, M. Asif, A. I. Mohammed, N. Baig, A. A. Al-Arfaj and T. A. Saleh, Poly(amidoxime) modified magnetic activated carbon for chromium and thallium adsorption: Statistical analysis and regeneration, Process Saf. Environ. Prot., 2019, 121, 254-262.

174 K. E. Greenstein, N. V. Myung, G. F. Parkin and D. M. Cwiertny, Performance comparison of hematite $\left(\alpha-\mathrm{Fe}_{2} \mathrm{O}_{3}\right)$-polymer composite and core-shell nanofibers as point-of-use filtration platforms for metal sequestration, Water Res., 2019, 148, 492-503.

175 R. Xiao, J. J. Wang, R. Li, J. Park, Y. Meng, B. Zhou, S. Pensky and Z. Zhang, Enhanced sorption of hexavalent chromium $[\mathrm{Cr}(\mathrm{vI})]$ from aqueous solutions by diluted sulfuric acid-assisted MgO-coated biochar composite, Chemosphere, 2018, 208, 408-416.

176 C. Li, L. Zhang, Y. Gao and A. Li, Facile synthesis of nano $\mathrm{ZnO} / \mathrm{ZnS}$ modified biochar by directly pyrolyzing of zinc contaminated corn stover for $\mathrm{Pb}(\mathrm{II}), \mathrm{Cu}(\mathrm{II})$ and $\mathrm{Cr}(\mathrm{VI})$ removals, Waste Manage., 2018, 79, 625-637.

177 Y. Chen, B. Wang, J. Xin, P. Sun and D. Wu, Adsorption behavior and mechanism of $\mathrm{Cr}(\mathrm{vI})$ by modified biochar derived from Enteromorpha prolifera, Ecotoxicol. Environ. Saf., 2018, 164, 440-447.

178 X. Xu, H. Huang, Y. Zhang, Z. Xu and X. Cao, Biochar as both electron donor and electron shuttle for the reduction transformation of $\mathrm{Cr}(\mathrm{vI})$ during its sorption, Environ. Pollut., 2019, 244, 423-430.

179 Z. Fan, Q. Zhang, B. Gao, M. Li, C. Liu and Y. Qiu, Removal of hexavalent chromium by biochar supported nZVI composite: Batch and fixed-bed column evaluations, mechanisms, and secondary contamination prevention, Chemosphere, 2019, 217, 85-94.

180 S. Zhang, H. Lyu, J. Tang, B. Song, M. Zhen and X. Liu, A novel biochar supported CMC stabilized nano zerovalent iron composite for hexavalent chromium removal from water, Chemosphere, 2019, 217, 686-694.

181 P. Kumarathilaka, V. Jayaweera, H. Wijesekara, I. R. M. Kottegoda, S. R. D. Rosa and M. Vithanage, Insights into Starch Coated Nanozero Valent Iron-Graphene Composite for $\mathrm{Cr}(\mathrm{vI})$ Removal from Aqueous Medium, J. Nanomater., 2016, 2813289.

182 H. Su, Y. Chong, J. Wang, D. Long, W. Qiao and L. Ling, Nanocrystalline celluloses-assisted preparation of hierarchical carbon monoliths for hexavalent chromium removal, J. Colloid Interface Sci., 2018, 510, 77-85.

183 Z. Dong and L. Zhao, Covalently bonded ionic liquid onto cellulose for fast adsorption and efficient separation of $\mathrm{Cr}(\mathrm{vI})$ : Batch, column and mechanism investigation, Carbohydr. Polym., 2018, 189, 190-197.

184 P. R. Choudhury, S. Majumdar, G. C. Sahoo, S. Saha and P. Mondal, High pressure ultrafiltration $\mathrm{CuO} /$ hydroxyethyl cellulose composite ceramic membrane for separation of $\mathrm{Cr}(\mathrm{VI})$ and $\mathrm{Pb}$ (II) from contaminated water, Chem. Eng. J., 2018, 336, 570-578.

185 S. Bo, W. Ren, C. Lei, Y. Xie, Y. Cai, S. Wang, J. Gao, Q. Nic and J. Yao, Flexible and porous cellulose aerogels/zeolitic imidazolate framework (ZIF-8) hybrids for adsorption removal of $\mathrm{Cr}(\mathrm{Iv})$ from water, J. Solid State Chem., 2018, 262, 135-141.

186 Z. Yang, L. Ren, L. Jin, L. Huang, Y. He, J. Tang, W. Yang and $\mathrm{H}$. Wang, In situ functionalization of $\operatorname{poly}\left(\mathrm{m}^{-}\right.$ phenylenediamine) nanoparticles on bacterial cellulose for chromium removal, Chem. Eng. J., 2018, 344, 441-452.

187 T. Hu, Q. Liu, Q. Liu, Y. Wu, C. Qiao and J. Yao, Toxic Cr removal from aqueous media using catechol-amine copolymer coating onto as-prepared cellulose, Carbohydr. Polym., 2019, 209, 291-298.

188 S. S. Pillai, M. D. Mullassery, N. B. Fernandez, N. Girija, P. Geetha and M. Koshy, Biosorption of $\mathrm{Cr}(\mathrm{vI})$ from 
aqueous solution by chemically modified potato starch: Equilibrium and kinetic studies, Ecotoxicol. Environ. Saf., 2013, 92, 199-205.

189 P. N. Singh, D. Tiwary and I. Sinha, Improved removal of $\mathrm{Cr}(\mathrm{vI})$ by starch functionalized iron oxide nanoparticles, J. Environ. Chem. Eng., 2014, 2, 2252-2258.

190 J. Wang, B. Ji, Y. Shu, W. Chen, L. Zhu and F. Chen, Cr(vi) Removal from Aqueous Solution Using Starch and Sodium Carboxymethyl Cellulose-Coated $\mathrm{Fe}$ and Fe/Ni Nanoparticles, Pol. J. Environ. Stud., 2018, 27, 2785-2792.

191 V. Gopalakannan and N. Viswanathan, One pot synthesis of metal ion anchored alginate-gelatin binary biocomposite for efficient $\mathrm{Cr}(\mathrm{vI})$ removal, Int. J. Biol. Macromol., 2016, 83, 450-459.

192 P. Geetha, M. S. Latha, S. S. Pillai, B. Deepa, K. S. Kumar and M. Koshy, Green synthesis and characterization of alginate nanoparticles and its role as a biosorbent for Cr(vi) ions, J. Mol. Struct., 2016, 1105, 54-60.

193 T. Zang, Z. Cheng, L. Lu, Y. Jin, X. Xu, W. Ding and J. Qu, Removal of $\mathrm{Cr}(\mathrm{vI})$ by modified and immobilized Auricularia auricular spent substrate in a fixed-bed column, Ecol. Eng., 2017, 99, 358-365.

194 A. M. Omer, R. E. Khalifa, Z. Hu, H. Zhang, C. Liu and $\mathrm{X}$. Ouyang, Fabrication of tetraethylenepentamine functionalized alginate beads for adsorptive removal of Cr (VI) from aqueous solutions, Int. J. Biol. Macromol., 2019, 125, 1221-1231.

195 Y. Yan, Q. An, Z. Xiao, W. Zheng and S. Zhai, Flexible coreshell/bead-like alginate@PEI with exceptional adsorption capacity, recycling performance toward batch and column sorption of $\mathrm{Cr}(\mathrm{vI})$, Chem. Eng. J., 2017, 313, 475-486.

196 S. Periyasamy, V. Gopalakannan and N. Viswanathan, Hydrothermal assisted magnetic nano-hydroxyapatite encapsulated alginate beads for efficient $\mathrm{Cr}(\mathrm{vI})$ uptake from water, J. Environ. Chem. Eng., 2018, 6, 1443-1454.

197 K. V. G. Ravikumar, S. V. Sudakaran, M. Pulimi, C. Natarajan and A. Mukherjee, Removal of hexavalent chromium using nano zero valent iron and bacterial consortium immobilized alginate beads in a continuous flow reactor, Environ. Technol. Innov., 2018, 12, 104-114.

198 O. M. Ontañon, P. S. González, G. G. Barros and E. Agostini, Improvement of simultaneous $\mathrm{Cr}(\mathrm{VI})$ and phenol removal by an immobilized bacterial consortium and characterisation of biodegradation products, New Biotechnol., 2017, 37, 172-179.

199 I. Sargin, G. Arslan and M. Kaya, Production of magnetic chitinous microcages from ephippia of zooplankton Daphnia longispina and heavy metal removal studies, Carbohydr. Polym., 2019, 207, 200-210.

200 M. E. A. Ali, Synthesis and adsorption properties of chitosan-CDTA-GO nanocomposite for removal of hexavalent chromium from aqueous solutions, Arabian J. Chem., 2018, 11, 1107-1116.

201 S. Gokila, T. Gomathi, P. N. Sudha and S. Anil, Removal of the heavy metal ion chromiuim(vi) using Chitosan and Alginate nanocomposites, Int. J. Biol. Macromol., 2017, 104, 1459-1468.

202 X. Chen, W. Zhang, X. Luo, F. Zhao, Y. Li, R. Li and Z. Li, Efficient removal and environmentally benign detoxification of $\mathrm{Cr}(\mathrm{VI})$ in aqueous solutions by $\mathrm{Zr}(\mathrm{IV})$ cross-linking chitosan magnetic microspheres, Chemosphere, 2017, 185, 991-1000.

203 X. Yang, Y. Li, H. Gao, C. Wang, X. Zhang and H. Zhou, One-step fabrication of chitosan- $\mathrm{Fe}(\mathrm{OH})_{3}$ beads for efficient adsorption of anionic dyes, Int. J. Biol. Macromol., 2018, 117, 30-41.

204 D. Jiang, D. Huang, C. Lai, P. Xu, G. Zeng, J. Wan, L. Tang, H. Dong, B. Huang and T. Hu, Difunctional chitosanstabilized $\mathrm{Fe} / \mathrm{Cu}$ bimetallic nanoparticles for removal of hexavalent chromium wastewater, Sci. Total Environ, 2018, 644, 1181-1189.

205 T. Xaba, J. Magagula and O. B. Nchoe, "Green” synthesis of $\mathrm{Cu}_{2} \mathrm{~S}$ nanoparticles from (Z)-1-methyl-2- (pyrrolidin-2ylidene) thiourea ligand for the preparation of $\mathrm{Cu}_{2} \mathrm{~S}$ chitosan nanocomposites for the removal of $\mathrm{Cr}(\mathrm{vI})$ ion from wastewater, Mater. Lett., 2018, 229, 331-335.

206 D. M. Guo, Q. D. Ana, Z. Y. Xiao, S. R. Zhaia and D. J. Yang, Efficient removal of $\mathrm{Pb}(\mathrm{II}), \mathrm{Cr}(\mathrm{VI})$ and organic dyes by polydopamine modified chitosan aerogels, Carbohydr. Polym., 2018, 202, 306-314.

207 M. S. Samuel, J. Bhattacharya, S. Raj, N. Santhanam, H. Singh and N. D. P. Singh, Efficient removal of Chromium(vi) from aqueous solution using chitosan grafted graphene oxide (CS-GO) nanocomposite, Int. J. Biol. Macromol., 2019, 121, 285-292.

208 M. Mozaffari, M. R. S. Emami and E. Binaeian, A novel thiosemicarbazide modified chitosan (TSFCS) for efficiency removal of $\mathrm{Pb}$ (II) and methyl red from aqueous solution, Int. J. Biol. Macromol., 2019, 123, 457-467.

209 J. O. M. Neto, C. R. Bellato and D. C. Silva, Iron oxide/ carbon nanotubes/chitosan magnetic composite film for chromium species removal, Chemosphere, 2019, 218, 391-401. 